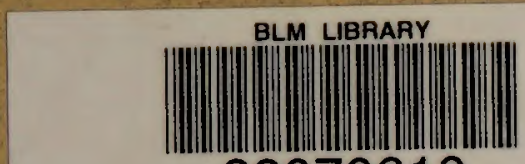 88070610 \\ Effective Cattle Management in Riparian Zones:
}

A Field Survey and Literature Review
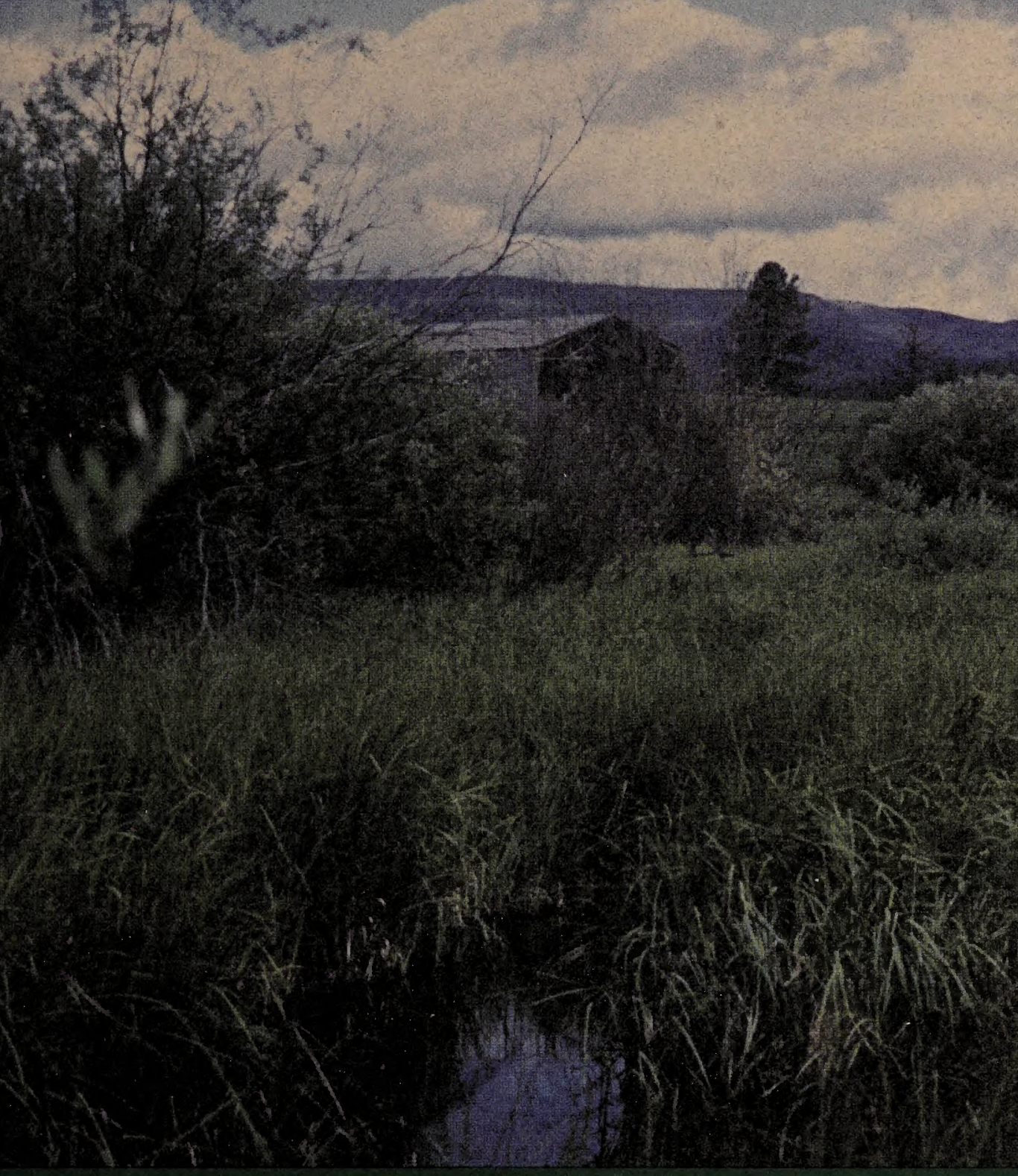

\begin{tabular}{l|ll} 
Mr & & M \\
Ri & SF & :hnical Bulletin No. 3 \\
Ni & 85.3 & 1997 \\
M & .5474 & rest and Conservation \\
1997 & ment Station \\
& c. 3 & ment
\end{tabular}

US Department of the Interior Bureau of Land Management Montana State Office Billings, Montana

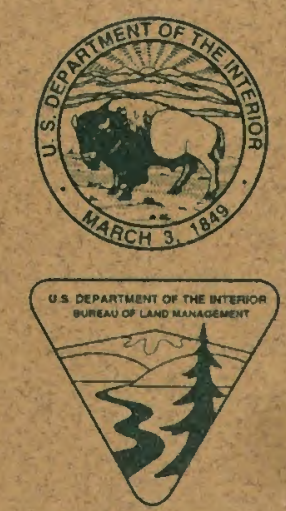







\title{
Effective Cattle Management in Riparian Zones: A Field Survey and Literature Review
}

Montana BLM Riparian Technical Bulletin No. 3

USDI Bureau of Land Management, Montana State Office

\author{
Prepared by \\ Robert C. Ehrhart and Paul L. Hansen \\ Riparian and Wetland Research Program \\ Montana Forest and Conservation Experiment Station \\ School of Forestry, The University of Montana \\ Missoula MT \\ November 1997 \\ BLM Library \\ Denver Federal Center \\ Bldg. 50, OC-521 \\ P.O. Box 25047 \\ Denver, CO 80225
}


The Bureau of Land Management is responsible for the stewardship of our public lands. It is committed to manage, protect, and improve these lands in a manner to serve the needs of the American people for all times. Management is based on the principles of multiple use and sustained yield of our nation's resources within a framework of environmental responsibility and scientific technology.These resources include recreation;rangelands;timber;minerals; watershed; fish and wildlife; wilderness; air; and scenic, scientific, and cultural values.

BLM/MT/ST-98/002+1610

The Montana Forest and Conservation Experiment Station Publications Program prepared this USDI Bureau of Land Management Technical Bulletin for publication. Nick Baker, Station Editor 


\section{Acknowledgements}

More, even, than most such research projects, this report would not have been possible without the support and assistance of a great many persons. First, we want to thank the Montana State Office of the Bureau of Land Management, and especially Dan Hinckley, for their financial support and encouragement. Thanks also are due to numerous individuals at each of the BLM Resource Areas in Montana who guided us through their files and pointed us in the direction of possible study sites. Likewise, conscientious persons at Natural Resources Conservation Service (NRCS) and Montana State University (MSU) Agricultural Extension Service offices throughout the state went out of their way to identify possible ranches for inclusion and to lay the groundwork with operators. Chris Phelps of the Montana Land Reliance also provided suggestions on possible participants, several of whom were included in the study. Scott Godfrey put in long days and hard miles measuring stream parameters.Bill Thompson and Tom Parker provided valuable suggestions for improving the report in its final stages. Ryan Benedetti guided us through the intricacies of computer programs, and Tricia Koch cheerfully entered field notes into the data base.

Our greatest debt is to the many operators and managers who graciously gave us permission to poke around their riparian areas and who took time out of busy schedules to talk about their ranches. Although not all of their operations wound up in the report, each of the following (and, where appropriate, their spouses) contributed greatly to whatever value it might have: Rick Anderson, Wayne Arnold, Ray Bannister, Jay and Neal Barnowsky, Francis Blake, Leonard Blixrud, Ellis Boyd, Stewart Burns, Barbara Clark, Martin Clark, Ken Cook, Lee Cornwell, Rod Coulter, Michael Curran, Dan Currie, Bob Dafoe, Willie Doll, Fred Drga,Ted Flynn, Bill French, Jim Gelhaus, Les Gilman, Jim Hagenbarth, Quinn Haughian, Jack Heyneman, Chase Hibbert, Bill Jones, Ronnie Korman, Chris Kounce, John Krutar,John Lane, Bob Lee,Tracy Manley, Dave and Bert Mannix, Clay McAlpine,Tom McClure, Jack and Mike Meuli,Tom Milesnick, Bill Milton, Richard Moe, George Morella,Jim Morton,John Nesselhof, Jack Norris, Steve Page, Charles Proff, Bob Pugsley, Mike and Mark Rafferty, Lon Reukauf, Rob Reukauf, Don Ross, Phil Rostad, Steve Roth, Stew Schwartz, Bob Scriver, Fred Sherrer, Joe Skinner, Maynard and Meg Smith, Snowline Grazing Association, Bert Twitchell, Larry Veverka, Craig Woodson, and Tony Zinne.

Finally, thanks to Nick Baker,The University of Montana School of Forestry Research Station editor, for the layout and design of this book. 


\section{Contents}

Acknowledgements ............................................................ ii

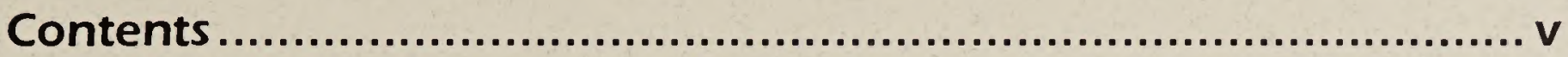

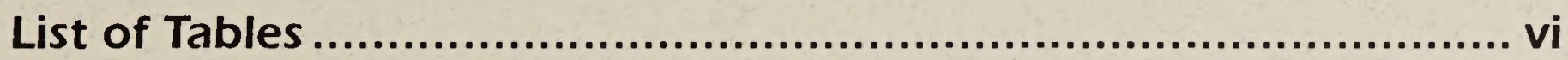

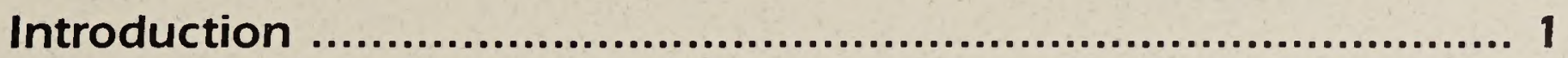

Characteristics and Functions of Riparian Areas ................................. 2

Impact of Cattle on Western Riparian Ecosystems .............................. 3

Successful Riparian Grazing in Montana ............................... 5

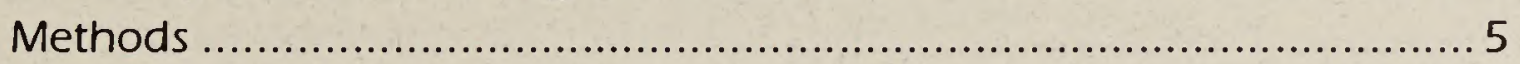

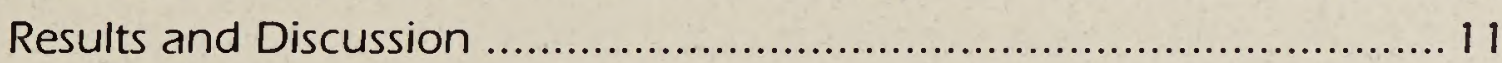

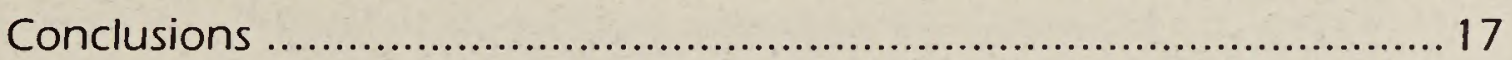

Principles and Techniques for Riparian Grazing ...................... 19

General Principles for Grazing Cattle in Riparian Zones ..................... 19

Determining Season of Use ....................................................... 23

Reducing Intensity of Use by Influencing Distribution ...................... 31

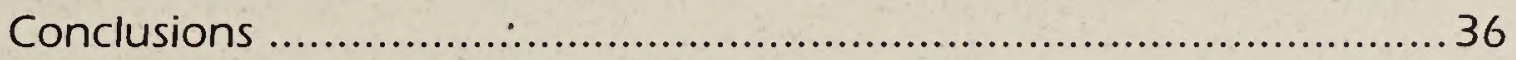

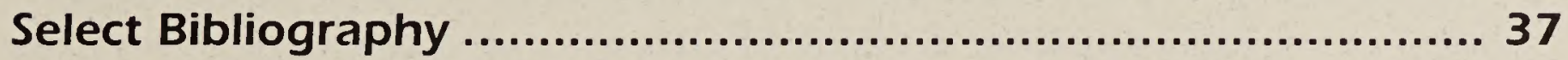

Literature Cited ................................................................. 41

Appendices ..................................................................... 48

Appendix A. Riparian grazing study field form ............................. 48

Appendix B. Field form codes and instructions .............................51

Appendix C. Riparian grazing study health evaluation form ............. 59

Appendix D. Health evaluation form codes and instructions .............60

Appendix E. Habitat types and community types in study reaches .....66 66

Appendix F. Individual reaches (polygons) grouped by life form .........68

Appendix G. Individual reaches (polygons)

grouped by season of grazing use .................................... 72

Appendix $\mathrm{H}$. Individual reaches (polygons) grouped by length of grazing period ................................... 75

Appendix I. Habitat types and community types present

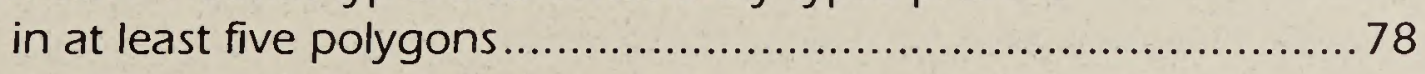

Appendix J. Individual reaches (polygons)

ranked by overall health score 86

Glossary 


\section{Tables}

Table 1. Habitat types and community types present in study reaches by life form

Table 2. Number of reaches (polygons) used during each season of use

Table 3. Number of reaches (polygons) used during each grazing length category

Table 4. Average health evaluations for reaches (polygons) grouped by season of use

Table 5. Percentage of each season of use group rating at least 90 percent in overall health evaluation

Table 6. Average health evaluations for reaches (polygons) grouped by length of grazing period

Table 7. Percentage of each length of grazing group rating at least 90 percent in overall health evaluation

Table 8. Number of reaches (polygons)

per Rosgen stream types 


\section{Introduction}

Despite their small proportion of the total landscape, riparian areas-the "green zones" between flowing water and uplands-are ecologically and economically important from any perspective. These may include water quality, biological diversity, wildlife and fisheries habitat, agricultural and ranching productivity, timber production, recreation, and simple aesthetics. Historically, private landowners and public land managers did not differentiate riparian zones from the surrounding uplands. Often, in fact, these areas were explicitly referred to as "sacrifice areas."

Recently, however, land managers in federal and state agencies have been tasked by society to develop specific approaches for maintaining and improving riparian areas. At the same time, many landowners are recognizing the economic as well as the ecological advantages of healthy riparian ecosystems.

The most extensive human-caused influence on riparian zones in the western United States has been livestock grazing. In 1979, for example, the USDI Bureau of Land Management (BLM) was responsible for some 88,000 acres of riparian habitat, most of which was being grazed by domestic livestock (Almand and Krohn, 1979, cited in Platts and Nelson 1985a). Within the intermountain area of the western range alone, the USDA Forest Service controls 12,400 miles of streams, many of which are in grazing allotments (Skovlin 1984).

To a large extent, the issue of livestock grazing on public lands stems from concern over the condition of the riparian zones and aquatic ecosystems in these areas:"Overgrazing by livestock is considered the most widespread cause of deterioration of riparian systems on public lands" (Knopf and Cannon 1982). Nor is public interest likely to decline in the foreseeable future. According to Elmore and Kauffman (1994), "Livestock grazing in riparian zones will continue to be one of the most controversial of land management issues."

It is well-known that improper grazing practices can adversely affect riparian sites. What is less obvious is which grazing management techniques are compatible with maintaining or improving these areas and under what conditions. In 1993 the Riparian and Wetland Research Program at The University of Montana was asked by the Montana State Office of the BLM to evaluate the compatibility of different grazing management approaches with different types of riparian areas in the state of Montana.The primary method for accomplishing this objective was to investigate grazing management strategies and techniques currently being practiced on healthy riparian systems in Montana and, if possible, to correlate these with specific riparian vegetation types (plant communities) as delineated in the Classification and Management of Montana's Riparian and Wetland Sites by Hansen and others (1995).

This report contains the following sections: (1) a brief review of the characteristics and functions of riparian ecosystems in the western United States and the impact livestock grazing has had on them; (2) presentation and analysis of the data collected over 
four field seasons; (3) a "Principles and Techniques" section which suggests general principles for developing successful grazing management strategies for riparian areas and offers examples of good management techniques based both on our field observations and the current literature; and (4) in addition to the standard literature cited section, a select bibliography identifying especially useful material readily available to land managers and private operators.

\section{Characteristics and Functions of Riparian Areas}

Riparian areas are the "green zones" which lie between channels of flowing water and uplands. They are the link between aquatic environments and upland, terrestrial ecosystems. Even with the recent emphasis on "The Riparian Zone," it is essential to keep in mind the fundamental interrelationships among aquatic, riparian, and upland ecosystems. An excellent reminder of these relationships is the observation that "management of salmonid habitats does not begin at the streambank but at the ridgeline [watershed boundary]"(Kauffman 1995).

Riparian areas are intimately related to their adjacent waterways since the presence of water for all or part of the growing season is their distinguishing characteristic. Moreover, the nature and condition of the riparian area abutting a stream channel fundamentally affects the aquatic ecosystem.

In addition to water, three other components of the riparian area essential for management consideration are soil, vegetation, and land form. In a healthy riparian ecosystem, the four are in balance and mutually supporting one another. While all four components are important, one might suggest that water and soil are the fundamental elements which define a riparian area and that vegetation reflects the nature and condition of the geomorphological and hydrological situations. Nevertheless, from a management perspective, vegetation is critical since often this is the element over which the manager has the most control, which is the easiest to manipulate, and which responds the quickest to human influences.

Riparian areas are usually much more dynamic than uplands (a term used in this report to refer to any part of the landscape beyond the non-streamside boundary of the riparian area). While plant communities may be especially susceptible to rapid change, it is not uncommon for hydrogeomorphological conditions to change dramatically, often in relatively short periods. These changes might include: flooding (either temporary or more long term, as when caused by beavers); deposition of sediment on banks and across floodplains; accumulation of organic materials in areas such as wet meadows and bogs; dewatering of a site by a variety of means (e. g. , irrigation diversions); and changes in actual channel location. Each of these physical modifications can change the associated vegetation negatively or positively. Conversely, vegetation, or the lack of it, may contribute to each of the above phenomena.

The natural variation of riparian areas is an important consideration in seeking to understand and subsequently to manage these areas because it is often difficult to distinguish between natural and human-caused impacts. In addition, the inherently dynamic nature of riparian areas and their associated stream channels is such that natural events may, and do, override human-caused impacts, including efforts at in-stream and riparian rehabilitation.

Healthy riparian areas provide several important ecological functions. These functions include water storage and aquifer recharge, filtering of chemical and organic wastes, sediment trapping, bank building and maintenance, flow energy dissipation, and primary biotic production.

Riparian areas provide for water storage and aquifer recharge. The soil in the banks and floodplains and the substrate under the channel act as a sponge to retain water.This 
stored water is released as subsurface water or groundwater over time, extending the availability of water in the watershed for a longer period in the summer or recharging the underground aquifer.

Riparian vegetation dissipates the energy of flowing water and stabilizes streambanks, thereby reducing erosion and the introduction of excessive sediment into the channel.Vegetation can also limit the movement of upland soil into the stream. These functions are particularly important during spring runoff periods and after major summer or fall rains.

Riparian vegetation traps sediments carried by the stream and by overland flow from the adjacent uplands. Trapping of sediment may lead to the development of new banks and bars, which become the location for new vegetation communities, further enhancing stability. Sediment retention is also important because excessive sediment loads reduce habitat quality for aquatic life (including fish) and destabilize the natural hydrologic regime of the system. Healthy riparian systems enhance water quality by filtering out organic and chemical pollutants before they reach the channel and as they move downstream.

Appropriate riparian vegetation shields soil and water from wind, sunlight, and rain drop impact.This reduces erosion due to wind and the disruptive impact of rainfall as well as reducing evaporation. Vegetative canopy cover also provides shade which reduces water temperatures and improves aquatic habitat. Dense vegetation may limit soil compaction through the presence of healthy root systems and by limiting accessibility of both domestic livestock and wild ungulates. Although an increase in vegetation may increase evapotranspiration, in natural riparian systems the overall benefits offset this loss.

Finally, riparian areas are rich in biotic production. The presence of water and essential nutrients make these areas among the most productive parts of a landscape, especially in such regions as the arid and semi-arid western United States."Riparian vegetation produces the bulk of the detritus that provides up to $90 \%$ of the organic matter necessary to support headwater stream communities" (Cummins and Spangler 1978). This productivity enhances livestock use as well. Biomass on mountain meadows, for example, may be "10 to 20 times higher than that of surrounding uplands" (Skovlin 1984). Roath and Krueger (1982) found that the riparian area in a Blue Mountain pasture in eastern Oregon provided more than 80 percent of the total herbaceous vegetation grazed by cattle, even though it comprised less than two percent of the total area of the pasture.

The ecological importance of riparian zones far exceeds the proportion of the landscape they comprise. While riparian areas make up only about two percent of the land area of the western United States, "It is believed that, on land, the riparian/stream ecosystem is the single most productive type of wildlife habitat, benefiting the greatest number of species" (Kauffman and Krueger 1982). More than 75 percent of all wildlife species in southeastern Wyoming are dependent upon riparian habitats (Chaney and others 1990). Riparian areas provide innumerable wildlife species with water, food, cover, and travel and migration routes. In the western United States, more bird species rely on riparian habitats than all other western rangeland vegetation types combined (Chaney and others 1990). In western Montana, 59 percent of the land bird species breed in riparian habitats and 35 percent of these do so only in riparian areas (Mosconi and Hutto 1982).

\section{Impact of Cattle on Western Riparian Ecosystems}

Domestic livestock (cattle, sheep, and horses) have been grazing rangelands in the western United States, including riparian areas, intensely for the past $125-150$ years. So pervasive has this practice been that in many parts of the West it is difficult to visualize what the landscape-and particularly its riparian segments-looked like before the middle of the last century. 
The literature, both academic and popular, contains numerous examples of the damage livestock can do to these critical ecosystems. (See, for example, Gifford 1981; Knopf and Cannon 1982; Platts and Raleigh 1984; Skovlin 1984; Clary and Medin 1990; Schulz and Leininger 1990; Kovalchik and Elmore 1992.) Platts (1986) summarized this body of knowledge by observing, "It is clear from the literature that improper livestock grazing can affect the riparian-stream habitat by eliminating riparian vegetation, widening stream channels, causing channel aggradation through increased sediment transport, changing streambank morphology, and lowering surrounding water tables."

According to some authors, almost any livestock grazing in riparian areas is by its nature "improper." Many of the early publications on the detrimental impacts of livestock grazing in riparian ecosystems were the work of fisheries biologists, whose professional concerns led them to focus on the implications of such impacts on fish habitat (Winegar 1977; Meehan and Platts 1978; Dahlem 1979; Duff 1979; Keller and others 1979; Van Velson 1979; Leege and others 1981; Keller and Burnham 1982; Rickard and Cushing 1982; Platts and Nelson 1985b; Stuber 1985; Schulz and Leininger 1990). Other wildlife biologists also looked at livestock-wildlife interactions, generally highlighting the adverse impacts to the latter (Crouch 1982; Taylor 1984; Goriup 1988; Medin and Clary 1989 and 1990; Kantrud 1990; Kantrud and Higgins 1992). Most of these studies were limited by one or more problems (Platts 1991). Most noticeably, many of them only compared the effects of long-term heavy grazing with complete cessation of grazing, or they did not state specifically the level of grazing involved in terms of livestock numbers, season of use, or length of use. Nevertheless, the sheer "weight of evidence" indicated livestock often had a very adverse impact on riparian and stream ecosystems.

The conclusion many people drew was that livestock grazing, particularly by cattle, was inherently incompatible with healthy, functioning riparian ecosystems. In 1994 ecologist Thomas L. Fleischner concluded, "Native ecosystems pay a steep price for the presence of livestock," and because of the ecological importance of riparian zones "the ecological costs of grazing are magnified in these sites." Gus Hormay, a pioneer in the field of range management and developer of the rest rotation grazing system, concluded that, since livestock will preferentially use riparian areas excessively in any grazing system, the only solution was to fence them out (cited in Platts 1979). In the late 1970's, William Meehan and William Platts (1978), the latter the leading researcher on the impact of grazing on fish habitat, "were unable to identify any widely used livestock grazing strategies that were completely capable of maintaining high levels of forage use while rehabilitating damaged streams and riparian zones" (cited in Platts and Wagstaff 1984).

Meehan's and Platts' reference to "any widely used livestock grazing strategies" provides the key to understanding the apparent incompatibility of cattle grazing and healthy riparian ecosystems. Until the mid-1980's grazing in riparian areas had for the most part been incorporated into conventional grazing systems such as season-long, rest rotation, deferred rotation, and other variations. Accordingly, many of the early studies focused on these systems. (For detailed reviews of the advantages and disadvantages of various grazing systems, see: Buckhouse and Skovlin 1979; Bryant 1985; Clary and Webster 1989; Elmore 1990; Platts 1991; Buckhouse and Elmore 1993).

By the middle of the 1980 's, instead of looking primarily at traditional grazing systems and the negative impacts of livestock on riparian areas and stream channels, researchers and managers alike had begun to ask a different question: "What types of grazing strategies might be compatible with healthy riparian and aquatic ecosystems?" The result of this broader approach was that evidence began to suggest "riparian grazing" and "improper riparian grazing" were not necessarily synonymous. Thus, by 1986 Platts, still on the cutting edge of this research, admitted, "The remarks of Meehan and Platts [of the 1970's] no longer apply" (1986b). 


\section{Successful Riparian Grazing in Montana}

\section{Methods}

The primary objective of this project was to investigate what cattle grazing practices might be compatible with maintaining healthy riparian ecosystems or improving those which are not functioning properly. This study did not address the several types of non-riparian wetlands such as potholes, seeps, and stock reservoirs. Because of the small number of sheep operations in Montana, the focus was limited to cattle.Accordingly, the word "livestock" when used in this report refers specifically to cattle. The approach initially selected was to correlate management strategies currently being practiced in Montana to specific types of riparian ecosystems judged to be functioning properly.

This approach required four steps: (1) selection of appropriate and accessible riparian sites; (2) inventory of the vegetative, hydrologic, and soil characteristics of each site and determination of the predominant habitat and community types as defined by Hansen and others (1995); (3) evaluation of the functional condition of the riparian areas; and (4) identification of the management strategies and techniques which have contributed to the current status of each site.

\section{Site selection}

For several reasons we focused our field research primarily on private lands. In the first place, it appeared many of the better riparian areas in the state of Montana are on private land. Second, we believed private operators might be more likely to engage in innovative techniques where they had the most control and were not constrained by regulations that limit flexibility of public land management agencies. We had hoped to make use of extensive data on BLM allotments from other work the Riparian and Wetland Research Program had been doing for several years. To do so, however, required a combination of three conditions: reaches assessed to be functioning properly or nearly so (i. e., performing the functions addressed in the previous section); the existence of consistent grazing records (including pastures which retained the same configuration over time); and relative consistency in time of use and number of animals. Because of the limited number of cases in which all three of these conditions coincided, it was not feasible to include this data.

Potential sites were identified by contacting Natural Resources Conservation Service (NRCS) and Montana State University (MSU) Agricultural Extension Service offices in each county as well as other sources within the ranching community and other state and federal agencies. We followed up recommendations with letters to prospective ranchers requesting their assistance. During the course of this project, we visited 70 ranches and looked at more than 90 streams, rivers, or woody draws. We completed inventories on 128 reaches. In addition, we went into the field with range conservationists or wildlife biologists in each BLM Resource Area and looked at more than 20 BLM allotments, primarily as part of an effort to find exclosures which we might use for compari- 
son sites. We subsequently determined there were not a sufficient number of exclosures to pursue this effort. Overall, the emphasis was on smaller streams (3rd order or smaller) and woody draws in central, southwestern, and eastern Montana.

After talking with an operator (generally a ranch owner, but occasionally a manager) about the overall nature of his or her operation and the riparian areas specifically, we surveyed the length of a given stream to determine a representative reach or reaches that reflected the overall nature and condition of the stream or woody draw as it existed within a management unit (pasture). Selected reaches ranged in length from $0.32 \mathrm{~km}(0$. $2 \mathrm{mi})$ to $1.93 \mathrm{~km}(1.2 \mathrm{mi})$, with an average of $0.97 \mathrm{~km}(0.6 \mathrm{mi})$. Because the objective was to compare specific management techniques with the condition of riparian areas, evaluated reaches never extended beyond the boundaries of one pasture. (An inventory unit is referred to as a "polygon"; thus, one reach equals one polygon.) Moreover, to reduce the influence of fences on livestock distribution and movement, polygons were not

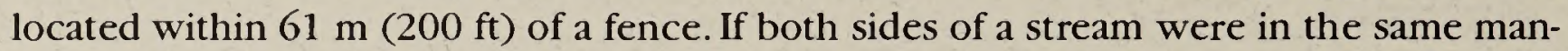
agement unit, evaluations included the riparian area on both sides of the stream. If the property was along a large stream or river where the same operator did not own or manage both sides of the channel or the channel was so large livestock could not walk across, the evaluation covered only the riparian area on the appropriate side.

We included in the data base 64 reaches which rated as functioning properly (healthy) as well as 7 which were evaluated as functioning but with problems and which we judged, based on data and personal observations, to be in an improving trend. (See subsection on inventory and evaluation processes, pp. 7-8, for a discussion of health determination.) The 71 reaches were located on 34 ranches (or BLM allotments) in 27 counties in Montana. In some cases, two or more polygons were inventoried on one stream if the stream ran through more than one pasture or if there were significant differences in vegetation or stream geomorphology.

There were several reasons for not using the other 57 inventoried polygons in the analysis portion of this report. Many were not in fully functioning condition, but this could not be determined until an inventory and assessment had been completed.These were not necessarily the result of grazing impacts. Some had recently been put under a new management approach, and insufficient time had elapsed to determine which impacts had been caused by the old and which by the new approach.A few were determined to constitute a different type of riparian ecosystem (e. g., large river systems such as the Missouri River). Nevertheless, each stream reach surveyed provided insight into some aspect of riparian ecosystem functioning and management.

The approach we took differed from a controlled experiment in that we looked for existing healthy riparian zones (or improving ones) and tried to determine how they have been kept in, or are getting to, this condition. In opting for a descriptive or case study approach, we deliberately traded the higher degree of statistical probability achievable with a very limited experiment for the more general suggestions which numerous workable approaches in a variety of landscapes might offer.

This approach did have several constraints. The selection of potential study locations was determined by the identification of possible participants and their willingness to cooperate. Consequently, with a few exceptions there is only a limited number of any one habitat type or community type. Offsetting this, however, is the breadth of vegetation types and regions of the state which were investigated. Similarly, rather than focusing on a single grazing strategy, we were able to include examples that ranged across the board in seasons of use, lengths of grazing period, and grazing systems.

The historical record we looked at also varied. In some cases, ranchers had detailed records going back twenty or more years. In most cases, we restricted our detailed inven- 
tories and evaluations to sites for which at least ten years of information was available. We made exceptions for cases in which there appeared to be an upward trend which clearly seemed the result of a more recent management change.

\section{Inventory and evaluation processes}

We conducted inventories of selected polygons using a modified version of the Riparian Inventory Form developed by the Riparian and Wetland Research Program (RWRP) in cooperation with the Montana State Office of the BLM (BLM/MSO).All measurements (except Wolman pebble counts) were visual estimates using class codes from the USDA Forest Service's ECODATA program (1989). (Appendix A contains a copy of the Riparian Grazing Study Field Form;Appendix B contains the codes and instructions which explain how data was to be collected and for what purpose.) Data was collected to provide information on the nature of the riparian ecosystem (vegetation characteristics, hydrology, and geophysical aspects), to determine habitat and community types, and to provide the basis for determining how well the riparian area was performing its ecological functions as described in the previous section.

Determination of habitat types and community types was accomplished using the keys in Classification and Management of Montana's Riparian and Wetland Sites by Hansen and others (1995). Assessment of the "health" of the reach (representative of the stream in which it occurred) was made using the Riparian Grazing Study Health Evaluation form, a version of another document developed by RWRP and BLM/MSO. (Appendix $\mathrm{C}$ contains a copy of the evaluation form;Appendix D contains the codes and instructions for filling out the form, along with an explanation of why each item was selected and its weighting.)

While application of the word "health" to ecosystems is likely to initiate vigorous debate among ecologists, in the context of this report it refers to the ability of a riparian reach to perform its ecological functions. Thus, a "healthy" system is one that is functioning properly. The items selected for inclusion in the health rating form and the possible points assigned to each are the result of a four-year effort between RWRP and BLM/MSO. The version used in this study has been field tested and judged appropriate by members of RWRP as well as by BLM Resource Area field people, the Bureau of Reclamation, the Bureau of Indian Affairs, various tribal governments, and several NRCS and MSU Agricultural Extension Service range, wildlife, and hydrology specialists.

The items selected for evaluation were chosen on the basis of the light they would shed on how well the riparian components were performing their natural ecological functions. The three categories into which factors were grouped were Vegetation, Soil, and Hydrology/Streambanks. The evaluation relies heavily on vegetation characteristics as an integrator of factors operating on the landscape. However, four of the 14 evaluative criteria for determining the health of a site address soil, streambank, and hydrologic conditions not directly related to vegetation; together these four comprise 24 of the 60 possible points.

No single factor or characteristic of a riparian site can provide a complete picture of either site health or the direction (improving or degrading) in which it might be heading. Because of the inherent dynamics of such systems, riparian sites often contain a mix of indicators. Moreover, characteristics that in traditional evaluations of ecological sites have been considered negative may not be so in riparian sites. For example, the percent of bare soil, which often reflects overgrazing or erosion on upland sites, may be only a reflection of normal riparian ecosystem activity, such as recent sediment deposits resulting from spring runoff or a high water event. The ratings on the evaluation form have been weighted to take such situations into consideration.

Because plants are more visible than soil or hydrologic characteristics, vegetation 
may provide early indications of riparian health as well as successional trend.These are reflected not only in the types of plants present, but also by the effectiveness with which the vegetation carries out its riparian functions of stabilizing the soil and trapping sediments. Furthermore, the utilization of certain types of vegetation by animals and the presence or absence of different age classes can indicate the current condition of the reach and may indicate trend toward or away from the potential natural community (PNC).

Riparian ecosystems buffer flood energies, filter water that enters the system, and hold water (acting as a sponge) for prolonged late season flow.A riparian site's soil depth and texture influence that site's capacity to carry out these functions and to support vegetation. Exposed soil negatively affects the functions of riparian areas in numerous ways. If the causes of bare ground are human-related or are accelerated by land management practices, this suggests a deteriorating situation. By not discounting for natural bare ground, the evaluation exempts locations where sediment deposition or other natural processes cause bare ground that may be beyond management control.

The hydrology of a riparian site is perhaps its most important characteristic. Hydrologic alteration can cause short term vegetative changes on the site as well as different vegetative potential. Obviously, the composition and condition of the streambanks influence their susceptibility to erosion and trampling. Reflecting the importance of non-vegetation factors in affecting long-term stability as well as the potential for recovery of a degraded site, the evaluation weights soil and hydrology/streambank factors twice as heavily as most direct vegetation factors.

The evaluation factors are weighted so that a riparian area in proper functioning condition scores between 100 percent and 80 percent. A properly functioning riparian system is not necessarily a pristine ecosystem. The health evaluation only assesses a reach's ecological capabilities and does not try to assess socially-determined values. In most cases a reach which has been grazed will look as if it had been grazed. It may, nevertheless, be capable of performing its riparian functions. Reaches judged to be "functioning , but with problems" - that is, performing most but not all of their riparian functions but with problems that could result in fairly rapid degradation-score between 79 percent and 60 percent. Sites with an overall score of less than 60 percent ("non-functioning") are considered to be degraded systems.

The number of variables which may influence or reflect the impact of grazing on riparian zones is impressive, as indicated in part by the number of items contained on the three-page field inventory form. Given these variables, it is not surprising that none of the polygons inventoried coincided in every area. Each was, truly, unique, even though the data did suggest certain relationships.

\section{Data correlation}

Our initial analysis effort focused on a search for correlations between (a) vegetation types and season of use and (b) vegetation types and length of grazing period. Because we were trying to identify the predominant vegetation types from a management perspective, we chose to group vegetation communities into fairly large groupings. The result was a total of 114 stands (spread among 35 different types) within the 71 polygons. Of these, eight constituted less than 25 percent of the polygon of which they were a part. We used only the 106 stands ( 34 different habitat and community types) which constituted more than 25 percent of their respective polygons. We selected a lower limit of more than 25 percent on the assumption that this was a large enough portion of a polygon to reflect impacts and to represent the character of the reach. (Appendix E shows the 34 different habitat and community types included in the study and the number of polygons in which each type contributed more than 25 percent of total canopy cover.)

Only eight of these 34 different types occurred more than five times. We analyzed 
these eight types in terms of season of use and length of grazing period. In addition, to provide a broader base for analysis, we grouped the 34 habitat and community types by life form as listed in Table 1. (Appendix F shows the individual polygons by life form.)

Table 1. Habitat types and community types present in study reaches by life form

\begin{tabular}{cc}
\hline Life Form & No. of Polygons \\
\hline Trees & 2 \\
Coniferous & 29 \\
Deciduous & \\
Shrubs & 32 \\
Willows & 7 \\
Non-willows & \\
Herbaceous & 14 \\
Grasses & 17 \\
Sedges & 5 \\
Grass-like (rush, spike sedge) & \\
\hline \hline
\end{tabular}

Because season of use is one of the most frequently addressed aspects of riparian grazingin the literature, we also considered this variable. It immediately became apparent that the specific periods of use varied greatly among the participating operators. Thus, to compare and contrast operations, it was necessary to group the specific periods of use within broader categories. The first step in this process was to break the calender year into four seasons based primarily on plant phenology and soil moisture. The categories we selected were: Early, Middle, Late, and Winter.

In general, Early season, or spring, encompasses the period from the end of supplemental feeding to seed ripe and includes the time during which soil moisture levels are likely to be high due to snow melt and spring rain. The Middle period includes the hotter part of the summer during which upland forage has dried, seed ripening has occurred, and soil moisture content in the riparian area has declined. Late season covers the period after seed set and, except for cool-season grasses benefiting from fall precipitation, the cessation of herbaceous plant growth outside portions of the riparian area (i. e. , the uplands). Winter covers the period during which supplemental feeding usually occurs and soils are usually frozen.

Obviously, the exact dates which each of these periods encompasses depend on geography, topography, weather conditions, and range condition. Plant phenology and soil moisture are the dominant criteria. For purposes of this report, the following time frames apply:

Early: late April/early May to early/mid July

Middle: early/mid July to mid/late September

Late: mid/late September to late December/early January

Winter: late December/early January to late April

In a few instances, the operations included in this report extended slightly on one side or the other of these groupings; however, the inconsistencies were not deemed sufficient to affect the results.

With these four seasons as a framework, we then assigned the operation in each of the 71 reaches to one of eight grazing strategies depending on when (and how long) the target pasture was used.These eight categories are as follows: 
Various Times from Early through Late with short duration grazing periods occurring more than once a year:

Grazing occurred sometime between late April and the end of December; each grazing period lasted no more than eight days, with several such periods occurring throughout the year. (Designated in tables and appendices as Various [ $\leq 8$ days].)

Various Times from Early through Late with periods of use occurring once a year: Grazing occurred sometime between late April and the end of December for a length of time greater than eight days. Some of these operations were traditional rest rotation or deferred rotation systems; others were less systematic. (Designated in tables and appendices as Various [ $>8$ days].)

Early and Late:

Livestock were put into a pasture early, but were removed before the middle of July (and in most cases well before that time); generally, they went back into that pasture after mid-October.

Early or Late:

The target pasture was used once a year, with use alternating annually between the early and late periods.

Early Only:

The pasture was grazed for a period of time exceeding eight days between late April and mid-July; length of the grazing period differed among operations and generally varied within a single operation from year to year.

\section{Middle:}

Livestock used the target pasture for some length of time exceeding eight days between mid-July and late September; length of the grazing period differed among operations and generally varied within a single operation from year to year.

Late Only:

The target pasture was used only once in any calender year, with livestock not put in before October and taken out by the end of December; length of the grazing period differed among operations and generally varied within a single operation from year to year.

Winter:

That period between late December and late April during which livestock were usually being fed hay. (Appendix $G$ contains the 71 polygons grouped by season of use.)

As was the case with season of use, participating ranchers grazed the target pastures for differing lengths of time (different from other ranchers and often at least slightly different in their own pastures from year to year).To capture this variety in a manageable format, we grouped the 71 polygons into six grazing length categories as follows:

No more than 8 days at any one time ( $\leq 8$ days)

Between 9 and 21 days (9-21 days)

Between 22 and 35 days (22-35 days)

Between 36 and 45 days (36-45 days)

More than 45 days, but not during winter season ( $>45 /$ non-winter)

More than 45 days during winter season ( $>45 /$ winter)

We split out the two longer term lengths into non-winter and winter periods to identify potential differences in impact resulting from differences in plant development stages and soil conditions between winter and other times of the year.As it turned out, 
there were no major differences in the ratings of these two categories.

In most cases, designated days of use occurred in a single time period. However, those operations grazing for eight days or less used the target pasture more than once a year.Additionally, one operator listed under $22-45$ days generally used the same pasture both early ( 12 days) and late ( 14 days), while another in the more than 45 days/non-winter category used the target pasture for about 30 days in the spring and 45 days in the fall. (Appendix $\mathrm{H}$ contains the 71 polygons grouped by length of grazing period.)

We also assigned a "Rosgen stream type" designation to each reach. Since general geomorphological character was one of the criteria for polygon delineation, in most cases we identified only the predominant type. In some instances, however, a reach consisted of several distinct types, in which case we delineated each. Determination of types was based on the methodologies and measurements laid out in Rosgen's Applied River Morphology (1996). In some instances, determination was made by visual estimation.

\section{Results and Discussion}

The most striking characteristic of the 71 reaches we analyzed was the great variety exhibited in the three major categories of interest: vegetation types, seasons of use, and lengths of grazing period.As noted above, we identified 34 different habitat or community types within the 71 reaches. In addition, participating operators employed the full range of seasons of use as well as lengths of grazing periods. Table 2 indicates the number of polygons in which grazing occurred in each of the eight designated seasons. Table 3 lists the number of occurrences by polygons of the six different lengths of grazing period encountered.

Table 2. Number of reaches (polygons) used during each season of use

\begin{tabular}{|c|c|}
\hline Season of Use & No. of Reaches \\
\hline Various $\mid \leq 8$ days $\mid$ & 10 \\
\hline \multicolumn{2}{|c|}{ (Between late April and December for no more than 8 days) } \\
\hline $\begin{array}{r}\text { Various }(>8 \text { days)' } \\
\text { (Between }\end{array}$ & 19 \\
\hline Early and Late & 6 \\
\hline \multicolumn{2}{|c|}{ (Grazing occurred both before mid-July and again after mid-October) } \\
\hline Early or Late & 3 \\
\hline \multicolumn{2}{|c|}{ (Grazing alternated annually between the early and late periods) } \\
\hline Early Only & 5 \\
\hline \multicolumn{2}{|c|}{ (Grazing occurred between late April and mid-July) } \\
\hline Middle & 5 \\
\hline \multicolumn{2}{|c|}{ (Grazing occurred between mid-July and late September) } \\
\hline Late Only & 10 \\
\hline \multicolumn{2}{|c|}{ (Grazing occurred between October and late December) } \\
\hline Winter & 13 \\
\hline \multicolumn{2}{|c|}{ (Grazing occurred between late December and late April) } \\
\hline For all periods excep & th of grazing was more than 8 da \\
\hline
\end{tabular}


Table 3. Number of reaches (polygons) used during each grazing length category

\begin{tabular}{lc}
\hline Length of Grazing Period & No. of Reaches \\
\hline No more than 8 days & 12 \\
Between 9 and 21 days & 8 \\
Between 22 and 35 days & 13 \\
Between 36 and 45 days & 14 \\
More than 45 days (between late April and late December) & 13 \\
More than 45 days (between late December and late April) & 11 \\
\hline \hline
\end{tabular}

\section{Habitat types and community types}

With regard to which grazing strategies (either in terms of season of use or length of grazing time) might be best within what habitat or community types, our results must be inconclusive because the data were evaluated only for "good" sites which were available to investigate and not on a "successful vs unsuccessful" comparison. In addition, the limited number of most of the habitat and community types encountered precluded drawing conclusions.

To investigate more closely the possible relationships between vegetation communities and either season of use or length of grazing, we looked at each stand in the eight habitat types and community types for which we had collected data on five or more stands. (Data is summarized in Appendix I). There was no preponderance of either season of use or length of grazing period evident for any of these types. While each habitat and community type exhibited a range of evaluation ratings for the three categories (Vegetation, Soil, Hydrology/Streambanks), the average overall ratings did not differ appreciably among the eight types, ranging as they did from 85 percent to 89 percent; with four at 85 percent, two at 86 percent, one at 87 percent, and one at 89 percent.

Thus, we cannot say which seasons of use or grazing lengths are "best" for what vegetation types. Nevertheless, since our objective was to determine "what works," it is significant that different seasons of use and different lengths of grazing time may be successful in maintaining or restoring the health of different riparian types. Collectively, these 71 different situations demonstrate clearly the most frequently recurring theme on riparian grazing: each situation must be considered on a site-specific basis.

In the course of the past four years, we looked at riparian zones which were being grazed using the various seasons and lengths addressed here, but which were not functioning as they should. So we know that no strategy works all the time. The data presented here, however, do demonstrate that both different seasons and different grazing lengths can be employed successfully in a variety of riparian ecosystems. Where no data exists, we cannot say a particular combination of vegetation type, season, and length of grazing period could not occur, and is not occurring, somewhere in the state. At the same time, however, the increasing literature on grazing in riparian areas does suggest there are general advantages and disadvantages associated with grazing pastures with riparian areas at different times of the year.The third section of this report addresses the advantages and disadvantages of different seasons of use in greater detail.

\section{Season of use}

To achieve our objective of identifying what management practices are being successfully employed to maintain or improve healthy riparian ecosystems, we analyzed the eight season of use groups and six grazing length periods in terms of the evaluated condition of each site regardless of vegetation types. The overall health evaluation rating for 
each polygon and the score for each of the three subcategories (Vegetation, Soil, Hydrology/Streambanks) grouped by season of use are presented in Table 4 .

Table 4. Average health evaluations for reaches grouped by season of use

\begin{tabular}{|c|c|c|c|c|c|}
\hline \multirow[b]{2}{*}{ Season of Use } & \multirow[b]{2}{*}{$\begin{array}{l}\text { Number of } \\
\text { Polygons }\end{array}$} & \multirow[b]{2}{*}{$\begin{array}{l}\text { Overall } \\
\text { Score }\end{array}$} & \multicolumn{3}{|c|}{ - Rating Categories - } \\
\hline & & & Vegetation & Soil & $\begin{array}{l}\text { Hydrology/ } \\
\text { Streambanks }\end{array}$ \\
\hline Various ( $\leq 8$ days) & 10 & $83 \%$ & $78 \%$ & $87 \%$ & $85 \%$ \\
\hline Various (> 8 days) & 19 & $86 \%$ & $81 \%$ & $91 \%$ & $87 \%$ \\
\hline Early and Late & 6 & $86 \%$ & $81 \%$ & $90 \%$ & $88 \%$ \\
\hline Early or Late & 3 & $81 \%$ & $78 \%$ & $86 \%$ & $82 \%$ \\
\hline Early Only & 5 & $86 \%$ & $87 \%$ & $90 \%$ & $86 \%$ \\
\hline Middle & 5 & $88 \%$ & $90 \%$ & $88 \%$ & $88 \%$ \\
\hline Late Only & 10 & $87 \%$ & $83 \%$ & $93 \%$ & $87 \%$ \\
\hline Winter & 13 & $86 \%$ & $84 \%$ & $88 \%$ & $86 \%$ \\
\hline Weighted Average' & & $85 \%$ & $82 \%$ & $90 \%$ & $86 \%$ \\
\hline
\end{tabular}

Because numerical values for each evaluation factor were based on visual estimations rather than precise measurements, minor differences in the averages presented should not be overemphasized. Nonetheless, several aspects stand out in Table 4. First, as might be expected considering our selection process (i. e., focusing on reaches in or near properly functioning condition), the range between the highest and lowest overall health ratings was limited, running from a high of 88 percent to a low of 81 percent. Second, no one season ranked highest in all three categories (vegetation, soil, hydrology/ streambanks). In fact, a different season of use ranked highest in each of the three categories. However, discounting the Early and Late group (which had only three samples), short duration systems rated lowest in all three subcategories as well as in overall score.

The relatively lower scores for short duration grazing periods suggests that, while limiting the time livestock can spend in the riparian zone is an important consideration, it is not sufficient by itself as a management approach. However, a closer look at the data illustrates the need to go beyond generalizations to consider specific situations. In the first place, the short duration group did have its proper proportion of polygons (based on its percentage of the total 71 polygons) which rated in the upper portion of properly functioning condition (at least 90 percent). In addition, the three lowest short duration reaches-which had overall scores of less than 80 percent-were definitely in upward trends following management changes which included implementation of the short duration approach.

The Vegetation category rated lowest in all but two of the season of use categories and also exhibited the highest range of scores. Moreover, the individual factors with the widest range of ratings were all vegetation factors (noxious weeds, tree regeneration, shrub regeneration, dead woody material, woody canopy cover, and utilization of woody species). This suggests vegetation may be the most responsive to impacts, whether or not these impacts are caused by grazing. It also suggests that as long as the physical (i.e., geomorphologic and hydrologic) aspects of the riparian area remain sound, vegetation can be in less than pristine condition without significantly impacting on the ability of the system to perform its riparian functions. 
Interestingly, the season generally considered potentially the most detrimental for riparian health-mid-July to mid-September, our Middle season-ranked highest in vegetation and highest in overall ranking. This would seem to be yet another indication of the operation-specific nature of successfully conducting riparian grazing operations. In four of the five Middle season operations livestock were in the target pasture no more than 45 days. Four of the operations (all but the shortest period) provided off-stream water, while four also had wooded upland areas to provide shade during hot periods.

To determine if any season or seasons of use contributed to healthier reaches than others, we identified all those polygons which rated at least 90 percent as an overall health score (Table 5). (Appendix J contains a list of all 71 polygons ranked by overall health evaluations.) The Middle season had twice the number of reaches (2 versus 1 ) which might be expected based on its proportion of the total 71 polygons. The Early through Late approaches used at different times (Various [ $>8$ days]) had five polygons rated at least 90 percent rather than the four which might have been expected.The Late Only approach had one reach rated at least 90 percent rather than the two which might have been expected.The other groups (except the limited sample group of Early or Late) were proportionately represented.

Of the four season of use groups which had more than half of their number rated in the upper half of all polygons (Various [ $>8$ days], Early and Late, Early Only, and Late Only), the majority in all four contained alternate water sources. Thus, we concluded that, within this study set, no season of use had a distinct advantage over other seasons. However, the presence of off-stream water does appear to be an influence.

Table 5. Percentage of each season of use group rating at least 90 percent in overall health evaluation

\begin{tabular}{llll}
\hline Season of Use & $\begin{array}{l}\text { Percent of } \\
\text { group with overall } \\
\text { rating of } \geq 90 \%\end{array}$ & $\begin{array}{l}\text { Percent of total } \\
\text { reaches made up } \\
\text { of this group }\end{array}$ & $\begin{array}{l}\text { Number of polygons } \\
\text { in group with overall } \\
\text { rating of } \geq 90 \%\end{array}$ \\
\hline Various ( 8 days) & $14 \%$ & $14 \%$ & 2 \\
Various (> 8 days) & $33 \%$ & $27 \%$ & 5 \\
Early and Late & $7 \%$ & $11 \%$ & 1 \\
Early or Late & $0 \%$ & $4 \%$ & 0 \\
Early Only & $7 \%$ & $7 \%$ & 1 \\
Middle & $14 \%$ & $7 \%$ & 2 \\
Late Only & $7 \%$ & $14 \%$ & 1 \\
Winter & $20 \%$ & $18 \%$ & 3 \\
\hline \hline
\end{tabular}

\section{Length of grazing period}

Summary evaluation data for the six grazing lengths are contained in Table 6. Although the overall average was the same as with season of use ( 85 percent), the range was narrower: from a high of 87 percent to a low of 82 percent. Contrary to what might be expected, the highest overall rating ( 87 percent) went to the group which grazed for more than 45 days in seasons other than winter.Again, short duration operations of eight days or less several times during the grazing season rated lowest overall of the six groups, while the 9-21 day period was the next lowest. 
Table 6. Average health ratings for reaches grouped by length of grazing period

\begin{tabular}{|c|c|c|c|c|c|}
\hline \multirow[b]{2}{*}{$\begin{array}{l}\text { Length of } \\
\text { Grazing Period }\end{array}$} & \multirow[b]{2}{*}{$\begin{array}{l}\text { Number of } \\
\text { Polygons }\end{array}$} & \multirow[b]{2}{*}{$\begin{array}{c}\text { Overall } \\
\text { Score }\end{array}$} & \multicolumn{3}{|c|}{ Rating Categories } \\
\hline & & & Vegetation & Soil & $\begin{array}{l}\text { Hydrology' } \\
\text { Streambanks }\end{array}$ \\
\hline$\leq 8$ days & 12 & $82 \%$ & $79 \%$ & $88 \%$ & $83 \%$ \\
\hline $9-21$ days & 8 & $85 \%$ & $77 \%$ & $91 \%$ & $89 \%$ \\
\hline 22-35 days & 13 & $86 \%$ & $82 \%$ & $90 \%$ & $87 \%$ \\
\hline $36-45$ days & 14 & $86 \%$ & $85 \%$ & $89 \%$ & $85 \%$ \\
\hline$>45$ days (Apr-De & ec) 13 & $87 \%$ & $84 \%$ & $91 \%$ & $88 \%$ \\
\hline$>45$ days (Dec-Ap & pr) 11 & $86 \%$ & $85 \%$ & $88 \%$ & $86 \%$ \\
\hline Weighted Average & & $85 \%$ & $82 \%$ & $89 \%$ & $86 \%$ \\
\hline
\end{tabular}

Nevertheless, given that both groups collectively were in proper functioning condition and individual reaches had reasons which explain why they were not, to say that short duration scores were lower than the other approaches in this study is not to say this strategy is "ineffective" or can't be effectively implemented for a healthy riparian system.That these groups also had the highest stocking densities (AU's per acre) and stocking rates (AUM's/acre) in those instances for which data were available does, however, suggest that the intensity of use certainly cannot be ignored.

Although the majority of reaches were grazed less than 45 days, 34 percent of the reaches were grazed for more than 45 days at a time: 11 during winter season (late December to April) and 13 during periods between April and December.There was no difference between these two groups in any of the major rating categories. Both the winter and non-winter extended grazing periods rated above the average in all three subcategories, and both had high overall ratings ( 86 percent and 87 percent, respectively). Given the absence of growing plant parts and the generally frozen soil conditions existing during winter operations, it might be expected winter use would have less impact and would thus rate high.

Although the rating of 87 percent for the 13 non-winter operations seems surprising, there appear to be reasons which contributed to the high degree of success. These included the presence of offstream water (in 10 of the 13), high bank rock content (more than 50 percent cobble or larger), and extended rest or deferred periods. While limiting the length of grazing period is a good general principle, there would appear to be no definite "cut-off" length of time beyond which grazing cannot be conducted while maintaining a functioning riparian ecosystem.

We also analyzed the hierarchy of overall ratings in terms of length of the grazing period (Table 7). Here there was no appreciable difference between overall proportions and the number of each group whose average overall rating was at least 90 percent. Thus, the length of grazing period by itself seemed to have no impact on the overall rating.Three of the grazing length periods had more than half of their polygons in the upper 50 percent of overall ratings. Of these, 73 percent of both the $36-45$ day group and those grazing more than 45 days between late April and late December had offstream water available. 
Table 7. Percentage of each length of grazing period group rating at least 90 percent in overall health evaluation

\begin{tabular}{lcccc}
$\begin{array}{l}\text { Length } \\
\text { of }\end{array}$ & $\begin{array}{c}\text { No. of } \\
\text { Grazing }\end{array}$ & $\begin{array}{c}\% \text { of group } \\
\text { with overall } \\
\text { rating } \geq 90 \%\end{array}$ & $\begin{array}{c}\% \text { of total reaches } \\
\text { made up } \\
\text { of thisgroup }\end{array}$ & $\begin{array}{c}\text { No. of polygons } \\
\text { in group with } \\
\text { rating } \mathbf{9 0} \%\end{array}$ \\
\hline$\leq 8$ days & 12 & $13 \%$ & $17 \%$ & 2 \\
$9-21$ days & 8 & $7 \%$ & $11 \%$ & 1 \\
$22-35$ days & 13 & $20 \%$ & $18 \%$ & 3 \\
$36-45$ days & 14 & $20 \%$ & $20 \%$ & 3 \\
$>45$ days (Apr-Dec) 13 & $20 \%$ & $18 \%$ & 3 \\
$>45$ days (Dec-Apr) 11 & $20 \%$ & $15 \%$ & 3 \\
\hline
\end{tabular}

Finally, we looked at the distribution of grazing periods within the different seasons (how many of each grazing length group were in each season of use group) and vice versa.There were no strong correlations either way. Likewise, comparison of the 14 specific factors addressed in the evaluation form failed to identify differences which would clearly demonstrate the superiority of one season or grazing length.

\section{Stream types}

As noted above, we assigned a Rosgen stream classification type designation to each reach (Rosgen 1996). All of the inventoried reaches were in B, C, and E stream types. With the exception of woody draws, which we did not classify by Rosgen type, 90 percent of the reaches had a D-50 of gravel, sand, or silt/clay (i. e. , 50 percent of the channel bottom material was that size or smaller). Generally, $\mathrm{C}$ and $\mathrm{E}$ stream types whose predominant channel materials are gravel, sand, or silt/clay are considered very highly sensitive to disturbance. Type B streams with these materials are deemed moderately sensitive (Rosgen 1996).

Table 8. Number of reaches (polygons) per Rosgen stream types

\begin{tabular}{lcc}
\hline Stream Type & No. of Polygons & Rating \\
\hline B3 & 1 & $88 \%$ \\
B4 & 9 & $84 \%$ \\
B5 & 2 & $80 \%$ \\
B6 & 3 & $82 \%$ \\
C3 & 6 & $86 \%$ \\
C4 & 15 & $85 \%$ \\
C5 & 6 & $82 \%$ \\
C6 & 6 & $86 \%$ \\
E4 & 7 & $90 \%$ \\
E5 & 8 & $90 \%$ \\
E6 & 0 & - \\
Woody draw & 8 & $84 \%$ \\
\hline \hline
\end{tabular}

The absence of stream types A, D, F, and $G$ reflects topographic considerations and our study site selection process. Rosgen type A channels are located predominately in steep, narrow, $\mathrm{V}$-shaped canyons. In Montana such areas are most often situated on public rather than private land and thus did not come under our scrutiny. Types $\mathrm{D}, \mathrm{F}$, and $\mathrm{G}$ are 
often disturbance-induced channels which are usually not functioning properly or are in the early stages of an improving trend. Since our selection criteria focused on properly functioning reaches, such non- or poorly-functioning systems were not selected.

There was no distinct correlation between stream types and health evaluation score, season of use, or length of grazing period. Moreover, according to the Riparian and Wetland Research Program's evaluation methodology, reaches whose streambanks do not contain at least 50 percent large rock material (greater than 2.5 inches) are susceptible to degradation. Eighty-seven percent of the reaches inventoried fell into this category. That operations were being successfully conducted in such streams reinforces the basic premise that any riparian grazing prescription must be site specific.

\section{Conclusions}

While not refuting the general advantages and drawbacks inherent in each season of use and the value of limiting livestock time in riparian areas as laid out in the literature (see the following section of this report), these results suggest that with proper management and under specific conditions many pastures containing a variety of riparian types may be grazed in various seasons and cattle may be in a pasture for various periods of time without adversely impacting the health of the riparian area.The condition of the reaches we analyzed and the wide range of approaches being used on them suggest that what operators do to encourage livestock not to loiter in the riparian zone while they are in a pasture is more important than either season of use or length of time in the pasture per se.

For more information on grazing specific habitat and community types, we recommend the detailed descriptions and management considerations of all 113 types covered in Classification and Management of Montana's Riparian and Wetland Sites by Hansen and others (1995). This document is available at all BLM Resource Areas, Forest Service Ranger Districts, NRCS and MSU Agricultural Extension offices in Montana, and from the School of Forestry, The University of Montana.

Despite the variety of seasons of use and lengths of grazing periods which characterize the operations in this study, two common threads do run through them. The first can be quantitatively measured; the second, while not numerically measurable, is even more important.

The one quantifiable factor which was highlighted no matter what grouping we looked at was the presence of offstream water. Forty-one of the 71 polygons ( 58 percent) are in pastures which contain at least one alternate water source accessible to livestock. More significantly, of the 48 polygons in pastures not used in winter or for periods of eight days or less, 71 percent have alternate water. Case studies, controlled experiments, and common experience all confirm that, unless discouraged from doing so, cattle tend to spend a disproportionate amount of time in the riparian portion of any pasture.Alternate sources of water appear to be an important tool to encourage livestock to move away from the riparian area.

The second theme, not obvious in the numerical data, is a high degree of operator involvement. For example, almost none of these grazing periods-regardless of season-were based on rigid schedules or calender dates. This consideration extends as well to the on/off dates upon which the time lengths were calculated. On several occasions when asked for specific dates, ranchers responded with a lecture on being aware of what was going on. To paraphrase one individual: "I can't give you an answer to that. Before you put 'em out there, you have to go look and see what's there. Then once they're there, you have to check on what's happening. Some years I can't go into that field at all. Other years, it may vary from five to 30 days." 
The only universal characteristic of the operators with whom we worked was that all were actively involved in managing their land and had a keen interest in the condition and trend of their riparian areas. Almost all of the ranchers who invited us on to their land did so, in part, so they could ask what others were doing and what they might do differently. While they employed a wide range of grazing strategies and management techniques, each spent considerable time and effort looking at and thinking about what they were doing, what they might do, and what the impacts might be. In some instances, this included formal and detailed monitoring efforts. In most cases, the monitoring consisted of keen observation and some written notes.

An essential corollary to this monitoring activity, whether formal or informal, was the capacity to adapt to what they observed.A willingness to try something else or to modify an approach that didn't seem to be working was a common trait. Leonard Blixrud, for example, commented that when he initiated a short duration grazing strategy north of Choteau, he had tried to go onto his pastures at a certain date. When he discovered this was detrimental to plant growth and vigor, he switched tactics. Phil Rostad thought he could get better results in forage production and cattle gains along the South Fork of the Smith River by shifting newly acquired pastures from season-long grazing to 5-8 days three or four times a summer. He now has willows beginning to establish where "there have never been willows."

Efforts to discover the "appropriate" system for grazing cattle in riparian areas and to implement it without constant attention are bound to fail, given the variation inherent in the natural world in which ranchers operate. When we began this project, we had intended to look specifically at grazing "systems," such as rest rotation and deferred rotation. It became obvious, however, that many of the useful techniques being employed throughout the state (e.g., off-stream water development) were not tied to any particular system. We concluded, therefore, that riparian grazing might be incorporated into each of the traditional grazing systems-except season-long-as long as the condition of the riparian zone itself remains of primary concern. Management, not the system, is the key.

The next section of this report addresses major factors which operators and land managers must consider when preparing to graze riparian areas and discusses specific techniques for implementing these considerations. 


\section{Principles and Techniques for Riparian Grazing}

\section{General Principles for Grazing Cattle in Riparian Zones}

In contrast to a decade ago, when Platts and Raleigh (1984) observed that "the literature ... is almost devoid of those management practices that are capable of mitigating and rehabilitating these effects [of grazing]," there now exists a growing body of work which addresses this problem. (The final section of this report contains a selected bibliography of some of the most useful of these.) This section consolidates examples we have seen in Montana and insights presented in the literature into general principles which public and private land managers should consider when preparing to graze cattle in pastures with riparian areas and suggests specific techniques for applying these principles. (Had the word guidelines not been perverted to mean "constraints" or "limitations," this section might properly have been entitled "Riparian Grazing Guidelines.")

Tailor the grazing approach to the specific riparian and stream ecosystems under consideration.

The dominant theme of virtually all the literature, experimental and anecdotal, on approaches to grazing riparian zones and their companion streams is that "no two stream systems are alike - each has its own level of ability to withstand natural and/ or buman-induced stress" (Buckhouse and Elmore 1993; italics in original).Accordingly, "no treatment or system of treatments will work everywhere" (Swanson 1986). This situation imposes a burden on land managers, private and public, for it requires that they understand the nature of the particular riparian and stream systems with which they are dealing, including: hydrologic and geomorphologic characteristics, current and potential plant species and communities and their responses to grazing and browsing, animal behavior, forage preferences, and the management feasibility of possible treatments (Krueger 1996).According to Green and Kauffman (1995),"Our results indicate that ... basing management recommendation[s] on [only] 1 component ignores the inherent complexity of riparian ecosystems."

Tailoring one's approach to a particular area also involves determining specific riparian objectives (May and Davis 1982). It is possible to maintain or even to improve riparian zones without identifying specific objectives beforehand. Several of the ranchers with whom we talked admitted they had undertaken actions to achieve a "non-riparian" goal and discovered one result was an improvement in their riparian area. Such situations, however, are the exception. Knowing where you want to go is specially important to rehabilitate a riparian area in a degraded condition. Only rarely will this happen without definite, positive steps on the part of the manager.

Ranchers and range conservationists traditionally have focused on herbaceous plant 
growth and utilization. Development of riparian vegetation objectives, therefore, may not be too difficult. On the other hand, given the importance of residual vegetation (see below), it is necessary to invert the emphasis from "what to take" to "what to leave" (Burkhardt 1986). In addition, objectives in riparian areas must include less familiar aspects such as woody species utilization and regeneration, streambank condition, and channel morphology. (Kinch [1989] and Krueger [1996] are especially good on what factors need to be considered and how to look at them.)

An important step toward the attainment of identified objectives is the development of a monitoring program designed specifically to track those aspects of the system which will provide information on whether conditions are moving in the right direction. For example, if a management objective is to increase willow canopy cover along a stream, the regeneration and development of willow plants must be monitored. It is not enough simply to monitor the growth and utilization of herbaceous vegetation as traditionally done in upland pastures (Hansen 1993). In the words of Wyoming rancher Jack Turnell, first recipient of the National Cattlemen Association's Environmental Stewardship Award, "If you're not monitoring, you're not managing"(1993).

Incorporate management of riparian areas into the overall management plan.

Because riparian areas comprise only a small portion of the area on any ranch or grazing allotment, they must be addressed within the context of an overall management plan. This does not contradict the previous guidance. Rather it recognizes the need to adopt approaches that are managerially feasible as well as ecologically sound. It also recognizes the essential ecological links among the stream channel, the riparian area, and the uplands: "Proper upland management is essential for obtaining a healthy riparian area, the two go hand in hand" (Tohill and Dollerschell 1990).

This principle serves as a reminder that any actions or decisions taken with regard to riparian zones will have an effect on other parts of the operation. Planning when and how long to use pastures with riparian areas, for example, will involve decisions on where the animals will be the rest of the year.An aspect of riparian management often overlooked is that the less time livestock spend in the riparian zone, the greater proportion of time they will be in the uplands. In situations in which wild ungulates also depend on upland forage, the impact of this redistribution must be carefully considered.

Focusing too narrowly just on actions within the riparian zone ignores the full complement of possible steps which might contribute to maintaining or improving this zone.As we have already indicated and will illustrate below, some of the most significant steps Montana ranchers have implemented to improve their riparian systems have taken place well out of the riparian area.

Select season of use so grazing occurs, as often as possible, during periods compatible with animal behavior, conditions in the riparian zone, and riparian objectives.

Livestock will affect riparian vegetation and physical conditions differently depending on many factors, including the site's physical characteristics and conditions, the stage of plant development, the nature of the plant communities in both the riparian zone and the uplands, and current weather.As Buckhouse noted in his 1995 report, to attain management objectives that mesh economic ends with ecological needs requires that "soil physics, watershed (especially infiltration), plant growth and development factors/responses, and animal behavioral responses all must be factored in."

While our study results suggest there is no universally applicable "best time" in which to graze riparian zones, there is increasing evidence that different seasons have identifiable characteristics that tend to result in fairly predictable impacts-predictable enough, at any rate, to provide the basis for initial planning. (See pp. 23-31 for a discus- 
sion on seasons of use.) One key reason for having clearly defined riparian objectives is to provide assistance in determining which season of use will best move a particular riparian zone toward specific objectives.

There are often tradeoffs in potential impacts with regard to time of use, and managers must keep in mind their objectives as well as the condition of the riparian zone. For example, while late summer use will reduce trampling impacts on streambanks, it may also result in heavy use of young woody plants. Varying the season of use annually will change the nature and extent of the possible impacts which can result from livestock grazing.

\section{Limit the time livestock spend in pastures with riparian areas.}

While there are different opinions regarding the best season of use, there is greater consensus that the length of time animals spend in a riparian area can be a significant factor in the condition of that area.According to Marlow and his colleagues (1991), "The most critical aspect in any grazing plan for the protection of riparian areas is the length of time cattle have access to a particular stream reach." Myers (1989), reviewing 34 allotments in southwest Montana, concluded, "Duration in grazing treatments becomes a key factor in determining the severity of damage" because of the tendency of cattle to hang out in the riparian area even when not actively feeding. Marlow (1985) made the point that "the length of the grazing period should be based on the areas cattle are actually using, not the entire pasture."

As noted in the preceding section, with the exception of winter grazing periods, less than 20 percent of the operations we evaluated as having healthy riparian areas exceeded 45 days in the target pasture and most were considerably shorter. Those ranchers who did graze a pasture more than 45 days had taken other steps to reduce the time livestock actually spent in the riparian area.

\section{Control the distribution of livestock within the targeted pasture.}

Left on their own, cattle tend to spend a disproportionate amount of time in the riparian area and to overutilize the forage which grows there.According to Clary and Webster (1989), domestic livestock will spend from "five to 30 times longer" in a riparian area than might be expected based on the relative size of the riparian area to the entire pasture. Bryant (1979) noted that, given the choice, both yearlings and cows with calves preferred the riparian area over the uplands for much of the summer grazing season.

Riparian areas are often only two to three percent of the area of a pasture, but they may produce 20 percent of the forage and receive up to 80 percent of the use if measures are not taken to redistribute animals (Krueger 1984, cited in Vavra 1984). In 23 of 25 cases in Idaho, Utah, and Nevada, cattle used streamside vegetation twice as heavily as overall pasture use (Platts and Nelson 1985c). Nor is the impact on vegetation the only concern. The presence of livestock has physical impacts as well, including soil compaction, bank trampling, and degraded water quality due to waste materials entering the stream channel.

Determining the most appropriate season for grazing a particular pasture with riparian areas is one method to control distribution because it allows the manager to use natural conditions and animal behavior to advantage. There are also numerous techniques to encourage livestock to venture away from the riparian zone. Both season of use and other techniques are discussed below. Except for individuals using short duration grazing periods, almost all of the ranchers we worked with were doing something to encourage livestock into the uplands.

\section{Ensure adequate residual vegetation cover.}

Vegetation cover is essential for maintaining almost all types of healthy riparian eco- 
systems. Myers (1989) concluded that, through a combination of rest and removing livestock in sufficient time to provide for regrowth, successful riparian grazing systems provided residual vegetative cover 75 percent of the years, whereas unsuccessful systems provided for this only 38 percent of the time.Although closely tied to utilization levels, an emphasis on residual vegetation cover offers a different perspective. Rather than emphasizing what the animals get, the focus is on the plants and their role in the ecosystem: "More important than knowing how much herbage can be removed ... is knowing how much should be left for ecosystem maintenance.Approaching utilization from this standpoint provides for the physiological needs of the plant species" as well as for the plant's capacity to perform riparian functions (Thilenius 1979).

How much and what type of vegetation exists on a site determines how well the riparian system performs its functions of reduction of flow velocity, sediment trapping, bank building, and erosion protection. What constitutes "adequate" cover depends on the location of the riparian pasture and the specific situation. In a simulation study of riparian stubble height, Clary and others (1996) concluded different stubble heights are needed to fulfill the two processes of sediment deposition (trapping) and sediment retention (bank building), with shorter heights (0.5-6.0 inches) better for the former and taller (8-12 inches) for the latter. It is, at any rate, important to remember that the vegetation which exists on site at the end of the growing season or at the end of a grazing period, whichever comes last, is what matters since this is essentially what will be available during the next runoff period. In many situations projections of residual vegetation must also include consideration of probable wildlife use prior to spring runoff.

Provide adequate regrowth time and rest for plants.

For plants to remain vigorous and productive, they must be provided time for growth, seed development, and storage of carbohydrates. Continual grazing during the plant's growth period eventually causes roots to die back, the plant to lose vigor, and seed development to cease. The result can be a change in plant community, usually from more productive, palatable species to a less productive and less palatable group of plants.All of the studies which have identified steps toward proper riparian grazing management stress the crucial need for adequate rest or at least the cessation of grazing in time to allow plant regrowth to occur.

\section{Be prepared to play an active role in managing riparian areas.}

At first glance, this statement seems trite and overly-obvious. However, it gets to the heart of the matter. In their extensive review of riparian grazing literature, Clary and Webster (1989) concluded, "Most riparian grazing results suggest that the specific grazing system used is not of dominant importance, but good management is-with control of use of the riparian area a key item ...."They also observed that, while specific "results" are often attributed to the implementation of a particular grazing system, these effects may well have stemmed from "the whole range management program" that accompanied the introduction of that grazing system. In other words, success in maintaining or enhancing riparian health is dependent more on the degree of operator involvement than on what grazing system is employed.

There are a variety of specific techniques operators can use-and are using-to translate the general principles outlined above to on-the-ground operations. Which ones, or what combination of them, might be effective will depend on the riparian area in question and the willingness of the manager to be actively involved in their implementation. For ease of presentation, we have divided these activities into two broad categories: (1) determination of an appropriate season for grazing the riparian zone and (2) methods for reducing intensity of use in the riparian area through control and distribution of livestock within a pasture. 


\section{Determining Season of Use}

Determination of an appropriate time of year for grazing a specific riparian area is one of the first steps in developing a riparian grazing management approach. Which season (or seasons) this might entail will depend on a broad range of factors. Perhaps the three most significant are the predicted response of different plant species, the impact on the overall plant communities which can result from grazing, and the degree of soil moisture on the site. Not surprisingly, there are advantages and drawbacks to grazing during each season. Moreover, because of the fluctuation in natural systems (e. g., variations in temperature, timing and amount of precipitation, and vegetation growth), the appropriateness of using a particular pasture may vary somewhat from year to year. It is also possible that the nature and condition of a given riparian area makes no grazing the only ecologically viable solution.

Early Season (Spring) Use.

Evidence suggests early season use may be best for those situations in which: (1) livestock can be attracted to the uplands by succulent, herbaceous forage; (2) cool temperatures may discourage cows from loitering in the bottoms or weather in the uplands is not such as to drive them into riparian areas; (3) soil in the riparian area may be so wet as to discourage cows from entering; or (4) well-drained soils reduce the possibility of compaction (Gillen and others 1985; Platts and Nelson 1985a; Clary and Webster 1989; Kinch 1989; Clary and Booth 1993).

Potential advantages. The availability of succulent upland vegetation may induce livestock to spend time out of the riparian zone and thus reduce use of riparian plants as well as reduce the amount of soil compaction and bank trampling. In addition, early use allows time for subsequent regrowth of plant species in the riparian zone as well as the uplands as long as animals are removed while sufficient soil moisture and appropriate temperatures remain (Elmore and Kauffman 1994). The presence of palatable herbaceous plants reduces pressure on woody plant species and allows them opportunity for maximum growth during this critical period (Kovalchik and Elmore 1992).

Platts and Nelson (1985a and 1985c) observed that livestock distributed themselves better throughout pastures and concentrated less in riparian areas during the spring. In a semi-arid portion of northcentral Wyoming, "relatively intense short-term grazing" in early summer apparently had little affect on the morphology of an ephemeral stream channel because cattle spent less time there during that period than later in the summer or fall (Siekert and others 1985). Both Crouse (1987) and Elmore (1988) reported improvements in riparian areas as a result of grazing them only in the spring (cited in Clary and Webster 1989). Krueger (1983) reported that forested riparian areas grazed in the spring had less than half the cattle occupancy compared to fall use (cited in Kovalchik and Elmore 1992).

Because of the essential role of woody species in maintaining riparian functions, reduced browsing pressure on trees and shrubs may be one of the most significant benefits of early season use (Swanson 1987). In eastern Oregon, cottonwood and willow seedling density was "somewhat greater" with moderate spring use than in moderate fallgrazed, season-long, or no grazing treatments (Shaw 1988, cited in Clary and Webster 1989).According to Kovalchik and Elmore (1992), early grazing "can be very beneficial to riparian areas, especially in establishing woody plants."They caution, however, that the impact of browsing during flowering and early seedling stages of willows, should this occur, needs more study. Clary and Webster (1989) concluded, "While no one management approach is best for all situations, spring grazing has shown promise in many areas of the Western United States." 
Scheduling of early season grazing must allow time for vegetation regrowth (Bryant 1985; Clary and Webster 1989; Kinch 1989; Kovalchik and Elmore 1992; Buckhouse and Elmore 1993; Buckhouse 1995). In reviewing 34 grazing allotments in southwest Montana, Myers (1989) observed that the nine operations which had healthy riparian areas allowed for an average of 35 days of vegetation regrowth versus 21 days for unsuccessful operations. Failure to allow for regrowth after grazing ceases will, over time, not only impact vegetation in the riparian zone, but will also reduce the vigor of upland plants and may result in changes in plant communities (Marlow and Poganick 1986).

Possible disadvantages. There are possible drawbacks to early season grazing in riparian areas, however. First, because of high soil moisture levels, the potential impacts in terms of soil compaction, bank trampling, and subsequent erosion are greatest during this period. Second, utilization occurs during the critical period of plant growth and development, and repeated grazing of desirable herbaceous species at this time may affect plant vigor and may lead to changes in plant communities. Third, from a livestock production standpoint, the nutritive value of upland forage may be low and may require supplemental feeding. Finally, early season grazing may adversely affect wildlife in the area.

While wet soil conditions may discourage livestock from entering the riparian area, these same conditions make the system susceptible to serious damage if they do so. In a study at Red Bluffs Experimental Station west of Bozeman, Montana, Marlow (1985) discovered the greatest bank damage occurred in late June and early July when cattle use of the riparian zone was lowest, but soil moisture content was 18-25 percent. By August soil moisture had declined to 8-10 percent, and damage in the grazed riparian reach was no greater than that in the ungrazed reach. In some well-saturated soils, grazing animals are more likely to uproot plants in the spring than during other seasons (Kinch 1989). Underscoring the site-specific nature of this factor, Buckhouse (1995) cautioned that while early spring grazing seemed to work on well-drained soils, it tended to result in compaction on poorly drained soils. Livestock use of these zones in spring is more likely in areas where steep topography inhibits livestock movements into other parts of the pasture. Such situations will probably require additional management actions such as installation of drift fences to reduce the tendency to congregate and remain in the accessible bottoms. (See sub-section on "Reducing Intensity of Grazing" below.)

Although the exact impacts of early season use on wildlife will depend on the species involved and the site itself, they may include disruption of birthing and nursing grounds and reduction in forage available to wild ungulates (Holecheck and others 1982).With appropriate timing, however, early season livestock grazing can "prepare" a pasture for later wild ungulate use by removing vegetation that would otherwise become rank and unpalatable (Anderson and Scherzinger 1975; Frisina and Morin 1991; Buckhouse 1995). Conflicts with birds, particularly those which nest and raise their young on the ground, are likely during this season (Bock and others 1993). Grazing during this or any other period does not impact all bird species the same, however, since the effects depend on the particular habitat involved, the bird species most likely to use that habitat, and the time of year (Dale 1984; Kantrud and Higgins 1992). Possible impacts of early season grazing on small mammals include loss of hiding cover and reduced food materials.

Study reaches. Forty-three of the polygons reviewed in the current study were grazed at least some years during the early part of the grazing year.Three of these alternated years between early use and late use (with the length of use ranging from 20 to 45 days); their average overall health score was the lowest of the eight grazing periods ( 81 percent). Six operators used the same pasture both early and late; the length of the grazing period ranged among the different operators from 0.5 days to 30 days during the 
early period. Their overall health score averaged 86 percent, slightly above the combined average of of 85 percent for all 71 polygons.

Five polygons were grazed only during the early season (with an average score of 86 percent) and in a variety of ways. Three of them were used for 22-35 days, but livestock were removed by late May. One was a short duration operation used for less than eight days in the spring.A pasture on the Little Powder River in southeastern Montana in properly functioning condition was grazed annually from the middle of May until mid-July (about 60 days). Its healthy condition ( 87 percent) may be attributed to the quality of offstream water (in contrast to that in the stream channel) and to the presence of older cottonwood groves away from the river which provide shade as temperatures rise.

Twelve polygons were part of short duration strategies which included early season use for no more than eight days during the course of any one year. The overall health score average for these polygons was 83 percent, although they ranged from 91 percent to 77 percent. Those with the two lowest ratings had both converted to short duration grazing recently and were in an upward trend. Of the 19 polygons which were part of strategies that included more than eight days of early use during a grazing season, only one operator went into his pasture about the same time annually, but not earlier than the 20 th of June. The others varied season of use either within a definite rotation pattern or based on their assessment of their pastures. Their average health rating was 86 percent and ranged from 95 percent to 78 percent. Significantly, all provided for early season rest at least one out of three years (if not more frequently) or moved livestock out of the pasture before the end of the growing season.

\section{Late Season (Fall) Grazing.}

Deferring grazing use until fall may offer distinct benefits to maintaining the health of the riparian area under the following conditions: (1) when riparian plant communities consist of herbaceous rather than tree or shrub ("woody") species; (2) when cool season grasses stimulated by timely precipitation provide palatable forage in the uplands; (3) where offstream water near accessible forage sources is available, or other inducements (e. g. , cold air pockets streamside or the absence of hot temperatures in the uplands) draw cattle out of the riparian area.

Potential advantages. The primary advantages of late season grazing are: most plants have completed their growth cycle, and grazing will not adversely affect plant development; soils are drier, which reduces the probability of compaction and bank trampling; and, generally, there is less impact on wildlife habitat.

Compared with spring use, fall grazing occurs when soil moisture is greatly reduced (Marlow 1985).This difference can be particularly significant where fine-textured soils are highly susceptible to compaction when wet. In Oregon, Buckhouse and Bunch (1985) determined there were no significant differences between streambank erosion in pastures moderately grazed in the fall and ungrazed control pastures. However, on a similar stream in the same area researchers concluded, "The late season grazing was found to significantly increase streambank erosion," although it did not appreciably affect soil compaction (Kauffman and others 1983).

One of the most important advantages of late season grazing is that for many herbaceous species seed set has already occurred, and defoliation will have less impact than during earlier development stages (Kauffman and Krueger 1984; Gillen and others 1985). In addition, with adequate precipitation, regrowth of upland forage may draw cattle out of the riparian bottom areas. Swanson (1987) suggested grasses, sedges, and rushes in Nevada can do well under late season use, and researchers in Oregon agreed late season grazing may be appropriate for herbaceous-dominated streams without natural woody components (Buckhouse 1995). Green (1991) found productivity and density of riparian 
meadows were maintained with late season grazing at moderate use levels (cited in Elmore and Kauffman 1994).

Late season grazing avoids conflict with ground nesting birds (Kauffman and others 1982; Vavra 1984; Bock and others 1993). It may, however, reduce the forage available for winter ungulate use and limit cover density for small mammals prior to the following year's green up (Kauffman and others 1982). Kauffman (1982) suggested late season grazing in eastern Oregon resulted in minimal short-term disturbance to wildlife as well as limited soil disturbance, improved livestock performance, and allowed for good plant vigor and productivity (cited in Kauffman and Krueger 1984).

Possible disadvantages. Late season use may be detrimental to the health of riparian areas. Where reduced soil moisture and declining temperatures are the norm, regrowth after the cattle are removed will not occur.This may limit the capability of plant communities to fulfill their riparian functions during the succeeding spring runoff. In addition, livestock are much more likely to browse woody species during this period. Finally, unless provided with incentives, cattle are less likely to range away from the riparian areas; moreover, the natural incentive of palatable upland forage often is not present.

While regrowth of cool season grasses and cooler weather may draw cattle out of the riparian zone in the fall, should weather in the uplands remain unpleasant or should palatable forage not be available there, they are likely to congregate in the riparian bottoms (Platts and Raleigh 1984; Green and Kauffman 1995). Even when positive conditions prevail, they are still less likely to distribute themselves as broadly as in the spring. Under these conditions, cattle have a tendency to remain in the riparian area and to continue to graze vegetation there even when the nutritive value of that forage has declined (Gillen and others 1985).Thus, it is particularly important to monitor the extent of residual vegetation to ensure enough remains to perform sediment trapping and streambank protection functions as well as to provide for continued plant vigor (Marlow 1985; Clary and Webster 1989).

Where woody species (trees and shrubs) are part of the potential natural community of a riparian site, perhaps the most detrimental aspect of late season grazing is its possible impact on shrubs and trees (Cheney, Elmore, and Platts 1990; Buckhouse and Elmore 1993; Krueger 1996). Cattle preference for woody species often increases significantly in late summer and fall. This seems to be due in the first instance to greater palatability and higher protein content when compared with most surrounding herbaceous species (Kovalchik and Elmore 1992). Higher browse use may also reflect the fact that cows are spending more time in the riparian area and have already consumed significant portions of the herbaceous forage available. While observing that riparian meadows remained healthy under moderate use, Green and Kauffman (1995) noted woody growth and succession on gravel bars were adversely affected.

Based on extensive experience in Nevada, Swanson (1987) recommended shrublined streams should be grazed in the spring and early summer since they are adversely affected by heavy late summer, fall, or winter grazing. Myers (1989), who considered the condition of woody plant communities as a paramount criterion for a "successful" riparian grazing program, noted successful systems involved "significantly less" late season grazing than unsuccessful systems (an average of 21 days versus 36.5 days) and less frequent grazing late in the year ( 31 percent of the years as opposed to 51 percent). One of the criticisms of many three pasture rest rotation systems is that the fall grazing period, even though only occurring every third year, may remove two to three years of willow growth, thus setting back succession or maintenance of willow communities (Buckhouse and Elmore 1993). 
Kovalchik and Elmore (1992) suggested willow use generally will remain low as long as palatable herbaceous forage is available, and they tentatively identified herbage utilization levels which trigger greater browse use. For initial planning, they recommended ending mid- and late-season grazing before herbaceous forage use in the riparian zone exceeds 45 percent. There is some evidence, however, that in certain circumstances livestock may prefer woody browse over herbaceous material even before some threshold of herbage utilization is reached (Personal observation). In one of our short duration polygons, for example, cattle were observed making frequent use of Acer negundo (box elder) saplings and seedlings the first day they went into the pasture and when palatable herbaceous forage was present.

Green suggested herbaceous utilization levels on riparian meadows "were an inadequate indication of willow recovery" (cited in Elmore and Kauffman 1994). For this reason, managers must monitor woody browse use rather than relying on traditional herbaceous utilization when healthy woody communities are a management objective (Hansen 1993).

In many cases, the reduction of shrubs in riparian zones results primarily from browsing of new, young plants rather than mechanical damage to older plants (Clary and Webster 1989). Kovalchik and Elmore (1992) observed first year seedlings are "very sensitive to grazing" and may easily be destroyed by browsing, trampling, or being uprooted. If woody regeneration is an objective, several years of non-use may be necessary to allow new plants to become established (Munther 1982; Skovlin 1984; Personal observation).

As with each of the other possible seasons of use, however, with proper management late season grazing need not be detrimental to the health of riparian zones. Manoukian (1994), evaluating 28 years of cattle grazing in the Centennial Valley of southwest Montana, determined that a four-pasture rest rotation strategy which included late season use had not reduced tall willow growth or development. Riparian areas in a BLM three-pasture rest rotation system on Blucher Creek in southern Wyoming was grazed late every third year and had all age classes of willows, good plant vigor, and predominantly stable streambanks (Kinch 1989).

Study reaches. Many of the ranchers in the current study grazed their riparian areas at least sometimes during the late season. Ten polygons (five operators) were used only in the fall. Interestingly, all ten of these riparian areas were primarily woody habitat or community types, and in all but one cattle remained in the pasture more than 30 days. Nevertheless, their average overall health rating was 87 percent, with a range from 83 percent to 93 percent. Seven of the ten (including those with the longest grazing times) contained alternate water; one operator deliberately grazed his pastures very hard and then provided two full years of rest; and two operators herded livestock regularly. Five operators grazed the target pasture both early and late in the same year. Only one of these did so for up to 45 days in the fall; the other four remained no more than 14 days. These five had an average health rating of 86 percent, with a range from 93 percent to 77 percent. Ten polygons were part of short duration strategies which included late season use for no more than eight days in any year.

Of the 19 polygons which were part of strategies that included late use from between 9 and 21 days during a grazing season, none grazed the target pasture in the fall two years in a row; many provided more rest than that. While there was a variety of grazing lengths involved in these operations, six of the 10 with the highest health scores $(\geq$ 86 percent) did not graze the target pasture in the fall even every other year. Collectively, the 19 polygons had an average health rating of 86 percent, ranging from 95 percent to 78 percent.Although rotation systems per se (particularly conventional three-pasture rest rotation) generally appear not to be the "solution" to riparian grazing requirements, alter- 
nating or at least not using a pasture the same time each year may alleviate the potential drawbacks to both late and early season grazing strategies.

\section{Hot Season (Mid-summer) Grazing.}

Next to season-long grazing, which is universally recognized as detrimental to riparian areas, repeated or extended grazing during the hot summer season is generally considered most injurious to riparian zones. However, under certain conditions, pastures with riparian areas can be grazed during the summer without harming the riparian area. The following situations are most likely to prevent deterioration of riparian areas during this period: (1) when the operator closely monitors conditions in the riparian area specifically and the period of grazing is limited in duration and frequency (Clary and Webster 1989); (2) when effective management actions have been taken to encourage livestock to move out of the riparian area; (3) when time of removal and climatic conditions provide opportunity for regrowth or cattle are not put into the pasture on an annual basis (Swanson 1987).

Possible disadvantages. Although there are some advantages to grazing during the hot period of the summer (see below), the possibilities of adversely affecting riparian areas is very high. These result from disadvantages of grazing during this period, including: (1) the greater tendency of livestock to remain in the riparian area and accompanying stream channel; (2) reduced plant vigor and possible changes in vegetation communities from the more intense use that results; (3) possible damage to tree and shrub species that play vital roles in the maintenance of riparian zone health.

Drying out of upland herbaceous vegetation and high temperatures in the uplands combine to push livestock into the riparian area during the summer. Along an ephemeral stream in northcentral Wyoming, cattle were found in the channel during the summer grazing period at a rate more than twice that at which they were sighted there during the spring (Siekert and others 1985). Once there, they tend to overgraze herbaceous plants even when the nutritional value they receive declines (Gillen and others 1985). Compounding the effect of this tendency is the increased vulnerability of the plant communities.

The hot season is the "period of greatest stress in the plant community" because there is less time for vegetative regrowth and for the replenishment of carbohydrate reserves necessary to maintain the plants during their dormant cycle (Kinch 1989). If grazing extends beyond the growing season, there will be no regrowth. Repeated grazing during this period (that is, every year) reduces the vigor of individual plants and, over time, will result in a shift in the plant communities from desirable to less desirable species. Often the latter are less capable of performing the functions required for a healthy riparian ecosystem as well as being less economically productive (Hansen and others 1995). Palatable shrubs such as willows are also particularly vulnerable before they complete carbohydrate storage (Kindschy, cited in Kinch 1989).

As palatability of herbaceous forage declines through the summer, livestock are increasingly likely to shift to browse species, often with detrimental effects.According to Kovalchik and Elmore (1992), "Unless grazing systems allow for sufficient [herbaceous] forage height growth during the mid- to late-summer period, they will fail to maintain willow-dominated plant communities."

In a four-year study in northeastern Montana, Populus deltoides (Great Plains cottonwood) seedlings sprouted readily, but were all eaten or trampled within two weeks of the introduction of cattle during both summer and fall grazing periods (Gjersing 1981). Following a ten-year study in Oregon, Green and Kauffman (1995) concluded, "Livestock browsing had significant [negative] affects on the density and height of woody species on gravel bar communities."Their study sites contained several tree and shrub species 
common to Montana, including Populus trichocarpa (black cottonwood), Salix bebbiana (Bebb willow), Salix exigua (sandbar willow), and Alnus incana (mountain alder).

In the course of our project, we observed summer use pastures with poor condition woody communities as a result of livestock use. Even in the sites we inventoried there was evidence that cattle were browsing young willow and cottonwood plants during this period, sometimes in wet meadows which still had herbaceous forage. Knopf and Cannon (1982) noted that, in addition to degradation due to browsing, livestock also damage woody plants during this period by rubbing against them and by breaking them as they seek other forage (cited in Kovalchik and Elmore 1992).

Myers (1989) concluded that one significant difference between unsuccessful and successful grazing programs in southwest Montana was that the former had almost three times the amount of hot season use as the latter.This relationship was seconded by the experience of the Snowline Grazing Association, also in southwest Montana, where the difference in functioning condition between two adjacent, similar reaches was determined to be twice as much hot season use in the "functioning, but with some problems" reach as in that evaluated as "functioning properly" (Barb Landgraf, pers. com. 1995).

Potential advantages. Despite these problems, there are some advantages to allowing cattle to graze in riparian areas during this season, provided managers maintain close control and monitoring (Clary and Webster 1989). Swanson (1987) noted that while streambanks are more stable than earlier in the year, there frequently is sufficient soil moisture to allow for regrowth. From a livestock production standpoint, herbaceous forage in the riparian zone may be considerably more palatable and nutritious than desiccated upland plant material.To avoid impacting plant vigor, Swanson recommended short grazing periods rotated between years. Bohn and Buckhouse (1985) showed that, over a five year period, grazing in September demonstrated "a positive hydrologic response, whereas late-season grazing in October was negative - probably due to the onset of fall rains and a change in soil moisture conditions."

Study reaches. Five ranchers in the current study grazed the study pasture only during the hot season. Their combined rating was 88 percent, the highest average of the eight grazing season groups. One did so only 10 to 20 days at different times each year; another grazed heavily each August and followed this with two years of complete rest; and a third grazed a mountain riparian zone every other summer with alternate water and shade available. The other two operators grazed their pasture every summer. One of them had taken other steps to induce cattle not to camp in the riparian area.The fifth situation was an anomaly. The rancher used the pasture each summer for more than 90 days; but, although his uplands aren't in particularly good shape, his riparian area had healthy bank-holding sedges and fish in the narrow channel. Of the ten ranchers (in 19 polygons) who grazed at various times between April and December, including the hot period from mid-July to mid-September, none grazed the study pasture every summer. In addition, 15 of the 19 polygons contained alternate water for livestock use, and most had shade available away from the riparian area.

Hot season use can be less detrimental when there is both alternate water and upland shade.Along Greyson Creek south of Townsend cattle were in the study pasture the third week of August, but had done little browsing on riparian willows and had not appreciably impacted either herbaceous vegetation or streambanks. This pasture contained wooded uplands and alternate water, and the operator distributed salt along ridgetops well away from the bottoms.

Conversely, several pastures we inventoried but rated not in proper functioning condition were summer use pastures in drier, eastern Montana with only limited woody shade and that generally confined to riparian zones with intermittent streams. In several 
of these operations, recent introduction of additional water tanks, and in one case a change in pasture arrangement, may result in improved conditions. When they were inventoried, however, insufficient time had elapsed to determine this.

The need to monitor conditions especially closely during this period was illustrated by two operations in our study. Both had been in excellent functioning condition when inventoried (one in 1994, the other in 1995). When we had the opportunity to look at them again in 1996, both clearly showed heavy use in the riparian zone due to circumstances to which the operator did not respond quickly enough or which were the result of climatic conditions affecting other portions of the ranch. Fortunately, livestock were removed in 1996 while an opportunity for regrowth remained. Because the reaches had been in high functioning condition, they should recover. Still, the visual differences between years were great, and several consecutive years of such treatment would result in detrimental long-term impacts.

Winter Use.

Winter use may be the least detrimental to riparian health and may, in fact, "benefit both range and riparian conditions by improving livestock distribution and plant response" (Masters and others 1996). It can be an especially useful management approach: (1) where soil type makes compaction and susceptibility to streambank trampling and deterioration during other seasons a high probability; (2) when the pasture is large enough to supplemental feed well away from the stream; and (3) when drainages are colder than surrounding uplands or open south-facing slopes reduce use of the riparian area.

Potential advantages. The advantages of winter use are obvious. Soil compaction should be minimal, and bank trampling should be limited because of frozen ground (Severson and Bolt 1978; Buckhouse and Skovlin 1979). Utilization of herbaceous species is not detrimental to plants because no growing parts are exposed at this time of year. In addition, this period may be the easiest in which to control livestock distribution through location of watering facilities and feeding stations.

Possible disadvantages. There are potential drawbacks to winter grazing operations. In the first place, grazing of dead standing material can reduce streambank protection capabilities and reduce sediment entrapment in the spring (Kinch 1989; Kovalchik and Elmore 1992). Depending on the species and their locations, browsing of shrubs and small trees remains a problem. For example, while sedge communities in flat, broad valleys in Montana increased under a winter grazing regime, shrubs continued to be overused (Myers, pers. com. cited in Elmore and Kauffman 1994). Even if there is little browsing, livestock can do significant physical damage to trees and shrubs by trampling and rubbing. Discussions with several ranchers and personal observations suggest bulls are especially likely to cause this type of damage.

Woody draws and other woody riparian communities provide valuable protection to livestock during extreme weather conditions, but repeated concentration of animals in these areas can result in deterioration of the woody community.This condition will be evidenced by a lack of regeneration and a predominance of dead and decadent mature plants. Moreover, if livestock are still present when spring thaw occurs, there is likely to be serious soil compaction, bank trampling, and erosion as well as physical damage to emerging herbaceous plants.

Significant damage, or at least changes, may occur during the winter as a result of natural causes, such as ice flows and jams, anchor ice, and high water. Buckhouse and Skovlin (1979) noted that overwintering periods along a streamside meadow in the Blue Mountains tended to be more erosive than any of their summer grazing treatments (rest rotation, deferred rotation, season-long) for both grazed and ungrazed areas. In his extensive review article, Skovlin (1984) referred to several researchers in various states as 
agreeing that, frequently, whatever trends might be apparent after summer grazing in different systems at moderate stocking levels "are erased by natural events such as peak flows and river ice conditions over winter." Additionally, the effects of soil compaction and the amount of trampling which occurs during the spring and summer may be ameliorated over winter by the alternation of freeze-thaw and wet-dry periods (Federer and others 1961, cited in Skovlin 1984).

Study reaches. Eleven operators in this study limited their use of the inventoried polygons to winter only, ranging from 30-45 days up to 120-200 days. Their average score was 86 percent, the same as the overall average for all 71 polygons.

Season of use, then, is an important element to successfully grazing pastures with riparian zones. Simply selecting a feasible season, however, does not constitute a complete approach since the time livestock spend in the riparian area itself must also be considered. Clary and Webster (1989) concluded, "The level of utilization occurring on a site-including riparian areas-is the most important consideration" (bold in original). Similarly, after reviewing 18 studies, Van Poollen and Lacey (1979) stressed riparian vegetation is more affected by grazing intensity than by grazing system. On the other hand, Krueger (1996) argued, "Intensity of use or stocking intensity is far less important than season of use, within reasonable limits of intensity."

Regardless of the relative importance of season and intensity per se, the more time cattle spend in the riparian area itself, the greater the potential for damage. Therefore, managers must look for ways to manage the amount of time cattle spend in the riparian area.

\section{Reducing Intensity of Use by Influencing Distribution}

Finding ways to control the amount of time livestock spend in the riparian area is an essential component of proper riparian management. Selecting the appropriate season of use is one basic, and often relatively easy, tool which can contribute to this objective. There are other techniques to encourage livestock to move out of the riparian area "by making the uplands more attractive to the grazing animal" (Krueger 1996). Of these, the single most important may be the development of off-stream (alternate) water.

\section{Off-stream water.}

Clawson (1993) found that installation of a water trough in an Oregon mountain meadow pasture reduced use of the stream from 4.7 to 0.9 minutes per cow per day, while use of a spring in the same pasture dropped from 8.3 to 3.9 minutes per cow per day. Cattle watered out of the trough 73.5 percent of the time, compared to only 3 percent from the stream and 23.5 percent from the spring. During a winter feeding operation, also in Oregon, the presence of a water trough 100 yards from the riparian zone reduced the time cattle spent at or in the stream by 90 percent (Miner and others 1992). Wyoming rancher Jack Turnell, often cited for his outstanding stewardship, declared that water developments are "the key" to successful grazing management (1993). Demonstrating that no one approach works everywhere, however, Bryant (1979) determined that neither alternate water nor mineral placement influenced distribution significantly in another Oregon mountain meadow. The appeal of alternate water sources includes water quality, temperature, and better footing (when excess water is piped away from the trough).

Developing water away from the riparian area may include running pipelines from the stream, fencing out and developing seeps and springs with pipes leading to troughs, and installing windmills. Technological improvements have significantly reduced the cost of such developments. For example, a hard, synthetic pipe is now available which can be laid on top of the ground rather than having to be entrenched and covered (Burleson, 
pers. com. 1995).This reduces the expense of installation and provides some flexibility in moving tanks to meet management objectives and local conditions.

The Snowline Grazing Association in Beaverhead County (southwest Montana) has placed several troughs fed by over-ground pipes with good success (Robinson, pers. com. 1996). Harding Land and Livestock Company east of Miles City has dug water tanks (fed by pipelines) into hillsides and covered each with a mound of dirt for insulation. These remain unfrozen and available to livestock at temperatures down to -40 degrees $F$ (Currie, pers. com. 1994). Hydraulic ram pumps, portable solar-powered pumps, and animal-activated (by nose) pumps are currently being used not only in Montana but in other states and Canada (Robinson pers. com. 1996; Ducks Unlimited n.d.).

Except for those using short grazing periods or engaged in winter only operations, 70 percent of the ranchers included in the present study have developed one or more off-site water sources in the study pastures. The significance of this action was especially noticeable in those areas where hilly topography or upland conditions would tend naturally to push and keep livestock in the riparian zone. While the majority of winter operations did not include off-site water, one-third of them did. In addition, most winter use operators took care to feed away from the riparian area. One rancher succinctly stated, "We never feed anywhere near a shrub that we want to live."

Stable access points.

A variation of off-stream water development is to encourage livestock use of only a small part of the stream. Providing stable access points to water can significantly reduce streambank trampling.There is evidence livestock prefer stable footing and clean water and will travel a considerable distance to reach them (Kellogg, pers. com. 1995). The installation of concrete walkways, with incised troughs to maintain water flow, on Big Warm Creek in Phillips County south of Malta provided livestock with easy access to water and a means to cross the stream without trampling the banks. It had the additional benefit of reducing what had been the loss of about a cow each year to mud and ice breakthroughs to none since their installation about eight years ago. Rock dams along Larb Creek in Valley County have contributed to streambank stability and revegetation by concentrating livestock access. Such in-stream structures, however, can affect a stream's hydrology and must be carefully planned and installed.

Large-gravel approachways laid down perpendicular to Ben Hart Creek north of Belgrade in a sedge-dominated meadow resulted in a marked improvement in stability of streambanks which previously had suffered considerable bank deterioration. Streams with a large percentage of bank rock greater than gravel-size have an inherent stability which makes such devices less necessary. Since the majority of operations in central and eastern Montana lack this characteristic, stable access points merit serious consideration. Proven designs are now available which reduce the impact of concentrating livestock at a few locations; these include "side bars" of logs or rock and web matting as well as gravel.

\section{Salt and mineral block placement.}

Although unlikely by itself to affect animal distribution significantly, placement of salt and mineral blocks can contribute to better distribution as well as improved forage utilization. Kinch (1989) recommended salt and supplements be placed a minimum of a quarter-mile from a stream and preferably at least a half-mile. In conjunction with other steps such as alternate water, this can be effective. None of the ranchers with whom we worked salted in the immediate vicinity of the streams. Many of them specifically commented on salt and mineral placement as a deliberate part of their management strategy. 


\section{Improve upland forage.}

Another approach to luring livestock out of the riparian area is to improve upland forage (Storch 1979; Kinch 1989; Krueger 1996). Again,"It is important to recognize that uplands must not be excluded from consideration of riparian areas, because they are an integral part of the system" (Elmore 1990). Several activities we observed in the field underscored the value of considering riparian zones within the context of an overall management plan. In Prairie, Custer, Phillips, and McCone counties, chiselling of upland areas resulted in significant increases in Agropyron smithii (western wheatgrass) production. This, in turn, pulled livestock out of the adjacent bottoms in the early spring when streambanks and adjacent meadows are most vulnerable to trampling and compaction.

Similarly, by disking and planting introduced species, including Medicago sativa (alfalfa) and Agropyron cristatum (crested wheatgrass) in his uplands, a rancher along the North Fork of Snow Creek north of Brusett not only increased forage production almost 100 percent, but also enticed stock out of the vulnerable streamside areas. The palatability of this succulent early season vegetation also allowed native species several additional weeks of unimpeded growth. The vigorous upland vegetation communities which have resulted from a system which includes extended rest between grazing uses contribute to the exceptionally healthy woody draws found on a ranch in Wibaux County.

\section{Riding.}

Riding is increasingly being used as a method to move stock out of riparian areas, especially by large operations (Storch 1979). Many ranches and grazing associations routinely ride their herds to check on their animals. Thus, applied to riparian management, riding represents an expansion of a traditional activity rather than implementation of a new technique. The purpose of the riders in this case is to move the cows away from the streamside area. Such activity has been used with some success by the Upper Ruby Grazing Association along the Ruby River south of Sheridan, by the Snowline Grazing Association south of Lima, and by the Lane Ranch in the foothills of the Adele Mountains south of Cascade. The efficiency of this technique is enhanced by the presence of alternate water to reduce the incentive to return to streamside immediately.

The experience of all three operations indicates that ensuring the riders know what is expected and the reasons behind such actions is critical to success. Poorly conducted riding can cause more harm to the riparian zone and to livestock performance than having the cows remain in the riparian area. Obviously, using riparian areas as gathering areas and collection points is exactly the opposite of riding to disperse cattle. Not unexpectedly, the results inevitably demonstrate this.

\section{Home ranges.}

Related to the idea of providing incentives to encourage cows to distribute more widely throughout the pasture is the issue of home ranges. According to Roath and Krueger (1982), cattle have home ranges much like wild ungulates, and animals which remain near the riparian area pass this behavior pattern to their off-spring. Several authors have suggested this could be one basis for culling decisions (May and Davis 1982; Kinch 1989).To our knowledge, the economic feasibility of such an approach has not been investigated, and it may not be feasible on a large scale. However, it may be worth considering for animals that are especially prone to such behavior or in situations where a riparian ecosystem is particularly important for its ecological role or because of human values.

\section{Fenceless fences.}

Experiments have been conducted with "fenceless fences" using electronic-impulse ear tags for boundary control and deterrents from site-specific areas, much like the de- 
vices used to train dogs to stay in their yards. To date, no conclusive results or products are available (Tibbs and others 1995).

\section{Drift fences.}

In hilly topography or incised channels, livestock are likely to use the riparian area and the streambed itself as a corridor and routinely meander up and down. Drift fences or other obstacles which deflect movement out of and away from this corridor can greatly reduce pressure on the riparian area and streambanks.

Along several study reaches in central and eastern Montana we observed that Bromus inermis (smooth brome) not only provided excellent soil stability; but also acted as a barrier to livestock when these pastures were grazed in late fall and winter. The coarseness of the plant reduces its palatability and enhances its capacity as a physical barrier. This is particularly the case when there are "designated" access points to the stream or, better, alternate water sources are available.

\section{Turn-in location.}

A common sight in pastures on private and public land alike is the location of gates near, if not immediately adjacent to, a riparian area. Often, particularly in the case of hilly terrain, this reflects the fact that the riparian and stream corridor is the easiest point of access since the lay of the land makes it a funnel for movement uphill and down. In a study in the Blue Mountains of Oregon, Gillen and others (1985) observed that the turnin location can delay up to two weeks the arrival of cattle to the riparian area. In an allotment in the Sula Ranger District south of Darby, moving the cattle directly to grassy, open hilltops above the narrow riparian bottoms combined with the development of water in these uplands to improve distribution significantly (McClure, pers. com. 1994). Similarly, the Snowline Grazing Association has relocated a gate into one of their pastures.Although it is too early to determine the long-term effect of this step, it appears to be improving distribution and easing the pressure on the riparian area (Robinson, pers.com. 1996).

\section{Riparian pastures.}

A major tool to control the time livestock spend in riparian areas (and thus reduce the intensity of use) is the establishment of riparian pastures (Kauffman and others 1983; Swanson 1987; Elmore 1990). These can be defined as "a small pasture within an allotment that is set aside to be managed independently to achieve a specific vegetative response." (Platts and Nelson 1985c). In three tributaries on USDA Forest Service allotments in Idaho, utilization of forage was less in the riparian area than in the upland portion of specifically designed riparian pastures. Researchers attributed this to the ratio of upland to riparian forage, the fact that the entire pasture was in the livestock's home range, and the placement of salt away from the stream (Platts and Nelson 1985c).

The purpose of riparian pastures is not to fence out the riparian areas, but to provide for closer management and control of their use. Such pastures should include not just narrow riparian strips but upland areas with sufficient forage so that cattle will not be forced into the riparian area for feed (Kinch 1989). Skovlin (1984) suggested a minimum size of 30-40 acres for mountain riparian pastures. Use patterns may have to be different from upland pastures because the riparian pastures may have to be grazed at different times of the year or for different lengths of time. Given the productive nature of many riparian areas, it may be possible to graze these pastures more frequently although not for so long a period of time at any one use (Myers 1989). Experiences with short duration grazing operations in our study, however, suggest this must be evaluated on a caseby-case basis. 


\section{Smaller pastures.}

Another variation of this approach is to establish smaller pastures with some riparian area in each rather than having only a few large pastures with a limited amount of riparian area (Elmore 1990). Smaller pastures can result in better distribution and forage utilization throughout each pasture due to the resulting higher stocking density (Marlow and others 1991). Along Birch Creek northwest of Valier, the creation of smaller pastures using easily portable electric fence and short duration grazing has contributed to a significant increase in young age classes (seedling and sapling) of Populus angustifolia (narrowleaf cottonwood), Salix lutea (yellow willow), and Salix exigua (sandbar willow). More pastures allow for greater control over the amount of time spent in any one riparian zone since livestock can be moved more frequently when use in each has reached the desired limit. Because of the higher stocking density, it is imperative to monitor herbaceous utilization, browse levels, and streambank conditions closely.

\section{Fencing.}

Exclusion of livestock through fencing is a riparian management technique that works. In some instances, permanent - or at least long-term-exclusion may be the easiest, most convenient, and most economical option to restore riparian areas. In a few situations, it may be the only ecologically feasible method. It is not, however, the optimum approach in most cases. None of the operations we studied involved total exclusion, yet the riparian areas in each were either functioning properly or recovering from a previously degraded condition.

There seems little doubt that "livestock exclusion [from riparian zones] has consistently resulted in the most dramatic and rapid rates of recovery" (Elmore and Kauffman 1994). Fencing out reservoirs and running pipes to outside troughs provided clean, cool water for livestock while simultaneously providing excellent habitat for waterfowl and other wildlife on the Diamond Willow Ranch south of Malta.

On the other hand, total exclusion may not be required to maintain riparian zones, including their stream channels, in properly functioning condition or to restore those that are not functioning as they should. Wayne Elmore and J. Boone Kauffman (1994), two of the most experienced practitioners and researchers in the field, recently concluded, "Livestock grazing can be present in some areas while streams are improving." Implementation of one or more of the other techniques discussed above-accompanied by clear objectives and an adequate monitoring program - may be sufficient for rehabilitation. While most of the sites we evaluated were being maintained in proper functioning condition, at least six were clearly improving due to management changes (four with shortening of the grazing period, one by adding an alternate water source, and one by converting to winter use instead of season long).

Temporary fencing to allow for the restoration of riparian systems which are not functioning properly may be necessary or at least may be the quickest method for reestablishing healthy and productive riparian areas (Platts and Wagstaff 1984). In four operations in this study in which at least two full years of rest had been provided within the five or six years prior to being inventoried, this rest was reflected in the amount of young shrubs and trees. Restoration of degraded woody plant communities is especially likely to require either complete rest for several years or, at the least, limited early season use only (Platts and Raleigh 1984; Clary and Webster 1989; Personal observation).

How much time is required to rehabilitate a degraded riparian ecosystem to functioning condition is a matter of some debate (See Skovlin [1984] and Platts and Raleigh [1984] for excellent summaries of this dialogue). Not unexpectedly, the answer must be site-specific and consider such factors as current physical and hydrologic conditions, ex- 
isting plant communities, potential and desired plant communities, topography, hydrology, and climate. At any rate, technical improvements in electric fencing and solar-powered batteries make temporary fencing more feasible than in the past.

Whether by total rest or by improved management techniques, restoration of degraded riparian ecosystems is rarely immediate. Vegetation will often respond within a few years. If the soil and hydrologic characteristics are severely degraded, however, restoration to a healthy condition may take an extended period (Platts and Raleigh 1984; Hubert and others 1986).

Canadian Lorne Fitch, co-author of a recent riparian grazing publication (Adams and Fitch 1996), has suggested exclosure fencing is an admission that we can't out-think a cow (pers. com. 1995). This homily, humorous on the surface, bears a fundamental truth: to out-think a cow requires that we do think, as well as implement, monitor, and respond to developments. The days when streamside zones could be written off as "sacrifice areas" are past. Successful management of cattle in riparian areas requires active management both in planning and in on-the-ground activities. As the operations in this study demonstrate, however, the rewards for this effort include both ecologically healthier ecosystems and economically more productive livestock operations.

\section{Conclusions}

For people who seek simple answers to complex issues or problems, the conclusions of this study will be disappointing. There is no single-let alone simple-solution on how to graze livestock in riparian areas in ecologically and economically feasible ways. Nor are there boiler-plate solutions that can be easily hammered into a shape to meet any situation (Myers 1989). What is required is not a catch-all remedy, but a carefully considered prescription drawn up to address the conditions at a specific site with its unique circumstances and desired objectives (Anderson 1993; Buckhouse and Elmore 1993). This approach, referred to as prescription grazing, is well-summarized by Dr. William Krueger (1996, emphasis in original): "By understanding the nuances of specific watersheds, in specific settings, during specific weather patterns, with specific livestock or big game herds, and involving specific people, a program with a bigh degree of potential for success can be developed."

There are numerous techniques available for developing and implementing an appropriate prescription for any given riparian ecosystem. The only required ingredients are a serious commitment and personal involvement on the part of operators and managers. The one theme which pervades both the riparian grazing literature and the operations studied in this project is that the manager is more important than a particular approach. 


\section{Select Bibliography}

In the past fifteen years, a considerable body of literature has evolved dealing with various aspects of livestock grazing in riparian areas throughout the western United States.To assist in finding these materials, several useful bibliographies are now available. Particularly extensive, although somewhat dated (which is an indication of how rapidly the field is developing), is $A$ Bibliography of Riparian Research and Management (1992) by John Van Deventer and the Idaho Riparian Cooperative. Oregon State University Extension Service has just published a more current compilation available on computer disk: Livestock Influences on Riparian Zones and Fish Habitat:A Bibliography (Larsen and others 1997).

This section makes no attempt to duplicate the works mentioned above. Its purpose is to identify for interested readers, both agency people and livestock operators, some of the most useful and available publications and to provide some insight into the strengths of each.The focus is on management considerations important to those who deal with riparian grazing on a regular basis in the field. Emphasis is on overview materials rather than specific studies or individual grazing strategies. Publication details are contained in the literature cited portion of this report.

The most recent, and the best, "How To" publication intended primarily for private ranch operators is Caring for the Green Zone: Riparian Areas and Grazing Management (1996) by Canadians Barry Adams and Lorne Fitch. Public land managers will also find it extremely helpful. Effectively using photographs and diagrams, the authors present information on riparian structure and function, the ingredients of a successful grazing management program, and techniques by which these ingredients might be applied to a piece.of ground. This glossy 36-page pamphlet is "must reading" for those who wish to prepare and implement a riparian grazing strategy.

Jon Skovlin's 1984 article, "Impacts of Grazing on Wetlands and Riparian Habitat:A Review of Our Knowledge," contains a wealth of information on the impact of livestock grazing on riparian and wetland ecosystems. Scholarly in tone and presentation, it is an excellent starting point for understanding the impact of livestock on all aspects of riparian and wetland ecosystems, including vegetation, erosion and stability, water quality, and fish and wildlife habitat and populations. Skovlin also briefly summarizes cattle behavior as it affects their activities in riparian areas and the reasons for high use of these areas by domestic grazing animals. Although information on management practices is limited, it does have an exceptional bibliography for those interested in more detailed articles on the many issues the author addresses. Contained in the same book (Developing Rangeland Strategies) is a commentary by William Platts and Robert Raleigh (1984) which expands on Skovlin's points. They particularly stress the importance of understanding the geomorphologic and hydrologic aspects of individual sites and emphasize the extended time periods which might be needed for full restoration of degraded reaches. Platts and Raleigh refer to their own extensive field experiences as well as to the literature. 
Although shorter than Skovlin's, another essential overview of grazing effects is "Livestock Impacts on Riparian Ecosystems and Streamside Management Implications ... A Review," by J. Boone Kauffman and William Krueger (1984). In a concise yet illuminating manner, the authors cover the importance of riparian areas to in-stream ecosystems, wildlife, and livestock. Having laid this background, they present tersely but comprehensively the available knowledge on the demonstrated effects of livestock on aquatic ecology, terrestrial wildlife, riparian vegetation, and soil and streambank stability. Again, given the date of publication, references to successful grazing strategies are limited.The literature cited section, however, is extensive. The ready availability of this article Journal of Range Management, September 1984) enhances its value as a source for understanding the nature of riparian zones and their associated in-stream systems and the impact that domestic grazing can have.

The two major land management agencies have also produced publications with guidance for managing domestic grazing in riparian areas. The USDA Forest Service's technical report, Managing Grazing of Riparian Areas in the Intermountain Region (1989) by Warren Clary and Bert Webster, focuses on that region, but is applicable to many parts of the West. The authors pay particular attention to the stubble heights required to maintain riparian functions, with recommendations on appropriate stubble height to retain when grazing in different seasons. Densely packed appendices address the relative merits of focusing on grazing system, stocking rate, intensity of use, and season of use as guidelines for developing proper grazing strategies. An additional appendix includes A. H. Winward's guide to calculating ecological status and resource value ratings in riparian areas.

The USDI Bureau of Land Management's contribution, Grazing Management in Riparian Areas by Gene Kinch (1989), is a somewhat longer document.After stressing the importance of management objectives, Kinch reviews the major considerations in grazing management, including season of use, distribution of use, appropriate utilization levels, and timing, duration, and frequency of grazing based on both a review of the literature and examples from BLM experiences. He notes briefly specific management activities which can influence distribution of livestock within a pasture.A large portion of the document presents examples of successful grazing treatments on BLM allotments broken out by season of use or specific grazing system.

For a review of the negative impacts of livestock grazing on western rangelands, including riparian areas, written from the perspective of conservation biology, a solidly written article is Thomas Fleischner's "Ecological Costs of Livestock Grazing in Western North America" (1994).

One of the most recent comprehensive reviews of livestock grazing management for maintaining and restoring riparian functions is Wayne Elmore's and J. Boone Kauffman's "Riparian Watershed Systems: Degradation and Restoration" (1994), in the Society of Range Management's excellent Ecological Implications of Herbivory in the West.After touching on the historical situations which led to present conditions, the authors' emphasis is on management strategies and their probable impacts. An extra bonus is the inclusion of tables which summarize key articles by Platts (1989), Myers (1989), Kovalchik and Elmore (1992), and Buckhouse and Elmore (1991, reprint in 1993). Although not comprehensive, the literature cited section does contain the more current materials.

Bernard Kovalchik's and Wayne Elmore's "Effects of Cattle Grazing Systems on Willow-Dominated Plant Associations in Central Oregon" (1992) is one of the few studies which looks specifically at a variety of grazing strategies and willow species. The authors evaluate eleven common grazing systems and their impact on willow-dominated communities. While the study sites were in central Oregon, most of the plant communities are found in other locations as well. 
One of the best short articles on the relationship between riparian vegetation and livestock grazing is "Managing Ungulates to Allow Recovery of Riparian Vegetation" (Krueger 1996). Stressing the need to develop grazing approaches based on site-specific vegetation responses, Krueger addresses briefly but effectively basic principles of animal behavior, forage palatability, plant responses to grazing, plant community responses, hydrology, and economic and social feasibility.

Lew Myers' 1989 paper on "Managing Livestock to Minimize Impacts on Riparian Areas" analyzes 34 grazing systems in operation in southwest Montana.Assessing riparian communities largely on the basis of their woody species components, Myers compared "successful" (properly functioning) and "unsuccessful" (not functioning properly) systems in terms of season of use, length of use, residual herbaceous material, stocking rates, duration of grazing in different seasons, and percentage of treatments with fall use.

The often negative impacts of livestock grazing on fisheries was one of the major reasons generating interest in grazing of riparian areas. William Platts, a leader in this effort, has authored or co-authored numerous articles on aspects of the topic. Perhaps the most comprehensive of these is his chapter entitled "Livestock Grazing" in Influences of Forest and Rangeland Management on Salmonid Fishes and Their Habitats (1991). After a brief history of grazing in the western United States and the current condition of riparian areas, Platts reviews the importance of riparian vegetation in terms of fish habitat, streambank stability, stream temperature, and production of fish prey.The meat of the chapter focuses on the effects which must be considered on streambanks, water column, stream channel, and riparian vegetation when developing a grazing strategy. He then evaluates the compatibility of 17 livestock grazing strategies (including different kinds of animals) with fishery needs.

Given the current emphasis on "stability" of stream and riparian ecosystems, the study by Thomas Myers and Sherman Swanson, "Variation of Stream Stability with Stream Type and Livestock Bank Damage in Northern Nevada" (1992), is useful in pointing out the significance of different stream types when making decisions in such areas as setting local use standards, writing management objectives, or determining grazing strategies. Specifically, the authors relate the Pfankuch (1975) stream stability rating procedure to Rosgen's stream type classification system (1996).

Although not dealing specifically with grazing of riparian areas, an excellent short discussion of the physical features of small streams useful to land managers and operators seeking to understand riparian and stream systems is "Morphological Features of Small Streams: Significance and Function" (1986) by Robert Beschta and William Platts. While focusing on physical characteristics, they are also good on stressing "the important role of riparian vegetation" in stream stabilization efforts.

The Environmental Protection Agency (EPA) has produced two eye-catching publications intended for the general public and private land managers and prepared by three key figures in research and management of riparian grazing: Ed Chaney, Wayne Elmore, and William Platts. The first, Livestock Grazing on Western Riparian Areas (1990), touches on the functions and values of western riparian zones, the causes and effects of degradation, and possible approaches to successful riparian grazing. The bulk of the pamphlet consists of case studies of riparian areas throughout the West which have been enhanced by management actions. A particular strength of the book is the photographs (especially the series of "before and after" comparisons) and diagrams which help to explain the points being made.

Managing Change: Livestock Grazing in Western Riparian Areas (1993) is a companion pamphlet aimed specifically toward "the men and women who move the stock." Its purpose is to get people to consider riparian areas from a variety of perspectives and to stimulate thinking about possible management improvements.Again, the use of "be- 
fore and after" photographs as well as computer enhancements of site potential overlaid on photos of existing conditions are particularly useful in understanding the key points. Although brief, the discussion of considerations for developing a riparian grazing strategy will be helpful to many operators. 


\section{Literature Cited}

Adams, B., and L. Fitch. 1995. Caring for the green zone: riparian areas and grazing management. Alberta Riparian Habitat Management Project, Lethbridge,Alberta.

Almand, J. D. , and W. B. Krohn. 1979. The policy of the Bureau of Land Management on the protection and management of riparian ecosystems. In: Strategies for the protection and management of floodplain wetlands and other riparian ecosystems. Coordinated by $\mathrm{R}$. R. Johnson and J. J. McCormick. USDA Forest Service General Technical Report WO-12. Washington, DC. pp. 359-361.

Anderson, E. William. 1993. Prescription grazing to enhance rangeland watersheds. Rangelands 15(1):31-34.

Anderson, E. William, and Richard J. Scherzinger. 1975. Improving quality of winter forage for elk by cattle grazing. Journal of Range Management 28(2):120-125.

Beschta, Robert L., and William S. Platts. 1986. Morphological features of small streams: Significance and function. Water Resources Bulletin 22(3):369-379.

Bock, Carl E. ,Victoria A. Saab, D. Rich Terrell, and David S. Dobkin. 1993. Effects of livestock grazing on neotropical migratory landbirds in western North America. In: Status and management of neotropical migratory birds. Edited by D. M. Finch and P.W. Stangel. USDA Forest Service General Technical Report RM-229. Rocky Mountain Forest and Range Experimental Station, Fort Collins, CO. pp. 296-309.

Bohn, C. C. , and John C. Buckhouse. 1985. Some responses of riparian soils to grazing management in northeastern Oregon. Journal of Range Management 38(4):378-381.

Bryant, Larry D. 1979. Livestock response to riparian zone exclusion. M. S. Thesis, University of Idaho, Moscow, ID.
Bryant, Larry D. 1985. Livestock management in the riparian ecosystem. In: Riparian ecosystems and their management: Reconciling conflicting uses. R. Roy Johnson, Charles D. Ziebell, David R. Patton, Peter F. Ffolliott, and R. H. Hamre, Technical Coordinators. First North American Riparian Conference,April 16-18, Tucson, AZ. USDA Forest Service General Technical Report RM-120. Rocky Mountain Forest and Range Experimental Station, Fort Collins, CO.pp. 285-289.

Buckhouse, John C. 1995. Lessons learned concerning livestock in riparian zones and the associated uplands of rangeland watersheds. In: Eastern Oregon Agriculture Research Center Field Day annual report. Oregon Agricultural Experiment Station Special Report 951. Oregon State University, Corvallis, OR. pp. 34-39.

Buckhouse, John C., and Thomas Bunch. 1985. Riparian erosion inside and outside of exclosures on Mill and McKay Creeks:A validation of management. In: Eastern Oregon Agriculture Research Center Field Day annual report. Oregon Agricultural Experiment Station Special Report 951. Oregon State University, Corvallis, OR. pp. 29-30.

Buckhouse, J., and Wayne Elmore. 1991 [reprint 1993]. Grazing practice relationships: Predicting riparian vegetation response from stream systems. In: Watershed management guide for the Interior Northwest. Edited by Thomas Bedell. Oregon State University Extension Service, Corvallis, OR. pp. 47-52.

Buckhouse, John C., and Jon M. Skovlin. 1979. Streambank erosion in a Blue Mountain stringer meadow in response to livestock and big game grazing management. In: Eastern Oregon Agriculture Research Center Field Day annual report. Oregon Agricultural Experiment Station, Special Report 549. Oregon State University, Corvallis, OR. pp. 2-4. 
Burkhardt, Wayne. 1986. Unpublished notes from BLM monitoring committee meeting held in Washington, DC. Cited in Hayes, Art. 1992.An annotated bibliography on the utilization of grasses with emphasis on riparian areas. N. p.

Burleson, Wayne. 1995. Certified Range Consultant.Absarokee, MT. Personal conversation with authors.

Chaney, Ed, Wayne Elmore, and William S. Platts. 1990. Livestock grazing on western riparian areas. Northwest Resource Information Center, Inc., for U.S. Environmental Protection Agency. Eagle, ID.

Chaney, Ed, Wayne Elmore, and William S. Platts. 1993. Managing change: Livestock grazing on western riparian areas. Northwest Resource Information Center, Inc. , for U. S. Environmental Protection Agency. Eagle, ID.

Clary, Warren P. , and Gordon D. Booth. 1993. Early season utilization of mountain meadow riparian pastures. Journal of Range Management 46:493-497.

Clary, Warren P. , and Dean E. Medin. 1990. Differences in vegetation biomass and structure due to cattle grazing in a northern Nevada riparian ecosystem. USDA Forest Service Research Paper INT-427. Intermountain Research Station, Ogden, UT.

Clary, Warren P. , and Bert F. Webster. 1989. Managing grazing of riparian areas in the Intermountain Region. USDA Forest Service General Technical Report INT-263. Intermountain Research Station, Ogden, UT.

Clary, Warren P. , and Bert F. Webster. 1993. Early season utilization of mountain meadow riparian pastures. Journal of Range Management 46(6):493-497.

Clary, Warren P. , Christopher I.Thorton, and Steven R.Abt. 1996. Riparian stubble height and recovery of degraded streambanks. Rangelands 18(4):137-140.

Clawson, Jeff E. 1993. The use of off-stream water developments and various water gap configurations to modify the watering behavior of grazing cattle. M. S. Thesis. Oregon State University, Corvallis, OR.
Crouch, Glenn L. 1982. Wildlife on ungrazed and grazed bottomlands on the South Platte River, northeastern Colorado.In: Wildlife-livestock relationships symposium: Proceedings 10 . University of Idaho Forest, Wildlife, and Range Experiment Station, Moscow, ID. pp. 186-197.

Crouse, Michael R. 1987. New approaches to riparian area management on public lands. In: Wetland and riparian ecosystems of the American West: Proceedings of the Society of Wetland Scientists' eighth annual meeting. May 26-29, Seattle, WA. N. p.pp. 32-35.

Cummins, K. W. , and G. L. Spangler. 1978. Stream ecosystems. Water Spectrum 10:1-9.

Currie, Dan. 1994. Manager, Harding Land and Livestock Company, Ismay, MT. Personal conversation with authors.

Dale, Brenda C. 1984. Birds of grazed and ungrazed grasslands in Saskatchewan. Blue Jay 42(2):102-105.

Dahlem, Eugene A. 1979. The Mahogany Creek watershed-with and without grazing. In: Proceedings: Forum-on grazing and riparian/ stream ecosystems. Trout Unlimited, Inc. , Vienna, VA. pp.31-34.

Ducks Unlimited. n. d. Quality water for livestock [video].Available from Society for Range Management, Denver, CO.

Duff, Donald A. 1979. Riparian habitat recovery on Big Creek, Rich County, Utah-A summary of 8 years of study. In: Proceedings: Forum-on grazing and riparian/stream ecosystems. Trout Unlimited, Inc., Vienna, VA. pp.91-92.

Elmore, Wayne. 1988. Stream processes and grazing strategies. Presentation at Riparian Management Workshop: Challenges and Opportunities. May 3. Elko, NV. Cited in Clary, Warren P. , and Bert F. Webster. 1989. Managing grazing of riparian areas in the Intermountain Region. USDA Forest Service General Technical Report INT-263. Intermountain Research Station, Ogden, UT.

Elmore, Wayne. 1990. Riparian responses to grazing practices. In: Watershed management: Balancing sustainability and environmental change. edited by Robert J. Naiman. SpringerVerlag, New York, NY. pp. 442-457. 
Elmore, Wayne, and J. Boone Kauffman. 1994. Riparian and watershed systems: Degradation and restoration.In: Ecological implications of livestock herbivory in the West. Edited by Martin Vavra, William A. Laycock, and Rex D. Piper. Society for Range Management, Denver, CO. pp. 212-231.

Fleischner, Thomas L. 1994. Ecological costs of livestock grazing in western North America. Conservation Biology 8(3):629-644.

Frisina, Michael R. , and Forest G. Morin. 1991. Grazing private and public land to improve the Fleecer Elk Winter Range. Rangelands 13(6):291-294.

Gifford, Gerald F. 1981. Watershed responses to grazing management.In: Interior West watershed management: Proceedings of symposium held April 8-10, 1980, Spokane, WA. Edited by David M. Baumgartner.Available from Washington State University Cooperative Extension, Pullman, WA. pp. 147-160.

Gillen, R. L. ,W. C. Krueger, and R. F. Miller. 1985. Cattle use of riparian meadows in the Blue Mountains of northeastern Oregon. Journal of Range Management 38(3):205-209.

Gjersing, Frank M. 1981. Effects of grazing on riparian zones in northcentral Montana.In: Management of riparian ecosystems. Proceedings of the Montana Chapter, Wildlife Society, February 3-5, Great Falls, MT. N. p.pp. 75-81.

Goriup, P. D. Editor. 1988. Ecology and conservation of grassland birds. ICBP Technical Publication No 7.Anagram Editorial Service, Guildford, Surrey, England.

Green, Douglas M. 1991. Soil conditions along a hydrologic gradient and successional dynamics in a grazed and ungrazed montaine riparian ecosystem. Ph. D. Diss. Oregon State University, Corvallis, OR. Cited in Elmore, Wayne, and J. Boone Kauffman. 1994. Riparian and watershed systems: Degradation and restoration.In: Ecological implications of livestock herbivory in the West. Edited by Martin Vavra, William A. Laycock, and Rex D. Piper. Society for Range Management, Denver, CO.pp. 212-231.
Green, Douglas M., and J. Boone Kauffman. 1995. Succession and livestock grazing in a northeastern Oregon riparian ecosystem. Journal of Range Management 48(4):307-313.

Hansen, Paul L. 1993. Developing a successful riparian-wetland grazing management plan for the Upper Ruby River cattle and horse allotment in southwestern Montana.In: Riparian management: Common threads and shared interests. Western Regional Conference on River Management Strategies, February 4-6,Albuquerque, NM. USDA Forest Service General Technical Report RM-226. Rocky Mountain Forest and Range Experiment Station, Ft Collins, CO. pp. 328-335.

Hansen, Paul L., Robert D. Pfister, Keith Boggs, Bradley J. Cook, John Joy, and Dan K. Hinckley. 1995. Classification and management of Montana's riparian and wetland sites. Montana Forest and Conservation Station, School of Forestry, The University of Montana, Missoula, MT.

Hays, Art. 1992. An annotated bibliography on the utilization of grasses with emphasis on riparian areas. N.p.

Holecheck, Jerry L., Raul Valdez, Sanford D. Schemnitz, Rex D. Pieper, and Charles A. Davis. 1982. Manipulation of grazing to improve or maintain wildlife habitat. Wildlife Society Bulletin 10(3):204-210.

Hubert, Wayne A. , Robert P. Lanka, Thomas A. Wesche, and Fred Stabler. 1985. Grazing management influences on two brook trout streams in Wyoming.In: Riparian ecosystems and their management: Reconciling conflicting uses. R. Roy Johnson, Charles D. Ziebell, David R. Patton, Peter F. Ffolliott, and R. H. Hamre, Technical Coordinators. First North American Riparian Conference,April 16-18, Tucson,AZ. USDA Forest Service General Technical Report RM-120. Rocky Mountain Forest and Range Experiment Station, Ft Collins, CO. pp. 290-294.

Kantrud, Harold A. 1990. Effects of vegetation manipulation on breeding waterfowl in prairie wetlands-A literature review. In: Can livestock be used as a tool to enhance wildlife habitat? USDA Forest Service. General Technical Report RM-194. Rocky Mountain Forest and Range Experiment Station, Ft Collins, CO. pp. 192-213. 
Kantrud, Harold A. , and Kenneth F. Higgins. 1992. Nest and nest site characteristics of some ground-nesting, non-passerine birds of northern grasslands. Prairie Naturalist 24(2):67-84.

Kauffman, J. Boone. 1982. Synecological effects of cattle grazing riparian ecosystems. M.S. Thesis, Oregon State University, Corvallis, OR.

Kauffman, J. Boone. 1995. An ecological basis for the management and recovery of riparian zones. In: Eastern Oregon Agriculture Research Center Field Day annual report. Oregon Agricultural Experiment Station Special Report 951. Oregon State University, Corvallis, OR. pp. 27-33.

Kauffman, J. Boone, and William C. Krueger. 1984. Livestock impacts on riparian ecosystem and streamside management implications-A review. Journal of Range Management 37(5):430438.

Kauffman, J. Boone, William C. Krueger, and Martin Vavra. 1982. Impacts of a late season grazing scheme on nongame wildlife in Wallowa Mountain riparian ecosystems. In: Wildlife-livestock relationships symposium: Proceedings 10. University of Idaho Forest, Wildlife, and Range Experiment Station, Moscow, ID. pp. 208-218.

Kauffman, J. Boone, William C. Krueger, and Martin Vavra. 1983. Effects of late season cattle grazing on riparian plant communities. Journal of Range Management 36(6):685-691.

Keller, Charles, Loren Anderson, and Paul Tappel. 1979. Fish habitat changes in Summit Creek, ID, after fencing the riparian area.In: Proceedings: Forum-on grazing and riparian/stream ecosystems. Trout Unlimited, Inc., Vienna, VA. pp. $46-52$.

Keller, Charles R., and Kenneth P. Burnham. 1982. Riparian fencing, grazing, and trout habitat preference on Summit Creek, Idaho. North American Journal of Fisheries Management 2:53-59.

Kellogg,Warren. 1995. Water quality specialist, Montana Department of Water Quality. Helena, MT. Personal conversation with authors.
Kinch, Gene. 1989. Riparian area management: Grazing management in riparian areas. USDI Bureau of Land Management Technical Report 1737-4. Denver, CO.

Knopf, Fritz L., and Richard W. Cannon. 1982. Structural resilience of willow riparian community to changes in grazing practices. In: Wildlife-livestock relationships symposium: Proceedings 10. University of Idaho Forest, Wildlife, and Range Experiment Station, Moscow, ID. pp. 198-207.

Kovalchik, Bernard L. , and Wayne Elmore. 1992. Effects of cattle grazing systems on willowdominated plant associations in central Oregon.In: Proceedings-Symposium on ecology and management of riparian shrub communities. Compiled by Warren P. Clary, E. Durant McArthur, Don Bedunah, and Carl L. Wambolt. May 29-31 1991, Sun Valley, ID. USDA Forest Service General Technical Report INT-289, Intermountain Research Station, Ogden, UT. pp. 111-119.

Krueger, W. C. 1996. Managing ungulates to allow recovery of riparian vegetation.In: W. D. Edge and S. L. Olson-Edge, Editors. Sustaining Rangeland Ecosystems Symposium. Oregon State University Special Report 953, Corvallis, OR. pp. 160-165.

Landgraf, Barb. 1995. Range Conservationist, Natural Resources Conservation Service, Dillon, MT. Personal conversation with authors.

Larsen, Royce, William C. Krueger, Mack Barrington, John Buckhouse, Melvin George, and Douglas Johnson. 1997. Livestock influences on riparian zones and fish habitat:A bibliography. EM 8660 (electronic database). Oregon State University Extension Service, Corvallis, OR.

Leege, Thomas A., Daryl J. Herman, and Benjamin Zamora. 1981. Effects of cattle grazing on mountain meadows in Idaho. Journal of Range Management 34(4):324-328.

Manoukian, Mark Edward. 1994. Evaluation of tall willows (Salix spp.) within a livestock grazing allotment in southwest Montana. M.S.Thesis, Montana State University, Bozeman, MT. 
Marlow, Clayton B. 1985. Controlling riparian zone damage with little forage loss. Montana AgResearch 2(3):1-7. Montana State University, Bozeman, MT.

Marlow, Clayton B., and Thomas M. Pogacnik. 1986. Cattle feeding and resting patterns in a foothills riparian zone. Journal of Range Management 39(3):212-217.

Marlow, Clayton B., Douglas Allen, and Kathyrn Olson-Rutz. 1991. Making riparian zone protection a workable part of grazing management. In: Proceedings of the international beef symposium. January 15-17, Great Falls, MT.Animal Range Sciences Department, Montana State University, Bozeman, MT. pp. 256-266.

Masters, Linda, Sherman Swanson, and Wayne Burkhardt. 1996. Riparian grazing management that worked: I. Introduction and winter grazing. Rangelands 18(5):192-195.

May, Bruce, and Barry Davis. 1982. Practices for livestock grazing and aquatic habitat protection on western rangelands. In: Wildlife-livestock relationships symposium: Proceedings 10. University of Idaho Forest, Wildlife, and Range Experiment Station, Moscow, ID. pp. 271-278.

McClure, Thomas. 1994. Range Conservationist, Sula Ranger District, Bitterroot National Forest, Sula, MT. Personal conversation with authors.

Medin, Dean E. , and Warren P. Clary. 1989. Small mammal populations in a grazed and ungrazed riparian habitat in Nevada. USDA Forest Service General Technical Paper INT-413. Intermountain Research Station, Ogden, UT.

Medin, Dean E., and Warren P. Clary. 1990. Bird and small mammal populations in a grazed and ungrazed riparian habitat in Idaho. USDA Forest Service General Technical Paper INT-425. Intermountain Research Station, Ogden, UT.

Meehan, William R., and William S. Platts. 1978. Livestock grazing and the aquatic environment. Journal of Soil and Water Conservation 33(6):274-278.
Miner, J. Ronald, John C. Buckhouse, and James A. Moore. 1992. Will a water trough reduce the amount of time hay-fed livestock spend in the stream (and therefore improve water quality)? Rangelands 14(1):35-38.

Mosconi, Sandra L. , and Richard L. Hutto. 1982. The effects of grazing on land birds of a western Montana riparian habitat. In: Wildlife-livestock relationships symposium: Proceedings 10. University of Idaho Forest, Wildlife, and Range Experiment Station, Moscow, ID.pp. 221-233.

Munther, Greg L. 1982. Beaver management in grazed riparian ecosystems. In: Wildlife-livestock relationships symposium: Proceedings 10. University of Idaho Forest, Wildlife, and Range Experiment Station, Moscow, ID. pp. $234-241$.

Myers, Lewis H. 1989. Grazing and riparian management in southwestern Montana.In: Practical approaches to riparian resource management:An educational workshop. Edited by Robert E. Gresswell, Bruce A. Barton, and Jeffrey L. Kershner, Editors). May 8-11, Billings, MT. BLM-MT-PT-89-001-4351. Bureau of Land Management, Washington, DC. pp. 117-120.

Myers, Thomas J. , and Sherman Swanson. 1992. Variation of stream stability with stream type and livestock bank damage in northeastern Nevada. Water Resources Bulletin 28(4):743754.

Pfankuch, D. J. 1975. Stream reach inventory and channel stability evaluation. USDA Forest Service $\mathrm{R}$ 1-75-002. Washington, $\mathrm{DC}$.

Platts, William S. 1986a. Managing fish and livestock on Idaho rangelands. Rangelands 8(5):213-216.

Platts, William S. 1986b. Riparian stream management.Transactions of the Western Section of the Wildlife Society 22:90-93.

Platts, William S. 1991. Livestock Grazing. In: Influences of forest and rangeland management on salmonid fishes and their habitats. Edited by William R. Meehan. American Fisheries Society Special Publication 19. American Fisheries Society, Bethesda, MD. pp. 389-423. 
Platts, William S. , and Rodger L. Nelson. 1985a. Impacts of rest-rotation grazing on stream banks in forested watersheds in Idaho. North American Journal of Fisheries Management 5:547-556.

Platts, William S. , and Rodger L. Nelson. 1985b. Stream habitat and fisheries response to livestock grazing and instream improvement structures, Big Creek, Utah. Journal of Soil and Water Conservation 40(4):374-379.

Platts, William S. , and Rodger L. Nelson. 1985c. Will the riparian pasture build good streams? Rangelands 7(4):7-11.

Platts, William S., and Robert F. Raleigh. 1984. Impacts of grazing on wetlands and riparian habitat.In: Developing strategies for rangeland management. National Research Council/National Academy of Sciences. Westview Press, Boulder, CO.pp. 1105-1118.

Platts, William S., and Fred J. Wagstaff. 1984. Fencing to control livestock grazing on riparian habitats along streams: Is it a viable alternative? Journal of Fisheries Management 4:266272.

Rickard,W. H. , and C. E. Cushing. 1982. Recovery of streamside woody vegetation after exclusion of livestock grazing. Journal of Range Management 35(3):360-361.

Roath, Leonard Roy, and William C. Krueger. 1982. Cattle grazing influence on a mountain riparian zone. Journal of Range Management 35(1):100-103.

Robinson, Art. 1996. Manager,.Snowline Grazing Association, Snowline, MT. Personal conversation with authors.

Rosgen, Dave. 1996.Applied river morphology. Wildland Hydrology, Pagosa Springs, CO.

Schulz,Terri Tucker, and Wayne C. Leininger. 1990. Differences in riparian vegetation structure between grazed areas and exclosures. Journal of Range Management 43(4):295-299.

Severson, K. E. , and Charles E. Boldt. 1978. Cattle, wildlife, and riparian habitats in the western Dakotas. In: Management and use of northern plains rangeland. Regional Rangeland Symposium, February 27-28,Bismarck, N.D.N.p.pp.90-103.
Siekert, Ronald E., Q. D. Skinner, M.A. Smith, J. L. Dodd, and J. D. Rodgers. 1985. Channel response of an ephemeral stream in Wyoming to selected grazing treatments. In: Riparian ecosystems and their management: Reconciling conflicting uses. R. Roy Johnson, Charles D.

Ziebell, David R. Patton, Peter F. Ffolliott, and R. H. Hamre, Technical Coordinators. First North American Riparian Conference, 16-18 April, Tucson, AZ. USDA Forest Service General Technical Report RM-120. Rocky Mountain Forest and Range Experiment Station, Ft Collins, CO. pp. 276-278.

Skovlin, Jon M. 1984. Impacts of grazing on wetlands and riparian habitat:A review of our knowledge. In: Developing strategies for rangeland management. National Research Council/ National Academy of Sciences. Westview Press, Boulder, CO. pp. 1001-1103.

Storch, Robert L. 1979. Livestock/streamside management programs in eastern Oregon. In: Proceedings: Forum-on grazing and riparian/ stream ecosystems. Trout Unlimited, Inc., Vienna,VA. pp. 56-59.

Stuber, Robert J. 1985. Trout habitat, abundance, and fishing opportunities in fenced vs. unfenced riparian habitat along Sheep Creek, Colorado.In: Riparian ecosystems and their management: Reconciling conflicting uses. R. Roy Johnson, Charles D. Ziebell, David R. Patton, Peter F. Ffolliott, and R. H. Hamre, Technical Coordinators. First North American Riparian Conference, April 16-18,Tucson, AZ. USDA Forest Service General Technical Report RM120. Rocky Mountain Forest and Range Experiment Station, Ft Collins, CO. pp. 310-314.

Swanson, Sherman. 1986. Options for riparian grazing management. Nevada Cooperative Extension Fact Sheet 86-77. University of Nevada, Reno, NV.

Swanson, Sherman. 1987. Riparian pastures. Nevada Cooperative Extension Fact Sheet 87-53. University of Nevada, Reno, NV.

Taylor, Daniel M. 1984. The effects of cattle grazing and other factors on passerine birds nesting in willow riparian habitat. M.S.Thesis, Idaho State University. Moscow, ID. 
Thilenius, John F. 1979. Range management in the alpine zone: Practices and problems. In: Special Management needs of alpine ecosystems:A symposium sponsored by the Society for Range Management. Edited by Douglas A. Johnson. February 14, Casper,Wyoming. N. p. n. p.

Tibbs, Teena M. ,T. DelCurto, M. McInnis,A. R. Tiedeman, and T. M. Quigley. 1995. Influence of electronic diversion from riparian areas on livestock grazing behavior, nutritional physiology, stress physiology, and performance. In: Eastern Oregon Agriculture Research Center Field Day annual report. Oregon Agricultural Experiment Station Special Report 951. Oregon State University, Corvallis, OR. pp. 7-9a.

Tohill,Al, and James Dollerschell 1990. "Livestock" the key to resource improvement on public lands. Rangelands 12(6):329-336.

Turnell, Jack. 1993. Presentation to Deer Lodge Conservation District, July 10. Deer Lodge, MT.

USDA Forest Service. 1989. Ecosystem classification handbook: ECODATA. USDA Forest Service, Northern Region, Missoula, MT.

US Environmental Protection Agency, and USDI Bureau of Land Management. 1979. Livestock grazing management and water quality protection (State of the art reference document). US Environmental Protection Agency, Seattle, WA.

Van Deventer, John S. 1992. A bibliography of riparian research and management: Fish, wildlife, vegetation, and hydrologic responses to livestock grazing and other land use activities. Idaho Riparian Cooperative, University of Idaho, Moscow, ID.

Van Poollen, H.Walt, and John R. Lacey. 1979. Herbage response to grazing systems and stocking intensities. Journal of Range Management 32(4):250-253.

Van Velson, Rodney. 1979. Effects of livestock grazing upon rainbow trout in Otter Creek, Nebraska.In: Proceedings: Forum-on grazing and riparian/stream ecosystems. Trout Unlimited, Inc., Vienna, VA. pp. 53-55.
Vavra, Martin. 1984. Livestock production possibilities on streamside meadows. In: Range management short course. Oregon State University, Corvallis, OR. pp. 35-44.

Winegar, Harold H. 1977. Camp Creek channel fencing: Plant, wildlife, soil, and water response. Rangeman's Journal 4(1):10-12. 


\section{Appendix A}

\section{RIPARIAN GRAZING STUDY FIELD FORM \\ - ADMINISTRATIVE INFORMATION -}

Use

1. Operator:

2. Area/Stream:

3. Polygon No.:

4. Date:

5. Observers: Sec:

6. Man. Unit:

78. Location: Township Rng:

7b. Quad Sheet:

8. River Miles (channel length):

9. Sinuosity (field observable only):

10. Size (acres)

11. Health:

12. TREE SPECIES BY CANOPY COVER CLASS AND PERCENT AGE GROUP SPECIES COV SDLG/DEC SAPIDEC POLEIDEC MATIDEC

DEAD

13. SDLG/SPLG UTILIZATION
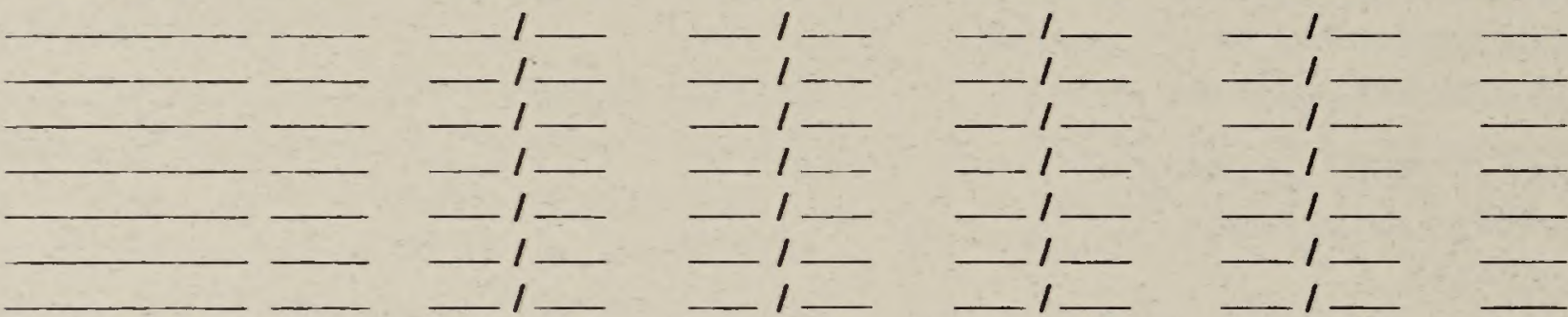

14. SHRUBS SPECIES CAN. COV. AGE/SIZE GROUPS, AND UTILIZATION SPECIES COV SDLG-SPLG/UTIL MATURENTIL

DEC-DEAD/UTIL

15. Shrub Growth Form $(N, F, U)$
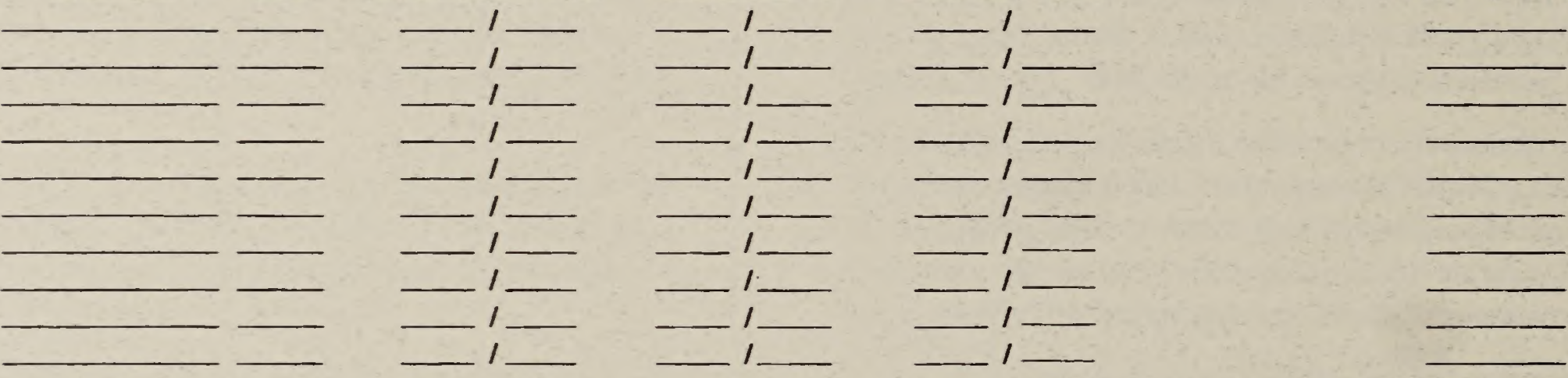

16. GRAMINOIDS SPECIES

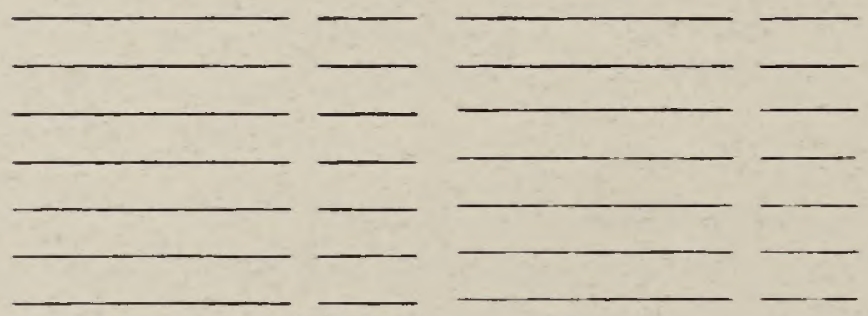

18. Total Canopy Cover by Woody Species:

17. FQRBS

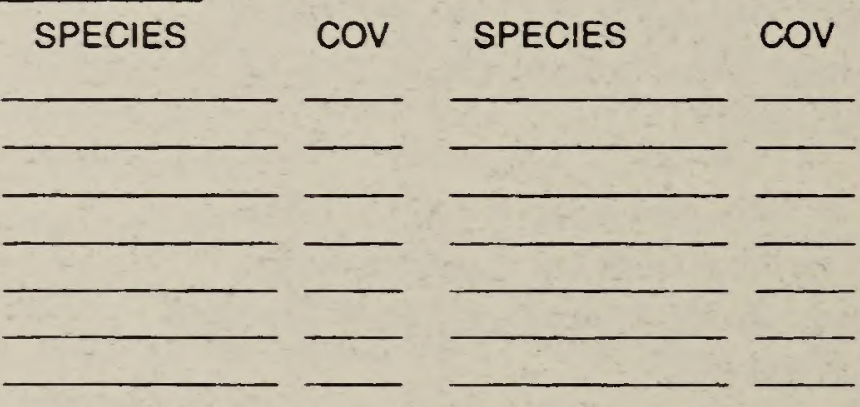

20. Life Forms as Percent of Delineated Habitat and Community Types

Trees Deciduous Trees Conifer Shrubs Willows Shrubs NonWillow
Herb Grasses Herb Sedges Herb Other 


\section{Classification Type Name}

Percent of

Polygon Successional Stage or Comments

22a. Are noxious weeds present in the polygon? (Yes; No):

If YES, 22b. Record the portion of the polygon

infested by each of the following noxious weed species:

Spotted Knapweed:

; Diffuse Knapweed:

: Russian Knapweed:

: Leafy Spurge:

Dalmatian Toadflax:

Canada Thistle:

Common Tansy:

; Salt Cedar (Tamerisk):

Common Hound's-tongue: ___ ; Purple Loosestrife:

; Sulphur Cinquefoil:

; Russian Olive:

Whitetop:

: Dyer's Woad:

; Others(and their areas):

23. Record the percent of the polygon inhabited by all of the weeds recorded in $22 \mathrm{~b}$ :

24. Record the combined canopy cover of the undesirable herbaceous species observed:

25. Photos (roll/number; description of view):

26. Adjacent (non-riparian) vegetation (looking downstream):

Left

27. Comments:
Right 
28. Valley Bottom Type:

30. Elevation $(\mathrm{ft})$ :

33. Soil Texture:

34. Rosgen stream types and \%'s of reach:

35. Wetland type $(1 ; 2 ; 3 ; 4 ; 5 ; 6 ; 7 ; 8 ; 9 ; 10 ; 11 ; 12)$

37. Riparian-wetland zone width range $(\mathrm{ft})$ :
29. Stream Order:

32. Stream Gradient (\%):

39. Entrench. ratio (flood-prone wd./onkfull wd.) (choose: $<1.4 ; 1.4-2.2 ;>2.2$ ):

40. D50:

41. Bank Rock Content:

42. Streambank materials. Give the percent of each size (must total to $100 \%$ ):

\begin{tabular}{ll}
$\longrightarrow$ & Bedrock \\
& $>10$ inches (Boulders) \\
& \\
\hline & $2.5 \cdot 10$ inches (Cobbles)
\end{tabular}

$0.08-2.5$ inches (Gravel)
$0.062 \mathrm{~mm}-2 \mathrm{~mm}$ (Sand)
$<0.062 \mathrm{~mm}$ (Silt and Clay)

43. Channel bottom materials. Give the percent of each size (must total to $100 \%$ ):

Bedrock

$>10$ inches (Boulders)

2.5 - 10 inches (Cobbles)
$0.08-2.5$ inches (Gravel)

$0.062 \mathrm{~mm}-2 \mathrm{~mm}$ (Sand)

$<0.062 \mathrm{~mm}$ (Sitt and Clay)

44. Percent of the streambanks, with deep, binding root mass (indicate category: $<35 \% ; 35-64 \% ; 65-84 \%$; $\geq 85 \%$ ):

45. Percent of the total streambank length which is unstable (indicate category: $<5 \% ; 5-24 \% ; 25-44 \% ; \geq 45 \%$ ):

46. Percent of strmbks w/ sufficient fine material to hold water and act as rooting med. $(<35 \% ; 35 \cdot 64 \% ; 65-84 \% ; \geq 85 \%)$ :

47. Indicate the best description of the incisement by the appropriate category choice $(A ; B+; B ; C ; D)$ :

48a. Is there active lateral cutting of stream? (Yes; No; NA)

If YES, 48b. How much of the stream within the polygon displays active lateral cutting:

49a. Active downcutting of the stream? (Yes; No; NA):

If YES, 49b. Percent of stream within the polygon that is undergoing active downcutting:

50a. Headcut(s) present? (Yes; No):

If YES, 50b. Number of Headcuts:

50c. Average height $(\mathrm{tt})$ :

51. Percent of the stream which is braided (has more than one active channel during normal flow):

52. Percent of the streambank-altered by human-caused activities:

53. Percent of the polygon which is bare ground caused by human-induced disturbance (Do not include the area within the non-vegetated stream channel, wood, rocks [ $>2.5$ ], or litter \& duff):

54. Percent of the polygon which is bare ground caused by natural processes (Do not include the area within the non-vegetated stream channel, wood, rocks [ $>2.5$ ], or litter \& duff):

55. Percent of streambank accessible to livestock:

56a. Livestock-caused hummocks and/or pugging present (Yes; No):

57. Season of Use:

If YES, 56b. Percent of polygon affected:

58. Offstream Water

59. Length of Graz Period

60. Stocking Rate

61. Management Information 


\section{Appendix B.}

\section{Riparian Grazing Study Inventory Codes And Instructions}

These codes and instructions refer to specific inventory data items on the Riparian Grazing Study Field Form and are numbered the same as the corresponding items on that form. Within these codes and instructions are comments about the data, the way it is collected, or its meaning. Both the Riparian Grazing Study Field Form and these codes and instructions are based on the MRWA Inventory methods prepared for the Bureau of Land Management.

Observers should use class codes below where a percent of the polygon or other "percent" data is recorded. These codes and range classes are from the USDA Forest' Service Northern Region's ECODATA (1989) program.

$$
\begin{array}{llll}
\mathrm{T}=0.1<1 \% & 2=15<25 \% & 5=45<55 \% & 8=75<85 \% \\
\mathrm{P}=1<5 \% & 3=25<35 \% & 6=55<65 \% & 9=85<95 \% \\
1=5<15 \% & 4=35<45 \% & 7=65<75 \% & \mathrm{~F}=95-100 \%
\end{array}
$$

\section{Administrative Information}

1. Use operator name if private land; for public leased land, include the appropriate land management agency abbreviation in parentheses.

2. If the stream is unnamed, record it as "Unnamed tributary of Creek" (fill in the blank with the name of the first named stream this stream flows into). If this is a non-riparian wetland (not a stream or river), name the area as best as possible. Use the name or indicator of the type of wetland (such as spring, seep, basin, etc.) that is used on the appropriate 7.5 minute topo quad or BLM land ownership map.

3. Indicate the polygon number. (Not all polygons will be included in the final report; but if a field form is completed, it should be given a polygon number.)

4. \& 5. Record the date the inventory was accomplished and the names of all observers.

6. Management Unit is optional; it can be filled in as necessary for future reference.

7a.The location is recorded for the center of the polygon. Quarter and quarter/quarter section delineations are as follows:

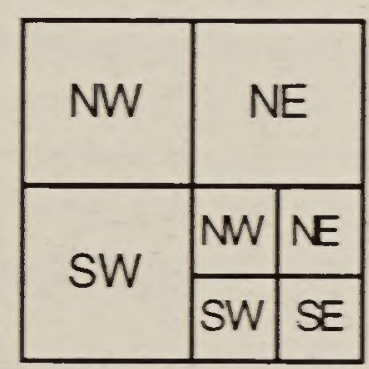

7b. Indicate the Quad Sheet on which the polygon is located.

8. Record the length of the stream channel inventoried.The reach(s) selected should be representative of the stream as it flows through that particular management unit.

9. Estimate the sinuosity of the stream channel through the length of the polygon.

10 . The size of the polygon will be calculated automatically by the data program based on the stream length (\#8) and the average width of the riparian area $(\# 36)$. 
11. The health of the inventoried reach will be determined by using the Riparian Grazing Study Health Evaluation Form.

\section{Vegetation Information}

12. Record the six-letter code for all tree species present in the polygon and their canopy covers. Within the total canopy cover of a particular species, determine the canopy cover of each of four age groups (i. e., SDLG = seedling, SPLG = sapling, POLE, and MAT = mature) and the dead trees (considered as a fifth group, but these are not strictly an "age" group). When the canopy covers for the five groups are added for a particular species, they must total $100 \%$ or more. If decadent individuals (30 percent or more of the upper canopy is dead) are present in an age group, record the percent (using codes) of the trees in that group which are decadent. Record the group canopy cover to the left of the slash (I) and the percent decadence to the right.

Note: The word "decadent" is used in a variety of ways by plant ecologists. The most common use may be to describe trees which are past the prime of their maturity (often called overmature) and which are beginning to lose vigor and may be dying. In contrast, we use the term decadent in a more encompassing manner, which is not restricted to overmature plants. Our use considers decadent plants to have 30 percent or more of the upper canopy which is dead. This use is confined to woody (tree and shrub) species.

\begin{tabular}{|c|c|c|}
\hline Group & Conifers $^{1}$ and Cottonwoods & Other Broadleaf Species 2 \\
\hline Seedling & $<4.5 \mathrm{ft}$ tall $O R<1.0$ inch dbh & $<3.0 \mathrm{ft}$ tall \\
\hline Sapling & $\geq 4.5 \mathrm{ft}$ tall $A N D 1.0$ inch to 4.9 inch $\mathrm{dbh}$ & $>3.0 \mathrm{ft}$ tall $A N D<3.0$ inch dbh \\
\hline Pole & 5. 0 inch to 8.9 inch dbh & $>6.0 \mathrm{ft}$ tall AND 3.0 inch to 5.0 inch $\mathrm{dbh}$ \\
\hline Mature & $>9.0$ inch dbh & $>5.0$ inch $\mathrm{dbh}$ \\
\hline Dead & $100 \%$ of canopy is dead & $100 \%$ of canopy is dead \\
\hline \multicolumn{3}{|c|}{$\begin{array}{l}\text { 'Rocky Mountain juniper (Juniperus scopulorum) and Utah juniper (Juniperus osteosperma) are exceptions to the } \\
\text { specifications given, as they do not have typical (or consistent) coniferous size, age, and growth form relationships. Assign } \\
\text { age classes to individuals of these two species based on size, reproductive ability, and overall appearance. } \\
{ }^{2} \text { Other Broadleaf Species - refers to green ash (Fraxinus pennsylvanica), box-elder (Acer negundo), peach-leaf willow (Salix } \\
\text { amygdaloides). quaking aspen (Populus tremuloides). Russian olive (Elaeagnus angustifolia), and American elm (UImus } \\
\text { americana). }\end{array}$} \\
\hline
\end{tabular}

13. Record the appropriate category which best describes the amount of utilization of the combined seedling and sapling age groups for each tree species.

\section{Category Description \\ 1 Light - 0 to $25 \%$ of the available second year and older leaders are clipped (browsed). \\ 2 Moderate -26 to $50 \%$ of the available second year and older leaders are clipped \\ 3 Heavy - greater than $50 \%$ of the available second year and older leaders are clipped (browsed). \\ $4 \quad$ Unavailable - woody plants have no browsed or unbrowsed material below $1.5 \mathrm{~m}$ in height or are unavailable due to their location or protection by other plants.}

14. For each shrub species in the polygon which has a canopy cover of $5 \%$ or more (class code of 1 or greater), first record the six-letter code, then canopy cover class code. (The recording of the age/size group and utilization information is described in the next paragraph.) Due to the importance of willows, record all willow species and their data. In any situation, observers may record any species observed, even if its canopy cover is less than $5 \%$.

Within the total area occupied by a particular species, determine the canopy cover of each of the following groups: SDLG/ 
SPLG, MATURE, and DEC/DEAD. Note: For shrubs, all decadent individuals are included in one group with dead individuals. This contrasts to the recording of the decadence amounts within the tree species, where the percent of each age group which is decadent is recorded. When the canopy covers of these three age/size groups for a particular species are added together, they must equal $100 \%$ or more. In general, the seedling/sapling age group can be divided from the mature group on the following basis: For normally tall shrubs, which have an average mature height of greater than 6. $1 \mathrm{ft}$, the seedlings and saplings will be individuals growing only into the first and second vegetation layers (up to $6.0 \mathrm{ft}$ ). For shrubs which have a normal mature height between 1.6 and $6.0 \mathrm{ft}$, the seedlings and saplings will be individuals growing only into the first vegetation layer (up to $1.5 \mathrm{ft}$ ). For very short shrubs whose mature height is around $1.5 \mathrm{ft}$ or less, the observers will judge the individual plants as to height, reproductive structures, and other characteristics which give clues as to the relative age of the individuals. Decadent shrubs have $30 \%$ or greater dead canopy. Record this data in the blank to the left of the slash.

In the space to the right of the slash for each age/size group, record the category which best describes shrub utilization for that age/size group (use the four categories from item 13 above).

15. Record the appropriate category that best describes the dominant appearance of the shrubs in the polygon.

\section{Category Description}

N

$\mathrm{F}$

$\cup$
Normal Growth Form - no apparent deviation from the normal appearance of the life form.

Flat-Topped Growth Form - shrubs with the tallest leaders hedged (e. g., hedging from the top down). (Moose in the winter time with deep snow will browse those branches that are exposed.)

Umbrella-Shaped/High-Lined - shrubs that have most of the lower branches /up to

1. $5 \mathrm{~m}$ in height) removed by hedging (hedging from the bottom up).

16. and 17. Record the six-letter code and the canopy cover class designation for each graminoid and forb species in the polygon which might help to determine the appropriate habitat or community type as well as all noxious weed species and undesirable weedy species. (See $\# 23$ a and $\# 24$ of these instructions for lists of these species).

18. Record the combined total canopy cover for trees and shrubs (woodies). Do not sum all the individual species canopy covers; that is, do not "double count" areas that are covered by more than one woody species. The total amount cannot exceed $100 \%$

19. Record the total combined canopy cover of all four plant groups. Again, do not sum all the individual species canopy covers; that is, do not "double count" areas that are covered by more than one woody species. The total amount cannot exceed $100 \%$.

20. List the percentages of the delineated habitat and community types from \# 21 by life form.

21. List the riparian and wetland habitat types (Hansen and others 1995) found within the polygon. If the habitat type cannot be determined for a portion of the polygon, then list the appropriate community types of that portion. If neither the habitat type nor community type can be determined for any portion of the polygon, list the appropriate dominance types (Hanson and others 1995). For each type listed, estimate the percent of the total polygon the type occupies (use the class codes). Use the available space to record the successional stage (i. e., early seral, mid-seral, late seral, and climax) or give other comments about the type when appropriate. List at least all of the "types" which cover $>5 \%$ of the polygon. The total must add to $100 \%$. Slight deviations due to the use of class codes or due to not listing types covering less than $5 \%$ of the polygon are allowed. Note: Dominance types are named for the species which has a minimum of $25 \%$ canopy cover and which has the greatest cover in the tallest layer of the stand.

$22 \mathrm{a}$ and $22 \mathrm{~b}$. Record noxious weed species observed in the polygon. Common species are listed, and space is allowed for the listing of "other" species. Using the class codes, record the percent of the total polygon infested by each species. DO 
NOT record the canopy cover for the species. Instead, determine both the area under the canopy of the individual plants and the ground between individual plants within an inhabited area. (In contrast, canopy cover includes only the area actually under the outline of the canopy of individual plants. Thus, the numbers recorded here will be greater than the canopy covers of these species recorded in item 17.)

23. Record the total area infested by all weed species recorded in $22 \mathrm{~b}$. Count overlapping areas only once.

24. Areas (especially in forested ecosystems) with historically high grazing use often have high canopy covers of a variety of low productivity, short herbaceous species. Record the collective canopy cover (use class codes) of the following groups of plants: dandelion (Taraxacum spp.), strawberry (Fragaria spp.), plantain (Plantago spp.), 'cheatgrass (Bromus tectorum), Japanese brome (Bromus japonicus), Kentucky bluegrass (Poa pratensis), pussy-toes (Antennaria spp.), the weedy members of the mustard (Brassicaceae) family, and small clovers (Trifolium spp.). Count overlapping areas only once.

25. Photographs, where possible, should include at least one overview which places the polygon within its landscape. Include photographs of representative portions of the polygon as well as anything which might help to "explain" the condition of the reach. Unless indicated in the description, all photographs should be shot at "standard" $35 \mathrm{~mm}$ setting.

26. Briefly identify the vegetation immediately outside the riparian zone using six-letter codes.

27. Record additional comments on any administrative, vegetation or physical factors not covered elsewhere on the form. Summarize any unique or unusual characteristics in the system which are not evident from the data collected elsewhere on the form.

\title{
Soil, Stream, and Hydrologic Information
}

28. List the valley bottom type according to the categories described below. If the channel is deeply incised, record the type according to the description relevant to the incisement. In addition, record the surrounding valley type description in parentheses.

\author{
Valley Form: \\ (1) U-shaped, (2) V-shaped, (3) Trough-like, (4) Flat bottom, (5) Box-canyon \\ Valley Bottom Gradient: \\ (1) Very Low [<2\%], (2) Low [2-4\%], (3) Moderate [>4-6\%], (4) High [>6-8\%], \\ (5) Very High [>8\%] \\ Valley Bottom Width: \\ (1) Very Narrow [<10m], (2) Narrow [10-30m], (3) Moderate [>30-100m], \\ (4) Broad (>100-300m), (5) Very Broad[(>300m] \\ Valley Side Slopes: \\ (1) Low [<30\%], (2) Moderate [30-60\%], (3) Steep [>60\%]
}

29. Indicate the order of the stream being inventoried (1st, 2 nd, etc.).

30. Record the elevation in the middle of the polygon.

31. Since all but a handful of polygons will include both sides of the stream, the aspect is considered to be the general direction of flow of the stream. The categories of aspect are N, NE, E, SE, S, SW, W, and NW.Aspect may be recorded in the office and/or in the field.

32. Determine and record the gradient as a percent using the stream elevation change from the upper end of the polygon to the lower end of the polygon and the river miles $(\# 8)$ or by the use of a clinometer or abney.

33. Estimate the general soil texture of a representative sample taken from the streambank using the "ribbon test." 
34. Record the predominant Rosgen geomorphology types which were observed within the polygon and the percent of the total stream reach which is correctly classified by each type. Do not include small segments that are not representative of a significant portion of the overall reach.

35. Classify the stream-wetland type associated with the polygon by recording the most appropriate number from the following table.

\section{Category Description}

1 Perennial Stream - A stream or stretch of a stream that flows continuously. These are generally fed in part by springs, and their upper surfaces generally stand lower than the water table in localities through which they flow.

Intermittent Stream - A stream or stretch of stream which flows only at certain times of the year when it receives water from springs or from some surface source such as melting snow in mountainous or other cold tributary areas. Thesestreams generally flow continuously during periods of at least one month or more during the year. Ephemeral Stream - A stream or stretch of a stream that flows only in direct response to precipitation. It receives no water from springs and no long-continued supply from melting snow or other surface source. These streams do not flow continuously during periods of as much as one month. Subterranean Stream - A stream that flows underground for part of the stream reach. Pooled Channel Stream - An intermittent stream with significant surface pool area and without flowing surface water. The water sources for the pools are springs within the channel.

6 Lotic Wet Meadow: An example is a mountain meadow with a small first order stream flowing through it. These riparian wetland communities are dominated by herbaceous species, with saturated soils near the surface but without standing water for most of the year. These categories refer to wetland types not included in this study.

1 River - Rivers are usually larger than streams. They flow year round, in years of normal precipitation and when significant amounts of water are not being diverted out of them. Those watercourses called rivers on USGS 7. 5 minute topo quads will be categorized as rivers for the purpose of this inventory.

36. To determine the riparian zone width, subtract the non-vegetated stream channel width from the distance between the two opposite riparian/upland ecosystem borders. (The non-vegetated stream channel is the portion of the stream which remains unvegetated due to the scouring action of the stream or river or due to the presence of continual standing water.) Record the average zone width for the polygon.

37. Record the range of widths (narrow to wide, in feet) of the riparian zone within the polygon. Include both sides of the stream where appropriate.

38. Record the average non-vegetated stream channel width for the polygon.

39.The entrenchment ratio is the ratio of the flood-prone area to the bankfull channel width. The flood-prone area is the width measured at an elevation which is twice the bankfull depth. Circle the category which best describes the average ratio for this polygon. 
40.The D-50 represents the most prevalent of one of six channel material sizes as determined from a channel material size distribution analysis. For those polygons in which Wolman pebble counts are completed, use the appropriate number from the data sheet annotated with the letter " $\mathrm{m}$ " in parentheses. When pebble counts are not completed, estimate the D-50 from the data in item 43 without annotation.

41. Refer to item 42 to complete this item. Beginning with bedrock (1) and going from largest to smallest, determine by which category $50 \%$ occurs. (For example, if the streambank contained no bedrock, boulders, or cobbles and $30 \%$ gravels, $30 \%$ sand, and $40 \%$ silt/clay, the annotation would be "sand." If the content were $10 \%$ boluders, $40 \%$ cobbles, $20 \%$ gravel, and $20 \%$ sand, the annotation would be "cobble." The purpose of this calculation is to determine bank susceptibility for use on the Health Evaluation form.

42. Use class codes to record the percent of each size category of streambank materials present. The sum of these figures must be $100 \%$.

43. If the channel bottom is visible (that is, the depth or turbidity of the water does not prevent seeing the bottom), use class codes to record the percent of the channel bottom materials in each size group. The sum of these figures must be $100 \%$.

44. Indicate the percent of the total streambanks having a deep, binding root mass by recording the appropriate category. Note: Where the polygon incorporates both sides of the stream, all observations referring to "streambanks" should include both banks.

Note:There have been few studies documenting the depth and extent of the root systems of the various plant species which are found in Montana wetlands. Despite this lack of documented evidence, there are some generalizations which can be made.All tree and shrub species should be considered to have deep, binding root masses.Among riparian and wetland herbaceous species, the first rule is that annual plants do not have deep, binding root masses. Of the perennial species, there is a wide variety of situations. Some rhizomatous species, such as the deep rooted sedges (Carex spp.), are excellent bank stabilizers. Other rhizomatous species, such as Kentucky bluegrass (Poa pratensis), have only shallow root systems and are poor bank stabilizers. Still other species, such as Baltic rush (Juncus balticus), appear to have root systems which are intermediate in their ability to stabilize banks. In all situations, the density and vigor of any species, or group of species, growing on a bank will influence the stability of that bank.

45. Unstable streambanks (due to natural and/or human-induced causes) are found along many stream reaches. Record the percent of the total stream reach length which is unstable by noting the appropriate percent category. Unstable banks can be described in one of the following ways: Undercut banks most often indicate a binding root mass which will allow upper bank layers to persist for some time without support from underneath. Highly cohesive soils in the upper banks may also persist above an undercut lower layer without a binding root mass, but this is less common. Vertically eroded banks are usually composed of cohesive soils (silts and clays), but have a root mass which does not significantly increase the ability to resist erosion. As the stream erodes away the bottom of the bank, the top of the bank almost immediately falls into the stream. Shumping banks usually indicate the most unstable situations (i. e. , the lack of cohesive soils or a binding root mass), with upper banks giving way back from the stream edge and the material sliding down toward the stream. Slumping may occur in many ways, ranging from small amounts of material being dislodged and moving down the bank face to large masses of bank materials sliding toward the stream as an intact piece. The instability of all three types of unstable banks will increase with further disturbance.

46. Two basic functions of soil (or substrate materials) in riparian and wetland areas are to: 1) act as a sponge in the storage of water, and 2) support riparian and wetland vegetation by acting as a rooting medium. The amount of soil materials present will determine how well these roles can be potentially fulfilled. Record the percent of the polygon which has sufficiently thick soil to carry out these roles by noting the appropriate category.

Note: The amount of soil (its thickness) required to perform the two listed functions on a site is not well defined. Even thin soils can perform either role to some degree.A "sufficiently thick" soil is assumed to be able to support the vegetative communities which are commonly found on functioning sites similar to the one being inventoried.That same soil thickness is also assumed to be able to store (hold) a similar amount of water as those other similar, and functioning, sites. Rather than defining exact soil amounts for various situations (e. g. large rivers vs. small headwater streams), we have left 
the term "sufficiently thick" unquantified. This allows the field observers to use their experience in judging this data item by comparing the soil of this site to similar sites.

47. A stream is incised when downcutting of the stream has resulted in a width-to-depth ratio so low that average two-year floods do not come out of the banks. Record the category code from the following table which best describes the observed incisement of the stream within the polygon.

\section{Category Description}

A Stream not incised; downcutting, if present, is very limited.
Bt
Old incisement; floodplain developed but significant active lateral cutting is not occurring.
Downcutting, if present, is very limited. Stream channel is currently stable.
Old incisement; floodplain partially developed at new level, but it is much narrower than it
will eventually become as lateral cutting is actively widening the new floodplain.
Downcutting, if present, is very limited and likely represents a new downcutting event since
the initial formation of the first (old) incisement.
Deeply incised; widening of gully is occurring due to active lateral cutting. Initial floodplain
development is observable. Some active downcutting may be observed, but lateral cutting
resulting in widening of the gully is the dominant process. Twoyear floods do not come out
of old banks, but many larger floods do.
Deeply incised; no floodplain development; only extreme floods come out of banks; active
downcutting is probably occurring.

$48 \mathrm{a}$ and $48 \mathrm{~b}$. Lateral cutting of a stream is indicated by new stream-caused bank disruption along the outside of stream curves and less commonly along the straight portions of a stream. Any lateral cutting which has occurred during the past year is considered active lateral cutting. Use class codes to record the percent of the total stream length within the polygon which displays active lateral cutting. Since lateral cutting is almost always restricted to one side of the stream in any given location, do not consider both banks in determining the total stream length. In other words, a 100 foot length of stream with 10 feet of lateral cutting would have $10 \%$ lateral cutting. In contrast, a 100 foot length of stream with 10 feet of bank alteration (item 52) would have $5 \%$ bank alteration, as both banks (200 feet in this case) of a stream are equally subject to alteration. If there is a significant amount of lateral cutting occurring on exactly opposite banks, describe and record this situation in the comment section of item 27.

49a,b.Active downcutting of a stream is often hard to recognize. Perched wetland vegetation and streambank features, plus the lack of a separate layer of channel bottom materials (i. e., the stream flows directly on the substrate materials), can be clues to downcutting. Use class codes to best describe the percentage of the stream channel length which has experienced active downcutting.

50a-c. Record the presence, number, and average height of gully erosional headcuts in the polygon. Do not consider headcuts which are less than one foot high.

51. Use class codes to record the percent of the stream reach within the polygon which is braided (has more than one active channel during normal flow).

52. We define altered streambanks as having impaired structural integrity (strength or stability). Record the percent of the total streambank length which has been altered by human-induced activities (including livestock grazing). Each bank is considered separately, so the total streambank length for this information is at least twice the reach length (more if the stream is braided). 
53. Use class codes to record the percent of bare ground within the polygon (not just along the streambank) resulting from human-induced processes. Do not include bare ground within the non-vegetated stream channel.

54. Use class codes to record the percent of bare ground within the polygon resulting from natural processes. Do not include bare ground within the non-vegetated stream channel.

55. Record the percent of the total stream reach length which is accessible to livestock. In general, only consider topography (steep banks, deep water, etc.) and dense vegetation as causing banks to be inaccessible. Fences, unless they are part of a small exclosure, may not have restricted livestock access in the not-too-distant past, even though they may appear to be restricting that access at the time of the inventory. If the channel configuration and condition are such that livestock or wildlife would be likely to walk along the stream channel bottom, consider these portions of the bank accessible.

$56 a, b$. Record the presence and amount of area of the polygon which has undergone hummocking and/or pugging. Hummocking is considered to be a partially natural, micro-topographic relief caused by a combination of frost heaving, vegetative influences, and possibly large animal trampling. It is characterized by raised pedicels of vegetated soil, one half to two feet higher than the surrounding ground level. These pedicels usually have different vegetation than the non-pediceled lower area due to the difference in surface moisture between the two elevations. Hummocking usually occurs in relatively wet areas. Pugging is the result of large animals walking or standing in mud which is dry enough to hold its shape after the animal has lifted its feet. Upon further drying, areas with pugging will have a honeycomb appearance, and the hard, dried irregular surface will be difficult for humans to walk across. Bare soil in areas with pugging is common. An area with hummocking may also have pugging if the vegetation has been sufficiently removed to allow hoof imprints in the lower level, or if the soil was very moist during the presence of livestock or other large animals. In contrast, bare soil in hummock areas is the exception, as the hummocks are often vegetated with well-rooted plants, such as sedges, which are not removed completely by grazing.

Note: Items 57.61 will be recorded after discussion with the operator about the pasture in which the polygon is located.

57. Record the historic season of use for the pasture in which the polygon is located. The specific dates will be converted in the office to one of eight categories for analysis.

58. Indicate if there is at least one off-stream water development available to livestock.

59. Indicate the average length of the grazing period for the pasture. The specific dates will be converted in the office to one of six categories for analysis.

60. Calculate the average stocking rate for this pasture when possible.

61. Record any information regarding the management of this pasture which may help to explain the condition, and, if possible, the trend of the riparian area. 


\section{Appendix C.}

\section{Riparian Grazing Study Health Evaluation}

\begin{tabular}{|c|c|c|c|}
\hline $\begin{array}{l}\text { Category } \\
\text { Factor } \\
\end{array}$ & Polygon \#: & $\begin{array}{l}\text { Possible } \\
\text { Score }\end{array}$ & $\begin{array}{l}\text { Actual } \\
\text { Score }\end{array}$ \\
\hline \multicolumn{4}{|c|}{ Vegetation } \\
\hline \multicolumn{2}{|c|}{ Canopy cover of woody species (\#18) } & 3 & \\
\hline \multicolumn{2}{|c|}{ Combined canopy cover of four plant lifeforms (\#19) } & 3 & \\
\hline \multicolumn{2}{|c|}{ Total area inhabited by noxious weed species (\#23) } & 3 & \\
\hline \multicolumn{2}{|c|}{ Cover of "weedy" herbaceous species (\#24) } & 3 & \\
\hline \multicolumn{2}{|c|}{ Utilization of trees and shrubs (\#13\& $\&$ 14) } & 3 & \\
\hline \multicolumn{2}{|c|}{ Tree regeneration (\#12) } & 3 & \\
\hline \multicolumn{2}{|c|}{ Shrub regeneration (\#14) } & 3 & \\
\hline \multirow{2}{*}{\multicolumn{2}{|c|}{$\begin{array}{r}\text { Woody dead and decadent amounts (\#12 \& 14) } \\
\text { Vegetation subtotals }\end{array}$}} & $\underline{3}$ & \\
\hline & & & \\
\hline \multicolumn{4}{|c|}{ 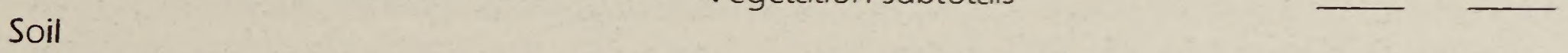 } \\
\hline \multicolumn{2}{|c|}{ Sufficient soil to act as sponge and support riparian vegetation (\#46) } & 6 & \\
\hline \multicolumn{2}{|c|}{ Percent of polygon which is human-induced bare ground (\#53) } & $\underline{6}$ & \\
\hline \multicolumn{4}{|c|}{ Soils subtotals } \\
\hline \multicolumn{4}{|c|}{ Hydrology/Streambanks } \\
\hline \multicolumn{4}{|c|}{$\begin{array}{l}\text { Percent of the streambanks and closely associated areas with a deep, } \\
\text { binding root mass (\#44) }\end{array}$} \\
\hline \multicolumn{2}{|c|}{ Stream incisement (\#47) } & 6 & \\
\hline \multicolumn{2}{|c|}{ Percent of streambank which is altered by human-induced activities (\#52) } & 6 & \\
\hline \multicolumn{2}{|c|}{ Lateral Cutting (\#48b) } & $\underline{6}$ & \\
\hline
\end{tabular}

(Actual Score/Possible Score) $\times 100=$ Rating Percent

Descriptive Category*

Vegetation
Soils
Hydro/Banks

\begin{tabular}{ll} 
Rating Percent & Descriptive Category \\
\hline $80-100$ & Healthy (Proper Functioning Condition) \\
$60-79$ & Unhealthy (Functioning - At Risk) \\
$<60$ & Unhealthy (Non-functioning)
\end{tabular}

${ }^{*}$ In addition to the Rating Percents and Descriptive Categories, any area where the streambanks do not contain a high percentage $(>50 \%)$ of large materials $(>2.5$ inches) should be considered susceptible to degradation.

${ }^{* *}$ Where two of the Descriptive Categories are lower than the total Descriptive Category, the Total Descriptive Category will be lowered one category. For example, if Vegetation and Soils/Geology have 19 and 8 points (79\% and 67\%), but Hydrology/Streambank has 22 points (92\%), the total points would be 49 (Total Rating Percent $=82 \%$; Healthy [Proper Functioning Condition]). Here, the overall Descriptive Category would be lowered to At Risk (rather than Healthy), due to the two At Risk subgroups. 


\section{Riparian Grazing Study Health Evaluation Codes and Instructions}

The information presented below provides guidance on how to rate each item on the health evaluation form. The numbers in parentheses refer to the appropriate item on the Riparian Grazing Study Field Form from which to obtain the necessary data.

\section{Vegetation}

The vegetation in riparian zones performs the primary physical functions of filtering sediments from overland and instream flow and stabilizing the soil with a binding root mass. Additionally, there are a variety of biological functions which depend on the amount, types, and condition of the vegetation. Vegetation, being more visible than either soil or hydrologic site characteristics, can provide early indications of changes in a riparian reach.

\section{Canopy Cover of Woody Species (\#18).}

Vegetative cover is vital to the ability of the system to trap sediments and to reduce the velocity of water moving over the floodplain or along the streambanks. The vegetative canopy cover helps reduce raindrop impact, other erosive forces, and the rate of soil water evaporation. Furthermore, the tree and tall shrub canopy may shade the channel, keeping stream temperatures cooler, increasing available oxygen and providing cover and feeding habitat for fish and other aquatic animals.

\begin{tabular}{cl}
\hline Score & Amounts or description \\
\hline 3 & $45 \%$ or greater \\
2 & $25-44 \%$ \\
1 & $5-24 \%$ \\
0 & $<5 \%$ \\
\hline \hline
\end{tabular}

\section{Combined Canopy Cover of Four Plant Lifeforms (\#19).}

Vegetation cover is instrumental in the ability of the system to trap sediments and to reduce the velocity of water moving over the floodplain or along the streambanks. The extent of vegetative canopy cover is a factor in mitigating raindrop impact, all erosive forces, and the rate of evaporation.

\begin{tabular}{cl}
\hline Score & Amounts or description \\
\hline 3 & $95 \%$ or greater \\
2 & $85-94 \%$ \\
1 & $75-84 \%$ \\
0 & $<75 \%$ \\
\hline \hline
\end{tabular}

\section{Total Area Inhabited by Noxious Weed Species (\#23).}

The presence of large amounts of noxious or exotic weeds (listed below) indicates a degradation of ecosystem function. While some of these species may contribute to some riparian functions, their negative impacts on the ecosystem reduce the overall ecological health of that site.

\begin{tabular}{cl}
\hline Score & Amounts or description \\
\hline 3 & $<5 \%$ \\
2 & $5-24 \%$ \\
1 & $25-44 \%$ \\
0 & $45 \%$ or greater \\
\hline \hline
\end{tabular}




\section{Cover of "Weedy" Herbaceous Species (\#24).}

The presence of a large cover of disturbance-caused species (either native or introduced) indicates change from a potential natural community (PNC) and a reduction in riparian health. These species are less productive and generally have shallow roots. The presence of these species is usually the result of some disturbance which removes the more desirable, later seral species.

\begin{tabular}{cl}
\hline Score & Amounts or description \\
\hline 3 & $<5 \%$ \\
2 & $5-24 \%$ \\
1 & $25-44 \%$ \\
0 & $45 \%$ or greater \\
\hline
\end{tabular}

Utilization of Trees and Shrubs. (Only consider those woody species that are commonly utilized; conifers and the various sage species are, in general, not commonly utilized) (\#13 \& 14).

Many riparian woody species are browsed by livestock and/or wildlife. Heavy browsing can prevent establishment of woody species and thus block succession of the community toward later seral stages. Excessive use of these species can result in their elimination from the community and their replacement by undesirable invaders. If either the seral stage(s) (community type) or the PNC(s) (habitat type) (\#20 on the Inventory Form) do not have the potential for trees or shrubs, then replace the Possible Score value with a "0" and enter "NA" (not applicable) in the Actual Score column.Also, enter "NA" if all the woody material is unavailable (category E).

\begin{tabular}{cl}
\hline Score & Amounts or description \\
\hline 3 & $0-25 \%$ \\
2 & $26-50 \%$ \\
1 & $>50 \%$, but majority plants not clubbed or hi-lined \\
0 & $>50 \%$, with majority clubbed or hi-lined \\
\hline
\end{tabular}

Tree Regeneration (amounts are the percent of the total lifeform canopy cover accounted for by the combined canopy cover of seedlings and saplings) (\#12).

One of the clearest indicators of the health and ecological stability of a site with woody species potential is the presence of plants in all age classes (seedling, sapling, pole, and mature) of the characteristic species of that habitat type.The presence of all age classes indicates the long term stability inherent to potential natural communities (PNC's). Likewise, but less apparently, a community types' ecological stability and functional capacity are reflected by one of these conditions:(1) for late seral communities, the presence of seedling, sapling, and pole age classes of climax woody species, and mature or older individuals of later seral stages, OR (2) for early seral communities, the presence of seedling, sapling, and pole age classes of seral species, and the absence of any age classes of climax woody species. (Note: For a woody species age class to be considered present, the evaluator must find a minimum of ten individuals per age class per acre.)

\begin{tabular}{cl}
\hline Score & Amounts or description \\
\hline 3 & $>20 \%$ \\
2 & $6-20 \%$ \\
1 & $>0-5 \%$ \\
0 & $0 \%$ \\
\hline
\end{tabular}


Shrub Regeneration (amounts are the percent of the total lifeform canopy cover accounted for by the combined canopy cover of seedling/sapling age group) (\#14).

Another clear indicator of a habitat type's ecological stability, and therefore, health, is the presence of shrubs representing all age classes (seedling, sapling, mature, decadent, and dead) of the species characteristic of that habitat type. The presence of all age classes ensures the "self-perpetuating" stability inherent to all potential natural communities. Similarly, but less apparent in determining a seral community type's ecological stability and health is the existence of one of the following conditions:A) for late seral communities, the presence of seedlings and saplings climax shrub species and mature and older individuals of later seral stages, Or B) for early seral communities, the presence of seedlings and saplings of seral species and the absence of any age classes of climax shrub species. (Note: For a woody species age class to be considered present, the evaluator must find a minimum of ten individuals per age class per acre.)

\begin{tabular}{ll}
\hline Score & Amounts or description \\
\hline 3 & $>20 \%$ \\
2 & $6-20 \%$ \\
1 & $>0-5 \%$ \\
0 & $0 \%$ \\
\hline \hline
\end{tabular}

\section{Woody Dead and Decadent Amounts (amounts are the combined percent of total tree and shrub canopy} cover by dead and decadent individuals) ( $\# 12 \& 14)$.

The amount of decadent and dead woody material can be an indication of the overall health of a riparian wetland. Large amounts of decadent and dead woody material can indicate severe stress due to high levels of browsing. In addition, large amounts may indicate a dewatering of the riparian wetland site due to either artificial or natural causes. The dewatering of the site, if severe enough, may change the potential of the site from riparian wetland species to upland species. Large amounts of decadent and dead woody material may indicate fluctuations in climate, such as severe winter temperatures that winter kill certain species such as thorny buffaloberry (Shepherdia argentea), or cyclic insect infestations such as in stands of sandbar willow (Salix exigua). In all cases, the overall biotic "health" of the riparian wetland has been affected, which may have implications on physical features such as streambank integrity, incisement, and lateral cutting.

If either the seral stage(s) (community type) or the PNC(s) (habitat type) does not have the potential for trees, then replace the Possible Score value with a "O" and place "NA" (not applicable) in the Actual Score column. Do not include the amount of decadent and dead material of cottonwood trees (Populus trichocarpa, P. deltoides, or P. angustifolia) which appear decadent due to old age (rough and furrowed bark extends substantially up into the crowns of the trees).

\begin{tabular}{ll}
\hline Score & Amounts or description \\
\hline 3 & $<5 \%$ \\
2 & $5-24 \%$ \\
1 & $25-4 \% \%$ \\
0 & $45 \%$ or greater \\
\hline
\end{tabular}




\section{Soils}

\section{Sufficient Soil to Act as a Sponge and Support Riparian Vegetation (\#46).}

In riparian wetlands, soil acts as a sponge to store water and supports riparian vegetation by acting as a rooting medium. The kind and amount of soil materials present are factors determining the potential of a site. For example, soils comprised of clay, silt and, to some degree, sand can store water until drier seasons and for periods important to the growth stages of riparian plant species. Coarser substrates (gravels, cobbles, and boulders) cannot do this. Likewise, an adequate rooting medium for plant growth depends on substrate particle size. Bedrock or substrates dominated by boulders or large cobbles do not provide an adequate rooting medium. (Certain high gradient mountain streams are commonly found in channels dominated by bedrock or large boulders. Such streams will score low in this category, which merely reflects their low capacity for water storage and primary biomass production. These sites usually are otherwise resistant to disturbance and will score high in other categories.)

6 Soil material sufficiently thick to potentially function as a sponge is present on at least $85 \%$ of the floodplain and streambank area.

4 Soil material sufficiently thick to potentially function as a sponge is present on $65 \%$ to $84 \%$ of the floodplain and streambank area.

2 Soil material sufficiently thick to potentially function as a sponge is present on $35 \%$ to $64 \%$ of the floodplain and streambank area.

0 Soil material sufficiently thick to potentially function as a sponge is present on less than $35 \%$ of the floodplain and streambank area.

\section{Percent of Polygon which is Human-Induced Bare Ground (\#53).}

Bare ground is subject to erosive forces since it is not protected by plants, litter or duff, downed woody materials, or rocks larger than 2.5 inches. Examples of human-caused bare ground include cattle trails and wallows, hiking and ATV trails, roads, logging skid trails, and mining activities. Bare ground negatively affects the function of riparian areas by: a) increasing vulnerability to erosion; b) contributing to streambank deterioration; c) providing less plant material for primary production, sediment entrapment and soil macropore development; and d) providing opportunities for invasion by noxious, and other weedy species. It is important to ask: What has caused the soil to be exposed? If the causes are human related or are accelerated by land management practices, this suggests a deteriorating situation. By not discounting for natural bare ground, this assessment exempts locations where sediment deposition or other natural processes cause bare ground that may be beyond management control.

\begin{tabular}{cl}
\hline Score & Amounts or description \\
\hline 6 & $<1 \%$ \\
4 & $1<5 \%$ \\
2 & $5-14 \%$ \\
0 & $15 \%$ or greater \\
\hline
\end{tabular}




\section{Hydrology/Streambanks}

The hydrology of a riparian site is perhaps its most important characteristic. Hydrologic alteration can cause short term vegetative changes on the site as well as different vegetative potential. Examples of such changes would include lower flow volumes (caused by dams, diversions, etc.), lowering of water table levels by channel incisement, altered timing of peak flows, and lateral movement of the stream channel. The composition and condition of the streambanks influence their susceptibility to erosion and trampling.

\section{Percent of Streambanks and Closely Associated Areas with a Deep, Binding Root Mass (\#44).}

Streamside vegetation stabilizes the soil to the degree that it provides a deep, binding root mass as long as it is right next to the stream. All woody species are considered to provide this deep, binding root mass.Among riparian herbaceous species, the first rule is that annual plants lack deep, binding root masses. Perennial species provide a wide range of root mass qualities. Some rhizomatous species, such as the deep rooted sedges (Carex spp.), are excellent streambank stabilizers. Other rhizomatous species, such as Kentucky bluegrass (Poa pratensis), provide only shallow root systems and are poor streambank stabilizers. Still others, such as Baltic rush (Juncus balticus), appear to have root systems intermediate in their bank stabilizing capacity. In all cases greater density and vigor of any streamside plants mean greater stability of that streambank.

\begin{tabular}{cl}
\hline Score & Amounts or description \\
\hline 6 & $85 \%$ or greater \\
4 & $65-84 \%$ \\
2 & $35-64 \%$ \\
0 & $<35 \%$
\end{tabular}

\section{Stream Incisement ( $\# 47)$.}

A stream is incised when downcutting of the stream has resulted in a width to depth ratio so low that the average two year flood does not come out of the banks. Incisement can lower the system water table which may change the current vegetation, as well as the site's potential natural community (PNC).

\begin{tabular}{cll}
\hline Score & Amounts or description \\
\hline 6 & A & $\begin{array}{l}\text { Stream not incised; downcutting, if present, is very limited. } \\
\text { Old incisement; floodplain developed, but significant active lateral cutting is not } \\
\text { occurring. Downcutting, if present, is very limited. Stream channel is currentlystable. } \\
\text { Old incisement; floodplain partially developed at new level, but it is much narrower than it } \\
\text { will eventually become as lateral cutting is actively widening the new floodplain. Down- } \\
\text { cutting, if present, is very limited and likely represents a new downcutting event since the } \\
\text { initial formation of the first (old) incisement. } \\
\text { Deeply incised; widening of gully is occurring due to active lateral cutting. Initial floodplain } \\
\text { development is observable. Some active downcutting may be observed, but lateral cutting } \\
\text { resulting in widening of the gully is the dominant process. Two year floods do not come out } \\
\text { of old banks, but many larger floods do. } \\
\text { Deeply incised; no floodplain development; only extreme floods come out of banks; active } \\
\text { downcutting is probably occurring. }\end{array}$ \\
C & B & D
\end{tabular}




\section{Percent of Streambank which is Altered by Human-Induced Processes (\#53).}

Streams are naturally dynamic and continually move across their floodplain. Therefore, all streams have some naturally unstable streambanks. However, in many instances, current land uses have accelerated this natural movement across the floodplain by degrading the streambanks. Currently there are many ways to measure or interpret altered streambanks. With this in mind, we define altered streambanks as those having impaired structural integrity (strength or stability) due to human-caused activities. These streambanks are susceptible to cracking and/or slumping.

\begin{tabular}{lll}
\hline Score & Amounts or description \\
\hline 6 & $<5 \%$ \\
4 & $5-14 \%$ \\
2 & $15-34 \%$ \\
0 & $35 \%$ or greater \\
\hline
\end{tabular}

\section{Percent of Streambank which has undergone Recent Lateral Cutting (\#48b)}

Lateral cutting of a stream is indicated by new stream-caused bank disruption along the outside of stream curves and, much less commonly, along the straight portions of a stream. Any lateral cutting which has occurred during the past year is considered active. Cutbanks with vegetation becoming established are considered healing and are not rated as active.

Some sites are naturally dynamic and will exhibit some cutting without any human disturbance, while other sites are so well armored or bedrock-controlled that they will not move under any amount of disturbance. Depending upon the geographic location and kind of substrate, the amount of natural lateral cutting can range from none to a large fraction of the total bank length. Lateral cutting (expressed as a percentage of the total bank length) reflects either a sensitivity to or a degradation of the site and thus carries management implications.

Some human-caused disturbances which can cause lateral bank cutting are increased flows from irrigation return, elimination of woody species and their roots along the streambank, increase in shallow-rooted undesirable herbaceous species, and physical erosion of banks by hoof action. In any case, moderate to high levels of active lateral cutting affect the health of the riparian reach.

\begin{tabular}{ll}
\hline Score & Amounts or description \\
\hline 6 & $<5 \%$ \\
4 & $5-14 \%$ \\
2 & $15-34 \%$ \\
0 & $35 \%$ or greater \\
\hline
\end{tabular}


Appendix E.

Habitat types and community types present in study reaches

Habitat Type (HT)/Community Type(CT)

No. of Reaches

\section{Trees (Deciduous)}

Acer negundo/Prunus virginiana $\mathrm{HT}$

(Box elder/common chokecherry HT)

Fraxinus pennsylvanica/Prunus virginiana $\mathrm{HT}$

(Green ash/common chokecherry HT)

Populus angustifolia/Cornus stolonifera CT

(Narrowleaf cottonwood/red-osier dogwood CT)

Populus angustifolia/Herbaceous CT

(Narrowleaf cottonwood/herbaceous $C T$ )

Populus tremuloides/Cornus stolonifera CT

(Quaking aspen/red-osier dogwood CT)

Populus trichocarpa/Cornus stolonifera CT

(Black cottonwood/red-osier dogwood CT)

\section{Trees (Coniferous)}

Picea/Cornus stolonifera HT

(Spruce/red-osier dogwood HT)

Pseudotsuga menziesii/Cornus stolonifera HT

(Douglas-fir/red-osier dogwood HT)

\section{Shrubs (Willows)}

Salix bebbiana CT

(Bebb willow CT)

Salix drummondiana/Carex rostrata HT

(Drummond willow/beaked sedge HT)

Salix exigua CT

(Sandbar willow CT)

Salix geyeriana/Carex rostrata HT

(Geyer willow/beaked sedge HT)

Salix geyeriana $C T$

(Geyer willow CT)

Salix lasiandra CT

(Pacific willow CT)

Salix lutea/Carex rostrata HT

(Yellow willow/beaked sedge HT)

Salix lutea $C T$

(Yellow willow $C T$ ) 


\section{Shrubs (Non-willow)}

Alnus incana $C T$

(Mountain alder CT)

Potentilla fruticosa/Deschampsia cespitosa HT

(Shrubby cinquefoil/tufted hairgrass $\mathrm{HT}$ )

Prunus virginiana $C T$

(Common chokecherry $C T$ )

Symphoricarpus occidentalis CT

Western snowberry $C T$ )

\section{Herbaceous (Grasses)}

Agropyron smithii HT

Nestern wheatgrass HT)

Agropyron stolonifera CT

(Redtop $C T$ )

Calamagrotis canadensis HT

(Bluejoint reedgrass $\mathrm{HT}$ )

Deschampsia cespitosa HT

(Tufted hairgrass HT)

Phalaris arundinacea HT

(Reed canarygrass $\mathrm{HT}$ )

Spartina pectinata HT

(Prairie cordgrass HT)

Undetermined

\section{Herbaceous (Sedges)}

Carex aquatilis HT

(Water sedge HT)

Carex lasiocarpa HT

(Slender sedge HT)

Carex nebraskensis $C T$

(Nebraska sedge CT)

Carex rostrata HT

(Beaked sedge HT)

\section{Herbaceous (Grass-like)}

Eleocharis palustris HT

(Common spikesedge HT)

Juncus balticus $\subset T$

(Baltic rush $C T$ )

Scirpus pungens HT

(Sharp bulrush HT) 
Appendix F.

Individual reaches (polygons) grouped by vegetative life form

F-1. Polygons which contain more than $\mathbf{2 5}$ percent deciduous tree vegetation types

\begin{tabular}{|c|c|c|c|c|}
\hline $\begin{array}{c}\text { Overall Health } \\
\text { Rating }(\%)\end{array}$ & $\begin{array}{c}\text { Season of } \\
\text { Grazing Use' }\end{array}$ & $\begin{array}{c}\text { Length of } \\
\text { Grazing Period }\end{array}$ & $\begin{array}{c}\text { Presence of } \\
\text { Offstream Water }\end{array}$ & $\begin{array}{c}\text { Rosgen Stream } \\
\text { Type }\end{array}$ \\
\hline 97 & Winter & $>45$ days/winter & No & C4 \\
\hline 95 & Various (>8 days) & $>45$ days/non-winter & Yes & B4a \\
\hline 93 & Late Only & $36-45$ days & Yes & E5 \\
\hline 90 & Various ( $\leq 8$ days) & $\leq 8$ days & No & C3 \\
\hline 90 & Middle & $36-45$ days & Yes & Woody draw \\
\hline 88 & Various (>8 days) & 22-35 days & Yes & C4 \\
\hline 88 & Late Only & $36-45$ days & Yes & Woody draw \\
\hline 88 & Various ( $>8$ days) & $36-45$ days & No & C3 \\
\hline 87 & Early Only & $>45$ days/non-winter & Yes & $\mathrm{C} 4$ \\
\hline 87 & Late Only & $36-45$ days & Yes & Woody draw \\
\hline 87 & Winter & $>45$ days/winter & Yes & $B 6 C$ \\
\hline 87 & Winter & $>45$ days/winter & Yes & C6 \\
\hline 86 & Early Only & 22-35 days & Yes & Woody draw \\
\hline 86 & Winter & $>45$ days/winter & Yes & Woody draw \\
\hline 85 & Late Only & $36-45$ days & Yes & C4 \\
\hline 83 & Various ( $>8$ days) & $9-21$ days & Yes & B4 \\
\hline 83 & Various ( $\leq 8$ days) & $\leq 8$ days & No & C4 \\
\hline 83 & Various ( $\leq 8$ days) & $\leq 8$ days & No & $\mathrm{C} 3$ \\
\hline 83 & Winter & $>45$ days/winter & No & C6 \\
\hline 82 & Winter & $36-45$ days & No & C5 \\
\hline 82 & Various (>8 days) & $>45$ days/non-winter & Yes & $\mathrm{C} 4$ \\
\hline 82 & Winter & $>45$ days/winter & No & $C 5$ \\
\hline 82 & Winter & $22-35$ days & No & $\mathrm{C} 4 \mathrm{D}$ \\
\hline 81 & Various ( $\leq 8$ days) & $\leq 8$ days & Yes & Woody draw \\
\hline 80 & Early or Late & $36-45$ days & Yes & C4 \\
\hline 80 & Various $1>8$ days & $36-45$ days & No & B4 \\
\hline 80 & Various (>8 days) & $22-35$ days & Yes & C4 \\
\hline 80 & Various (>8 days) & $22-35$ days & Yes & B4a \\
\hline 78 & Early Only & $22-35$ days & Yes & Woody draw \\
\hline 77 & Various $(\leq 8$ days) & $\leq 8$ days & No & $\mathrm{B} 6 \mathrm{C}$ \\
\hline
\end{tabular}

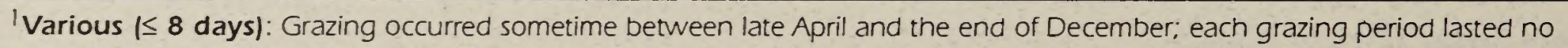
more than eight days, with several periods occurring throughout the year.

Various (>8 days): Grazing occurred at various times between late April and the end of December in a single period longer than eight days.

Early and Late: Pasture was grazed between later April and mid-July, then cattle went back in between mid-October and late December.

Early or Late: Pasture was used once a year, with use alternating annually between late April to mid-July and mid-October to late December.

Early Only: Pasture was grazed for a period exceeding eight days between late April and mid-July. Middle: Pasture used for a period exceeding eight days between mid-July and late September.

Late Only: Pasture used for a period exceeding eight days between mid-October and late December.

Winter: That period between late December and late April when livestock were being fed hay. 
F-2. Polygons which contain more than 25 percent coniferous tree vegetation types

\begin{tabular}{ccccc}
\hline $\begin{array}{c}\text { Overall Health } \\
\text { Rating (\%) }\end{array}$ & $\begin{array}{c}\text { Season of } \\
\text { Grazing Use }\end{array}$ & $\begin{array}{c}\text { Length of } \\
\text { Grazing Period }\end{array}$ & $\begin{array}{c}\text { Presence of } \\
\text { Offstream Water }\end{array}$ & $\begin{array}{c}\text { Rosgen Stream } \\
\text { Type }\end{array}$ \\
\hline 83 & Early or Late & $36-45$ days & Yes & $B 4$ \\
82 & Middle & $22-35$ days & Yes & $B 4$
\end{tabular}

F-3. Polygons which contain more than 25 percent willow vegetation types

\begin{tabular}{|c|c|c|c|c|}
\hline $\begin{array}{c}\text { Overall Health } \\
\text { Rating }(\%)\end{array}$ & $\begin{array}{c}\text { Season of } \\
\text { Grazing Use' }\end{array}$ & $\begin{array}{c}\text { Length of } \\
\text { Grazing Period }\end{array}$ & $\begin{array}{c}\text { Presence of } \\
\text { Offstream Water }\end{array}$ & $\begin{array}{c}\text { Rosgen Stream } \\
\text { Type }\end{array}$ \\
\hline 96 & Middle & $9-21$ days & No & C4 \\
\hline 92 & Various (>8 days) & $22-35$ days & Yes & E4 \\
\hline 90 & Various (>8 days) & $>45$ days/non-winter & No & E5 \\
\hline 89 & Early and Late & $>45$ days/non-winter & Yes & E4 \\
\hline 89 & Late Only & $36-45$ days & No & E4 \\
\hline 88 & Late Only & $>45$ days/non-winter & Yes & B3 \\
\hline 88 & Various (> 8 days) & $>45$ days/non-winter & No & E5 \\
\hline 88 & Various (>8 days) & $9-21$ days & Yes & C5 \\
\hline 88 & Early and Late & $\leq 8$ days & No & E4 \\
\hline 88 & Various (>8 days) & $36-45$ days & No & $\mathrm{C} 3$ \\
\hline 87 & Early and Late & $22-35$ days & Yes & $\mathrm{C} 3$ \\
\hline 87 & Early Only & $>45$ days/non-winter & Yes & C4 \\
\hline 86 & Various (>8 days) & $9-21$ days & Yes & B4 \\
\hline 85 & Late Only & $>45$ days/non-winter & Yes & E4 \\
\hline 84 & Various (>8 days) & $>45$ days/non-winter & Yes & $\mathrm{C} 4$ \\
\hline 84 & Middle & $36-45$ days & Yes & B4 \\
\hline 84 & Late Only & $9-21$ days & No & C3 \\
\hline 84 & Winter & $>45$ days/winter & No & C6 \\
\hline 83 & Late Only & $>45$ days/non-winter & Yes & $\mathrm{C} 4$ \\
\hline 83 & Late Only & $22-35$ days & No & C4 \\
\hline 83 & Early Only & $\leq 8$ days & No & C3 \\
\hline 82 & Early and Late & $9-21$ days & No & C5 \\
\hline 82 & Various (>8 days) & $22-35$ days & Yes & $\mathrm{C4}$ \\
\hline 81 & Various ( $>8$ days) & $36-45$ days & Yes & E5 \\
\hline 81 & Various ( $\leq 8$ days) & $\leq 8$ days & No & $\mathrm{B} 5 \mathrm{C}$ \\
\hline 81 & Winter & $>45$ days/winter & Yes & $B 4 C$ \\
\hline 80 & Early or Late & $9-21$ days & No & $C 5$ \\
\hline 79 & Various ( $\leq 8$ days) & $\leq 8$ days & Yes & $\mathrm{B} 5 \mathrm{C}$ \\
\hline 79 & Various ( $\leq 8$ days) & $\leq 8$ days & No & $\mathrm{C5}$ \\
\hline \multicolumn{5}{|c|}{$\begin{array}{l}\text { IVarious ( } \mathbf{8} \text { days): Grazing occurred sometime between late April and the end of December, each grazing period lasted no } \\
\text { more than eight days, with several periods occurring throughout the year. } \\
\text { Various (>8 days): Grazing occurred at various times between late April and the end of December in a single period longer than } \\
\text { eight days. } \\
\text { Early and Late: Pasture was grazed between later April and mid-July, then cattle went back in between mid-October and late } \\
\text { December. } \\
\text { Early or Late: Pasture was used once a year, with use alternating annually between late April to mid-July and mid-October to late } \\
\text { December. } \\
\text { Early Only: Pasture was grazed for a period exceeding eight days between late April and mid-July. } \\
\text { Midddle: Pasture used for a period exceeding eight days between mid-July and late September. } \\
\text { Late Only: Pasture used for a period exceeding eight days between mid-October and late December. } \\
\text { Winter: That period between late December and late April when livestock were being fed hay. }\end{array}$} \\
\hline
\end{tabular}




\section{F-4. Polygons which contain more than 25 percent non-willow shrub vegetation types}

\begin{tabular}{ccccc}
\hline $\begin{array}{c}\text { Overall Health } \\
\text { Rating (\%) }\end{array}$ & $\begin{array}{c}\text { Season of } \\
\text { Grazing Use' }\end{array}$ & $\begin{array}{c}\text { Length of } \\
\text { Grazing Period }\end{array}$ & $\begin{array}{c}\text { Presence of } \\
\text { Offstream Water }\end{array}$ & $\begin{array}{c}\text { Rosgen Stream } \\
\text { Type }\end{array}$ \\
\hline 92 & Various $(>8$ days) & $36-45$ days & Yes & E4 \\
90 & Winter & $>45$ days/winter & No & C6 \\
86 & Winter & $>45$ days/winter & Yes & Woody draw \\
85 & Various $(\leq 8$ days) & $\leq 8$ days & No & C4 \\
84 & Winter & $>45$ days/winter & No & C6 \\
78 & Winter & $>45$ days/winter & Yes & Woody draw
\end{tabular}

\section{F-5. Polygons which contain more than 25 percent grass vegetation types}

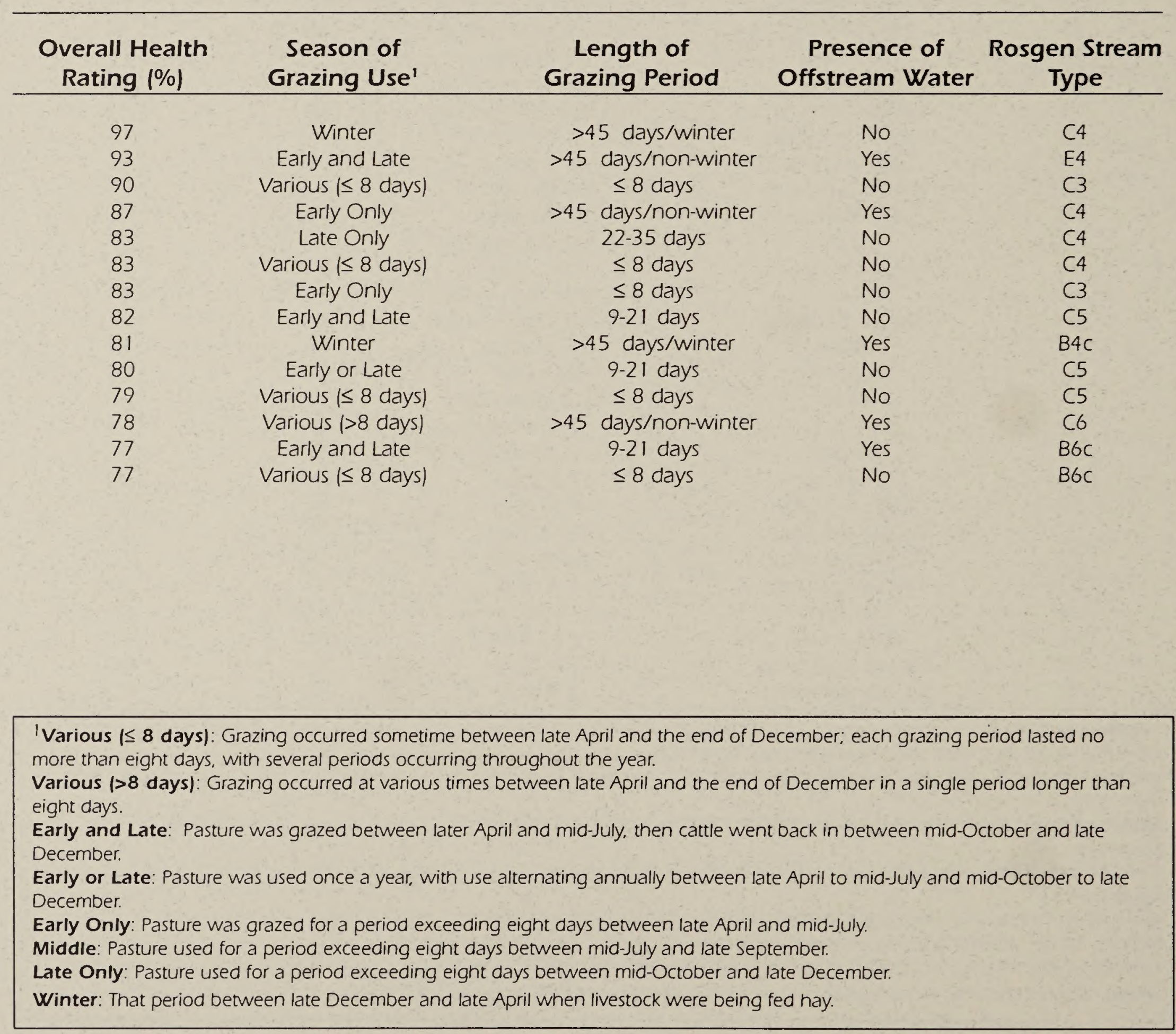


F-6. Polygons which contain more than 25 percent sedge vegetation types

\begin{tabular}{|c|c|c|c|c|}
\hline $\begin{array}{c}\text { Overall Health } \\
\text { Rating }(\%)\end{array}$ & $\begin{array}{c}\text { Season of } \\
\text { Grazing Use }\end{array}$ & $\begin{array}{l}\text { Length of } \\
\text { Grazing Period }\end{array}$ & $\begin{array}{c}\text { Presence of } \\
\text { Offstream Water }\end{array}$ & $\begin{array}{c}\text { Rosgen Stream } \\
\text { Type } \\
\end{array}$ \\
\hline 98 & Early Only & $22-35$ days & No & E5 \\
\hline 93 & Various (>8 days) & 22-35 days & Yes & E5 \\
\hline 92 & Winter & $>45$ days/winter & No & $\mathrm{Cb}$ \\
\hline 92 & Various $\mid>8$ days) & 22-35 days & Yes & E4 \\
\hline 92 & Various (>8 days) & $36-45$ days & Yes & E4 \\
\hline 91 & Various ( $\leq 8$ days) & $\leq 8$ days & No & E5 \\
\hline 90 & Winter & $>45$ days/winter & No & C6 \\
\hline 89 & Middle & $>45$ days $/$ non-winter & No & E5 \\
\hline 88 & Various (>8 days) & 22-35 days & Yes & C4 \\
\hline 88 & Early and Late & $\leq 8$ days & No & E4 \\
\hline 87 & Winter & $>45$ days/winter & Yes & C6 \\
\hline 83 & Winter & $>45$ days $/$ winter & No & C6 \\
\hline 81 & Various ( $\leq 8$ days) & $\leq 8$ days & No & $B 5 C$ \\
\hline 80 & Various (>8 days) & $22-35 d$ & Yes & C4 \\
\hline 79 & Various ( $\leq 8$ days) & $\leq 8$ days & Yes & $B 5 C$ \\
\hline 79 & Various ( $\leq 8$ days) & $\leq 8$ days & No & $\mathrm{C} 5$ \\
\hline
\end{tabular}

\section{F-7. Polygons which contain more than 25 percent rush or spike rush vegetation types}

\begin{tabular}{ccccc}
\hline $\begin{array}{c}\text { Overall Health } \\
\text { Rating }(\%)\end{array}$ & $\begin{array}{c}\text { Season of } \\
\text { Grazing Use' }\end{array}$ & $\begin{array}{c}\text { Length of } \\
\text { Grazing Period }\end{array}$ & $\begin{array}{c}\text { Presence of } \\
\text { Offstream Water }\end{array}$ & $\begin{array}{c}\text { Rosgen Stream } \\
\text { Type }\end{array}$ \\
\hline 98 & Early Only & $22-35$ days & No & E5 \\
97 & Winter & $>45$ days/winter & No & $C 4$ \\
93 & Late Only & $36-45$ days & Yes & E5 \\
89 & Middle & $>45$ days/non-winter & No & E5 \\
78 & Various $(>8$ days) & $>45$ days/non-winter & Yes & C6 \\
77 & Early and Late & $9-21$ days & Yes & B6c
\end{tabular}

'Various ( $\mathbf{8}$ days): Grazing occurred sometime between late April and the end of December; each grazing period lasted no more than eight days, with several periods occurring throughout the year.

Various (>8 days): Grazing occurred at various times between late April and the end of December in a single period longer than eight days.

Early and Late: Pasture was grazed between later April and mid-July, then cattle went back in between mid-October and late December.

Early or Late: Pasture was used once a year, with use alternating annually between late April to mid-July and mid-October to late December.

Early Only: Pasture was grazed for a period exceeding eight days between late April and mid-July.

Middle: Pasture used for a period exceeding eight days between mid-July and late September.

Late Only: Pasture used for a period exceeding eight days between mid-October and late December.

Winter: That period between late December and late April when livestock were being fed hay. 


\section{Appendix G.}

Individual reaches grouped by season of grazing use

G-1. Polygons grazed during various seasons but no more than 8 days at one time'

\begin{tabular}{cccc}
\hline $\begin{array}{c}\text { Overall Health } \\
\text { Rating }(\%)\end{array}$ & $\begin{array}{c}\text { Length of } \\
\text { Grazing Period }\end{array}$ & $\begin{array}{c}\text { Presence of } \\
\text { Offstream Water }\end{array}$ & $\begin{array}{c}\text { Rosgen Stream } \\
\text { Type }\end{array}$ \\
\hline 91 & $\leq 8$ days & No & E5 \\
90 & $\leq 8$ days & No & $C 3$ \\
85 & $\leq 8$ days & No & $C 4$ \\
83 & $\leq 8$ days & No & $C 4$ \\
83 & $\leq 8$ days & No & C3 \\
81 & $\leq 8$ days & Yes & Woody draw \\
81 & $\leq 8$ days & No & B5c \\
79 & $\leq 8$ days & Yes & B5c \\
79 & $\leq 8$ days & No & C5 \\
77 & $\leq 8$ days & No & B6c
\end{tabular}

G-2. Polygons grazed various seasons for more than 8 days at one time ${ }^{2}$

\begin{tabular}{|c|c|c|c|}
\hline $\begin{array}{c}\text { Overall Health } \\
\text { Rating }(\%) \\
\end{array}$ & $\begin{array}{c}\text { Length of } \\
\text { Grazing Period }\end{array}$ & $\begin{array}{c}\text { Presence of } \\
\text { Offstream Water }\end{array}$ & $\begin{array}{c}\text { Rosgen Stream } \\
\text { Type }\end{array}$ \\
\hline 95 & $>45$ days/non-winter & Yes & B4a \\
\hline 93 & $22-35$ days & Yes & E5 \\
\hline 92 & $22-35$ days & Yes & E4 \\
\hline 92 & $36-45$ days & Yes & E4 \\
\hline 90 & $>45$ days/non-winter & No & E5 \\
\hline 88 & 22-35 days & Yes & C4 \\
\hline 88 & $36-45$ days & No & C3 \\
\hline 88 & $>45$ days/non-winter & No & E5 \\
\hline 88 & $9-21$ days & Yes & $C 5$ \\
\hline 86 & $9-21$ days & Yes & B4 \\
\hline 84 & $>45$ days/non-winter & Yes & C4 \\
\hline 83 & 9-21 days & Yes & B4 \\
\hline 82 & $22-35$ days & Yes & $\mathrm{C} 4$ \\
\hline 82 & $>45$ days/non-winter & Yes & C4 \\
\hline 81 & $36-45$ days & Yes & E5 \\
\hline 80 & $36-45$ days & No & B4 \\
\hline 80 & 22-35 days & Yes & C4. \\
\hline 80 & $22-35$ days & Yes & B4a \\
\hline 78 & $>45$ days/non-winter & Yes & C6 \\
\hline
\end{tabular}

\footnotetext{
' Various ( 8 days): Grazing occurred sometime between late April and the end of December; each grazing period lasted no more than eight days, with several periods occurring throughout the year.

${ }^{2}$ Various (>8 days): Grazing occurred at various times between late April and the end of December in a single period longer than eight days.
} 
G-3. Polygons grazed during both early and late seasons in one year ${ }^{3}$

\begin{tabular}{cccc}
$\begin{array}{c}\text { Overall Health } \\
\text { Rating }(\%)\end{array}$ & $\begin{array}{c}\text { Length of } \\
\text { Grazing Period }\end{array}$ & $\begin{array}{c}\text { Presence of } \\
\text { Offstream Water }\end{array}$ & $\begin{array}{c}\text { Rosgen Stream } \\
\text { Type }\end{array}$ \\
\hline 93 & $>45$ days/non-winter & Yes & E4 \\
89 & $>45$ days/non-winter & Yes & $E 4$ \\
88 & $\leq 8$ days & No & $E 4$ \\
87 & $22-35$ days & Yes & $C 3$ \\
82 & $9-21$ days & No & $C 5$ \\
77 & $9-21$ days & Yes & $B 6 C$
\end{tabular}

G-4. Polygons grazed during either early or late seasons, but not both the same year

\begin{tabular}{cccc}
$\begin{array}{c}\text { Overall Health } \\
\text { Rating }(\%)\end{array}$ & $\begin{array}{c}\text { Length of } \\
\text { Grazing Period }\end{array}$ & $\begin{array}{c}\text { Presence of } \\
\text { Offstream Water }\end{array}$ & $\begin{array}{c}\text { Rosgen Stre } \\
\text { Type }\end{array}$ \\
\hline & & & Yes \\
83 & $36-45$ days & Yes & C4 \\
80 & $36-45$ days & No & C5
\end{tabular}

G-5. Polygons grazed only during the early season ${ }^{5}$

\begin{tabular}{cccc}
$\begin{array}{c}\text { Overall Health } \\
\text { Rating }(\%)\end{array}$ & $\begin{array}{c}\text { Length of } \\
\text { Grazing Period }\end{array}$ & $\begin{array}{c}\text { Presence of } \\
\text { Offstream Water }\end{array}$ & $\begin{array}{c}\text { Rosgen Stream } \\
\text { Type }\end{array}$ \\
\hline 98 & $22-35$ days & No & E5 \\
87 & $>45$ days/non-winter & Yes & C4 \\
86 & $22-35$ days & Yes & Woody draw \\
83 & $\leq 8$ days & No & C3 \\
78 & $22-35$ days & Yes & Woody draw
\end{tabular}

G-6. Polygons grazed only during the middle season ${ }^{6}$

\begin{tabular}{cccc}
$\begin{array}{c}\text { Overall Health } \\
\text { Rating }(\%)\end{array}$ & $\begin{array}{c}\text { Length of } \\
\text { Grazing Period }\end{array}$ & $\begin{array}{c}\text { Presence of } \\
\text { Offstream Water }\end{array}$ & $\begin{array}{c}\text { Rosgen Stream } \\
\text { Type }\end{array}$ \\
\hline 96 & $9-21$ days & No & C4 \\
90 & $36-45$ days & Yes & Woody draw \\
89 & $>45$ days/non-winter & No & E5 \\
84 & $36-45$ days & Yes & $B 4$ \\
82 & $22-35$ days & Yes & $B 4$
\end{tabular}

\footnotetext{
${ }^{3}$ Early and Late: Pasture was grazed between later April and mid-July, then cattle went back in between mid-October and late December.

${ }^{4}$ Early or Late: Pasture was used once a year, with use alternating annually between late April to mid-July and mid-October to late December.

${ }^{5}$ Early Only: Pasture was grazed for a period exceeding eight days between late April and mid-July.

${ }^{6}$ Middle: Pasture used for a period exceeding eight days between mid-July and late September.
} 
G-7. Polygons grazed only during the late season?

\begin{tabular}{cccc}
$\begin{array}{c}\text { Overall Health } \\
\text { Rating (\%) }\end{array}$ & $\begin{array}{c}\text { Length of } \\
\text { Grazing Period }\end{array}$ & $\begin{array}{c}\text { Presence of } \\
\text { Offstream Water }\end{array}$ & $\begin{array}{c}\text { Rosgen Stream } \\
\text { Type }\end{array}$ \\
\hline 93 & $36-45$ days & Yes & E5 \\
89 & $36-45$ days & No & E4 \\
88 & $>45$ days/non-winter & Yes & B3 \\
88 & $36-45$ days & Yes & Woody draw \\
87 & $36-45$ days & Yes & Woody draw \\
85 & $>45$ days/non-winter & Yes & E4 \\
85 & $36-45$ days & Yes & C3 \\
84 & $9-21$ days & No & C4 \\
83 & $>45$ days/non-winter & Yes & C4 \\
83 & $22-35$ days & No &
\end{tabular}

G-8. Polygons grazed only during winter season ${ }^{8}$

\begin{tabular}{cccc}
\hline $\begin{array}{c}\text { Overall Health } \\
\text { Rating }(\%)\end{array}$ & $\begin{array}{c}\text { Length of } \\
\text { Grazing Period }\end{array}$ & $\begin{array}{c}\text { Presence of } \\
\text { Offstream Water }\end{array}$ & $\begin{array}{c}\text { Rosgen Stream } \\
\text { Type }\end{array}$ \\
\hline 97 & $>45$ days/winter & No & $C 4$ \\
92 & $>45$ days/winter & No & C6 \\
90 & $>45$ days/winter & No & C6 \\
87 & $>45$ days/winter & Yes & B \\
87 & $>45$ days/winter & Yes & W6 \\
86 & $>45$ days/winter & Yes & Woody draw \\
84 & $>45$ days/winter & No & C6 \\
83 & $>45$ days/winter & No & C5 \\
82 & $>45$ days/winter & No & $C 5$ \\
82 & $36-45$ days & No & C4b \\
82 & $22-35$ days & No & B4C \\
81 & $>45$ days/winter & Yes & Woody draw \\
78 & $>45$ days/winter & Yes &
\end{tabular}

7 Late Only: Pasture used for a period exceeding eight days between mid-October and late December.

${ }^{8}$ Winter: That period between late December and late April when livestock were being fed hay. 


\section{Appendix H.}

\section{Individual reaches (polygons) grouped by length of grazing period}

\section{H-1. Polygons grazed no more than 8 days at one time}

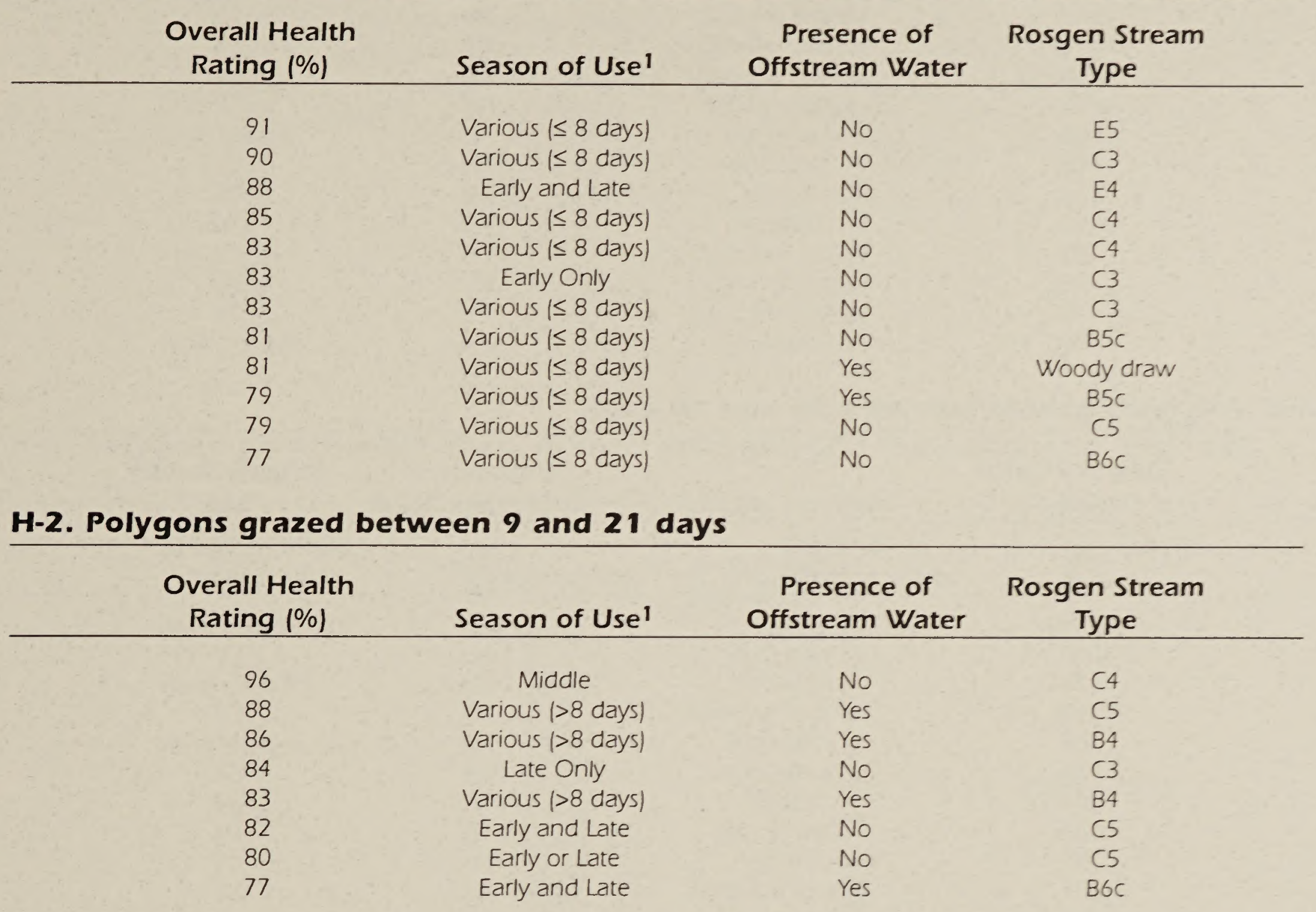

'Various ( $\leq \mathbf{8}$ days): Grazing occurred sometime between late April and the end of December; each grazing period lasted no more than eight days, with several periods occurring throughout the year.

Various (>8 days): Grazing occurred at various times between late April and the end of December in a single period longer than eight days.

Early and Late: Pasture was grazed between later April and mid-July, then cattle went back in between mid-October and late December.

Early or Late: Pasture was used once a year, with use alternating annually between late April to mid-July and mid-October to late December.

Early Only: Pasture was grazed for a period exceeding eight days between late April and mid-July. Middle: Pasture used for a period exceeding eight days between mid-July and late September.

Late Only: Pasture used for a period exceeding eight days between mid-October and late December.

Winter: That period between late December and late April when livestock were being fed hay. 
H-3. Polygons grazed between 22 and 35 days

\begin{tabular}{|c|c|c|c|}
\hline $\begin{array}{c}\text { Overall Health } \\
\text { Rating }(\%)\end{array}$ & Season of Use' & $\begin{array}{c}\text { Presence of } \\
\text { Offstream Water }\end{array}$ & $\begin{array}{c}\text { Rosgen Stream } \\
\text { Type }\end{array}$ \\
\hline $\begin{array}{l}98 \\
93 \\
92 \\
88 \\
87 \\
86 \\
83 \\
82 \\
82 \\
82 \\
80 \\
80 \\
78\end{array}$ & $\begin{array}{c}\text { Early Only } \\
\text { Various ( }>8 \text { days) } \\
\text { Various ( }>8 \text { days) } \\
\text { Various ( }>8 \text { days) } \\
\text { Early and Late } \\
\text { Early Only } \\
\text { Late Only } \\
\text { Middle } \\
\text { Winter } \\
\text { Various ( }>8 \text { days) } \\
\text { Various }>8 \text { days) } \\
\text { Various ( }>8 \text { days) } \\
\text { Early Only }\end{array}$ & $\begin{array}{l}\text { No } \\
\text { Yes } \\
\text { Yes } \\
\text { Yes } \\
\text { Yes } \\
\text { Yes } \\
\text { No } \\
\text { Yes } \\
\text { No } \\
\text { Yes } \\
\text { Yes } \\
\text { Yes } \\
\text { Yes }\end{array}$ & $\begin{array}{c}E 5 \\
E 5 \\
E 4 \\
C 4 \\
C 3 \\
\text { Woody draw } \\
\text { C4 } \\
B 4 \\
\text { C4D } \\
\text { C4 } \\
84 a \\
\text { C4 } \\
\text { Woody draw }\end{array}$ \\
\hline
\end{tabular}

H-4. Polygons grazed between 36 and 45 days

\begin{tabular}{cccc}
\hline $\begin{array}{c}\text { Overall Health } \\
\text { Rating }(\%)\end{array}$ & Season of Use' & $\begin{array}{c}\text { Presence of } \\
\text { Offstream Water }\end{array}$ & $\begin{array}{c}\text { Rosgen Stream } \\
\text { Type }\end{array}$ \\
\hline 93 & Late Only & Yes & E5 \\
92 & Various $(>8$ days) & Yes & E4 \\
90 & Middle & Yes & Woody draw \\
89 & Late Only & No & E4 \\
88 & Late Only & Yes & Woody draw \\
88 & Various $(>8$ days) & No & C3 \\
87 & Late Only & Yes & Woody draw \\
85 & Late Only & Yes & C4 \\
84 & Middle & Yes & B4 \\
83 & Earrly or Late & Yes & C5 \\
82 & Winter & No & E5 \\
81 & Various $(>8$ days) & Yes & C4 \\
80 & Early or Late & Yes & $B 4$ \\
80 & Various $(>8$ days $)$ & No &
\end{tabular}

'Various ( $\leq \mathbf{8}$ days): Grazing occurred sometime beween late April and the end of December, each grazing period lasted no more than eight days, with several periods occuming throughout the year.

Various (>8 days): Grazing occurred at various times between late April and the end of December in a single period longer than eight days.

Early and Late: Pasture was grazed bewween later Aonil and mid-luly, then cattle went back in between mid-October and late December

Early or Late: Pasture was used once a yeac, with use ahemating annually between late April to mid-Jully and mid-October to late December

Early Only: Pasture was grazed for a period exceeding eight days between late April and mid-July.

Middle: Pasture used for a period exceeding eight days between mid-July and late September.

Late Only: Pasture used for a period exceeding eight days beween mid-October and late December.

W/inter: That period between late December and late April when livestock were being fed hay 


\section{H-5. Polygons grazed more than 45 days between mid-April and late December}

\begin{tabular}{|c|c|c|c|}
\hline $\begin{array}{c}\text { Overall Health } \\
\text { Rating }(\%)\end{array}$ & Season of Use ${ }^{1}$ & $\begin{array}{c}\text { Presence of } \\
\text { Offstream Water }\end{array}$ & $\begin{array}{c}\text { Rosgen Stream } \\
\text { Type }\end{array}$ \\
\hline 95 & Various ( $>8$ days) & Yes & B4a \\
\hline 93 & Early and Late & Yes & E4 \\
\hline 90 & Various ( $>8$ days) & No & E5 \\
\hline 89 & Early and Late & Yes & E4 \\
\hline 89 & Middle & No & E5 \\
\hline 88 & Late Only & Yes & B3 \\
\hline 88 & Various (>8 days) & No & E5 \\
\hline 87 & Early Only & Yes & $C_{4}$ \\
\hline 85 & Late Only & Yes & E4 \\
\hline 84 & Various (>8 days) & Yes & $C_{4}$ \\
\hline 83 & Late Only & Yes & C4 \\
\hline 82 & Various (>8 days) & Yes & $C_{4}$ \\
\hline 78 & Various (>8 days) & Yes & C6 \\
\hline
\end{tabular}

H-6. Polygons grazed more than 45 days between late December and mid-April

\begin{tabular}{|c|c|c|c|}
\hline $\begin{array}{c}\text { Overall Health } \\
\text { Rating }(\%)\end{array}$ & Season of Use ${ }^{1}$ & $\begin{array}{c}\text { Presence of } \\
\text { Offstream Water }\end{array}$ & $\begin{array}{c}\text { Rosgen Stream } \\
\text { Type }\end{array}$ \\
\hline $\begin{array}{l}97 \\
92 \\
90 \\
87 \\
87 \\
86 \\
84 \\
83 \\
82 \\
81 \\
78\end{array}$ & $\begin{array}{l}\text { Winter } \\
\text { Winter } \\
\text { Winter } \\
\text { Winter } \\
\text { Winter } \\
\text { Winter } \\
\text { Winter } \\
\text { Winter } \\
\text { Winter } \\
\text { Winter } \\
\text { Winter }\end{array}$ & $\begin{array}{l}\text { No } \\
\text { No } \\
\text { No } \\
\text { Yes } \\
\text { Yes } \\
\text { Yes } \\
\text { No } \\
\text { No } \\
\text { No } \\
\text { Yes } \\
\text { Yes }\end{array}$ & $\begin{array}{l}\text { C4 } \\
\text { C6 } \\
\text { C6 } \\
\text { B6C } \\
\text { C6 } \\
\text { Woody draw } \\
\text { C6 } \\
\text { C6 } \\
\text { C5 } \\
\text { B4C } \\
\text { Woody draw }\end{array}$ \\
\hline \multicolumn{4}{|c|}{ 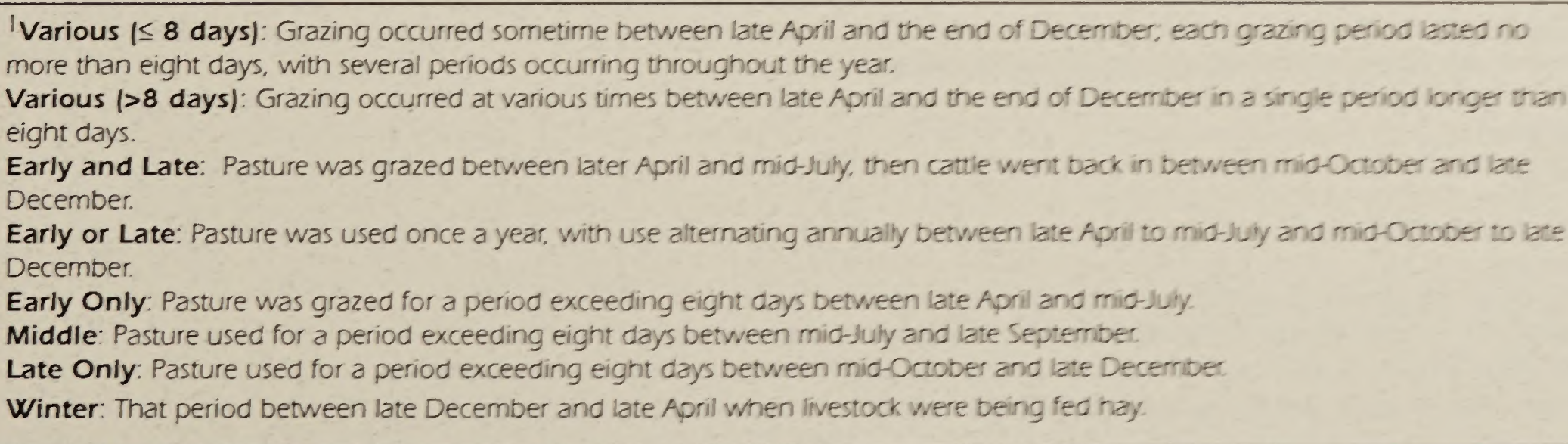 } \\
\hline
\end{tabular}




\section{Appendix 1.}

\section{Habitat types and community types present in at least 5 polygons}

\section{I-1. Fraxinus pennsylvanica/Prunus virginiana HT (Green ash/common chokecherry HT)}

a. Summary data on individual polygons containing this habitat type

\begin{tabular}{ccccc}
\hline $\begin{array}{c}\text { Overall Health } \\
\text { Rating (\%) }\end{array}$ & Season of Use' & $\begin{array}{c}\text { Length of } \\
\text { Grazing Period }\end{array}$ & $\begin{array}{c}\text { Presence of } \\
\text { Offstream Water }\end{array}$ & $\begin{array}{c}\text { Rosgen Stream } \\
\text { Type }\end{array}$ \\
\hline 93 & Late Only & $36-45$ days & Yes & E5 \\
90 & Middle & $36-45$ days & Yes & Woody draw \\
88 & Late Only & $36-45$ days & Yes & Woody draw \\
87 & Late Only & $36-45$ days & Yes & Woody draw \\
87 & Early Only & $>45$ days/non-winter & Yes & C4 \\
87 & Winter & $>45$ days/winter & Yes & B6c \\
86 & Early Only & $22-35$ days & Yes & Woody draw \\
86 & Winter & $>45$ days/winter & Yes & Woody draw \\
85 & Late Only & $36-45$ days & Yes & C4 \\
81 & Various (58 days) & $\leq 8$ days & Yes & Woody draw \\
78 & Early Only & $22-35$ days & Yes & Woody draw \\
$86 \%$ & & & &
\end{tabular}

\section{b. Number of times habitat type appeared in each season of grazing category}

\begin{tabular}{lc}
\hline Season of Grazing Use & No. of Polygons \\
\hline Various (I 8 days) & 1 \\
Early Only & 3 \\
Middle & 1 \\
Late Only & 4 \\
Winter & 2
\end{tabular}

c. Number of times habitat type appeared in each length of grazing period category

Length of Grazing Period No. of Polygons

$\begin{array}{ll}\leq 8 \text { days } & 1 \\ 22-35 \text { days } & 2 \\ 36-45 \text { days } & 5 \\ >45 \text { days/non-winter } & 1 \\ >45 \text { days/winter } & 2\end{array}$

\footnotetext{
'Various ( $\leq 8$ days): Grazing occurred sometime between late April and the end of December; each grazing period lasted no more than eight days, with several periods occurring throughout the year.

Various (>8 days): Grazing occurred at various times between late April and the end of December in a single period longer than eight days.

Early and Late: Pasture was grazed between later April and mid-July, then cattle went back in between mid-October and late December.

Early or Late: Pasture was used once a year, with use alternating annually between late April to mid-July and mid-October to late December.

Early Only: Pasture was grazed for a period exceeding eight days between late April and mid-July. Middle: Pasture used for a period exceeding eight days between mid-July and late September.

Late Only: Pasture used for a period exceeding eight days between mid-October and late December.

Winter: That period between late December and late April when livestock were being fed hay.
} 


\section{1-2. Populus tremuloides/Cornus stolonifera HT \\ (Quaking aspen/red-osier dogwood HT)}

a. Summary data on individual polygons containing this habitat type

\begin{tabular}{ccccc}
$\begin{array}{c}\text { Overall Health } \\
\text { Rating }(\%)\end{array}$ & Season of Use' & $\begin{array}{c}\text { Length of } \\
\text { Grazing Period }\end{array}$ & $\begin{array}{c}\text { Presence of } \\
\text { Offstream Water }\end{array}$ & $\begin{array}{c}\text { Rosgen Stream } \\
\text { Type }\end{array}$ \\
\hline 95 & Various $(>8$ days) & $>45$ days/non-winter & Yes & B4a \\
90 & Various $\mid \leq 8$ days) & $\leq 8$ days & No & $C 3$ \\
88 & Various $>>8$ days) & $22-35$ days & Yes & $C 4$ \\
88 & Various $(>8$ days) & $36-45$ days & No & $C 3$ \\
83 & Various $\mid \leq 8$ days) & $\leq 8$ days & No & $C 3$ \\
83 & Various $(>8$ days) & $9-21$ days & Yes & B \\
82 & Winter & $36-45$ days & No & $C 5$ \\
82 & Winter & $22-35$ days & No & $C 5$ \\
80 & Various $(>8$ days) & $36-45$ days & No & B \\
80 & Various $(>8$ days) & $22-35$ days & No & $C 4$ \\
80 & Early or Late & $36-45$ days & Yes & $C 4$ \\
$85 \%=$ Average & & & &
\end{tabular}

\section{b. Number of times habitat type appeared in each season of grazing use category}

\section{Season of Grazing Use ${ }^{1}$}

Various $(\leq 8$ days)

Various ( $>8$ days)

Early or Late

Winter
No. of Polygons

\section{c. Number of times habitat type appeared in each length of grazing period category}

\begin{tabular}{c} 
Length of Grazing Period \\
\hline$\leq 8$ days \\
$9-21$ days \\
$22-35$ days \\
$36-45$ days \\
$>45$ days/non-winter
\end{tabular}

No. of Polygons

$>45$ days/non-winter

\footnotetext{
'Various ( $\leq \mathbf{8}$ days): Grazing occurred sometime between late April and the end of December; each grazing period lasted no more than eight days, with several periods occurring throughout the year.

Various (>8 days): Grazing occurred at various times between late April and the end of December in a single period longer than eight days.

Early and Late: Pasture was grazed between later April and mid-July, then cattle went back in between mid-October and late December.

Early or Late: Pasture was used once a year, with use alternating annually between late April to mid-July and mid-October to late December.

Early Only: Pasture was grazed for a period exceeding eight days between late April and mid-July. Middle: Pasture used for a period exceeding eight days between mid-July and late September. Late Only: Pasture used for a period exceeding eight days between mid-October and late December. Winter: That period between late December and late April when livestock were being fed hay.
} 


\section{1-3. Salix drummondiana/Carex rostrata HT (Drummond willow/beaked sedge HT)}

a. Summary data on individual polygons containing this habitat type

\begin{tabular}{ccccc}
$\begin{array}{c}\text { Overall Health } \\
\text { Rating (\%) }\end{array}$ & Season of Use & $\begin{array}{c}\text { Length of } \\
\text { Grazing Period }\end{array}$ & $\begin{array}{c}\text { Presence of } \\
\text { Offstream Water }\end{array}$ & $\begin{array}{c}\text { Rosgen Stream } \\
\text { Type }\end{array}$ \\
\hline 92 & Various (>8days) & $22-35$ days & Yes & E4 \\
89 & Early and Late & $>45$ days/non-winter & Yes & Yes \\
85 & Late Only & $>45$ days/non-winter & Yes & E4 \\
83 & Late Only & $>45$ days/non-winter & Yes & C4 \\
82 & Various (>8days) & $22-35$ days & &
\end{tabular}

\section{b. Number of times habitat type appeared in each season of grazing use category}

\section{Season of Grazing Use'}

Various $1>8$ days

Early and Late

Late Only
No. of Polygons

\section{c. Number of times habitat type appeared in each length of grazing period category}

\section{Length of Grazing Period}

22-35 days

45 days/non-winter
No. of Polygons

3

\footnotetext{
'Various ( $\leq 8$ days): Grazing occurred sometime between late April and the end of December; each grazing period lasted no more than eight days, with several periods occurring throughout the year.

Various (>8 days): Grazing occurred at various times between late April and the end of December in a single period longer than eight days.

Early and Late: Pasture was grazed between later April and mid-July, then cattle went back in between mid-October and late December.

Early or Late: Pasture was used once a year, with use alternating annually between late April to mid-July and mid-October to late

December.

Early Only: Pasture was grazed for a period exceeding eight days between late April and mid-July.

Middle: Pasture used for a period exceeding eight days between mid-July and late September.

Late Only: Pasture used for a period exceeding eight days between mid-October and late December.

Winter: That period between late December and late April when livestock were being fed hay.
} 


\title{
1-4. Salix exigua CT
}

(Sandbar willow CT)

a. Summary data on individual polygons containing this community type

\begin{tabular}{ccccc}
$\begin{array}{c}\text { Overall Health } \\
\text { Rating }(\%)\end{array}$ & Season of Use' & $\begin{array}{c}\text { Length of } \\
\text { Grazing Period }\end{array}$ & $\begin{array}{c}\text { Presence of } \\
\text { Offstream Water }\end{array}$ & $\begin{array}{c}\text { Rosgen Stream } \\
\text { Type }\end{array}$ \\
\hline 97 & Winter & $>45$ days/winter & No & $C 4$ \\
88 & Various $(>8$ days) & $>45$ days/Nonwinter & No & $E 5$ \\
87 & Early and Late & $22-35$ days & Yes & $C 3$ \\
84 & Winter & $>45$ days/winter & No & $C 6$ \\
83 & Late Only & $22-35$ days & No & $C 4$ \\
83 & Early Only & $\leq 8$ days & No & $C 3$ \\
81 & Various $(\leq 8$ days) & $\leq 8$ days & No & $B 5 C$ \\
79 & Various $\mid \leq 8$ days) & $\leq 8$ days & No & $B 5 C$ \\
$85 \%=$ Average & & & &
\end{tabular}

\section{b. Number of times habitat type appeared in each season of grazing use}

\section{Season of Grazing Use' No. of Polygons}

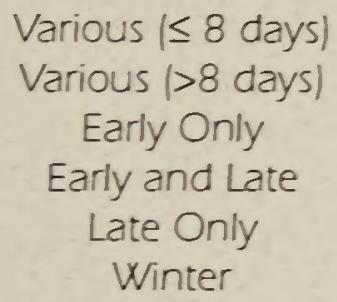

c. Number of times habitat type appeared in each length of grazing period category

\section{Length of Grazing Period}

\author{
$\leq 8$ days \\ 22-35 days \\ $>45$ days/non-winter \\ $>45$ days/winter
}

\section{No. of Polygons}

\footnotetext{
'Various ( $\mathbf{8}$ days): Grazing occurred sometime between late April and the end of December; each grazing period lasted no more than eight days, with several periods occurring throughout the year.

Various (>8 days): Grazing occurred at various times between late April and the end of December in a single period longer than eight days.

Early and Late: Pasture was grazed between later April and mid-July, then cattle went back in between mid-October and late December.

Early or Late: Pasture was used once a year, with use alternating annually between late April to mid-July and mid-October to late December.

Early Only: Pasture was grazed for a period exceeding eight days between late April and mid-July.

Middle: Pasture used for a period exceeding eight days between mid-July and late September.

Late Only: Pasture used for a period exceeding eight days between mid-October and late December.

Winter: That period between late December and late April when livestock were being fed hay.
} 
1-5. Salix geyeriana/Carex rostrata HT

(Geyer willow/beaked sedge HT)

a. Summary data on individual polygons containing this community type

\begin{tabular}{ccccc}
$\begin{array}{c}\text { Overall Health } \\
\text { Rating }(\%)\end{array}$ & Season of Use' & $\begin{array}{c}\text { Length of } \\
\text { Grazing Period }\end{array}$ & $\begin{array}{c}\text { Presence of } \\
\text { Offstream Water }\end{array}$ & $\begin{array}{c}\text { Rosgen Stream } \\
\text { Type }\end{array}$ \\
\hline $96 \%$ & Middle & $9-21$ days & No & $C 4$ \\
$88 \%$ & Various $>8$ days) & $9-21$ days & Yes & C5 \\
$88 \%$ & Late Only & $>45$ days/non-winter & Yes & B3 \\
$84 \%$ & Late Only & $9-21$ days & No & $C 3$ \\
$84 \%$ & Various $>8$ days) & $>45$ days $/$ non-winter & Yes & $C 4$ \\
$82 \%$ & Early and Late & $9-21$ days & No & $C 5$ \\
$81 \%$ & Various $(>8$ days) & $36-45$ days & Yes & E5 \\
$80 \%$ & Early or Late & $9-21$ days & No & $C 5$ \\
$85 \%$ Average & & & &
\end{tabular}

b. Number of times habitat type appeared in each season of grazing use category

Season of Grazing Use' No. of Polygons
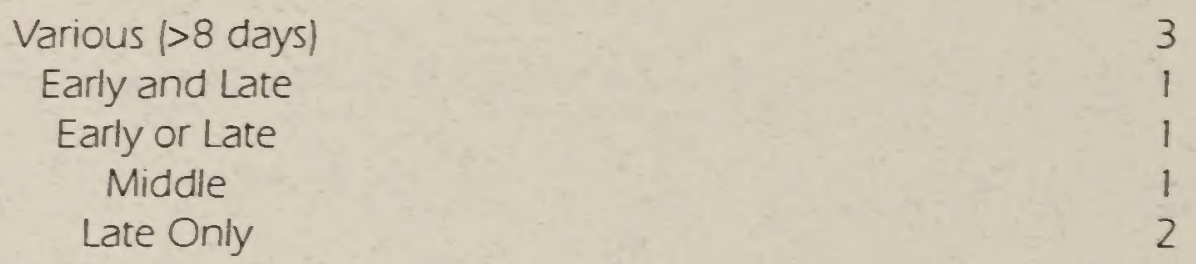

c. Number of times habitat type appeared in each length of grazing period category

Length of Grazing Period

No. of Polygons

9-21 days
$36-45$ days
$>45$ days/non-winter

\footnotetext{
'Various ( $\leq \mathbf{8}$ days): Grazing occurred sometime between late April and the end of December; each grazing period lasted no more than eight days, with several periods occurring throughout the year.

Various (>8 days): Grazing occurred at various times between late April and the end of December in a single period longer than eight days.

Early and Late: Pasture was grazed between later April and mid-July, then cattle went back in between mid-October and late December.

Early or Late: Pasture was used once a year, with use alternating annually between late April to mid-July and mid-October to late

December

Early Only: Pasture was grazed for a period exceeding eight days between late April and mid-July.

Middle: Pasture used for a period exceeding eight days between mid-July and late September.

Late Only: Pasture used for a period exceeding eight days between mid-October and late December.

Winter: That period between late December and late April when livestock were being fed hay.
} 


\section{I-6. Salix lutea/Carex rostrata HT (Yellow willow/beaked sedge HT)}

a. Summary data on individual polygons containing this habitat type

\begin{tabular}{ccccc}
$\begin{array}{c}\text { Overall Health } \\
\text { Rating }(\%)\end{array}$ & Season of Use' & $\begin{array}{c}\text { Length of } \\
\text { Grazing Period }\end{array}$ & $\begin{array}{c}\text { Presence of } \\
\text { Offstream Water }\end{array}$ & $\begin{array}{c}\text { Rosgen Stream } \\
\text { Type }\end{array}$ \\
\hline 90 & Various $(>8$ days) & $>45$ days/non-winter & No & $E 5$ \\
89 & Late Only & $36-45$ days & No & E4 \\
88 & Various $(>8$ days) & $>45$ days/non-winter & No & E5 \\
88 & Various $(>8$ days & $36-45$ days & No & $C 3$ \\
87 & Early Only & $>45$ days/non-winter & Yes & $C 4$ \\
84 & Middle & $36-45$ days & Yes & $B 4$ \\
81 & Winter & $>45$ days/winter & Yes & $B 4 C$ \\
$87 \%=$ Average & & & &
\end{tabular}

b. Number of times habitat type appeared in each season of grazing use category

Season of Grazing Use' $\quad$ No. of Polygons

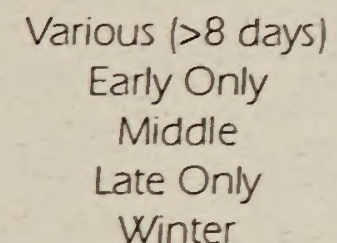

\section{1-6. Salix lutea/Carex rostrata HT \\ (Yellow willow/beaked sedge HT) (cont.)}

c. Number of times habitat type appeared in each length of grazing period category

Length of Grazing Period No. of Polygons

$\begin{array}{cc}36-45 \text { days } & 3 \\ >45 \text { days/non-winter } & 3 \\ >45 \text { days/winter } & 1\end{array}$

\footnotetext{
'Various ( $\mathbf{8}$ days): Grazing occurred sometime between late April and the end of December; each grazing period lasted no more than eight days, with several periods occurring throughout the year.

Various (>8 days): Grazing occurred at various times between late April and the end of December in a single period longer than eight days.

Early and Late: Pasture was grazed between later April and mid-July, then cattle went back in between mid-October and late December.

Early or Late: Pasture was used once a year, with use alternating annually between late April to mid-July and mid-October to late December.

Early Only: Pasture was grazed for a period exceeding eight days between late April and mid-July. Middle: Pasture used for a period exceeding eight days between mid-July and late September. Late Only: Pasture used for a period exceeding eight days between mid-October and late December. Winter: That period between late December and late April when livestock were being fed hay.
} 


\section{I-7. Carex aquatilis HT}

(Water sedge HT)

a. Summary data on individual polygons containing this community type

\begin{tabular}{ccccc}
\hline $\begin{array}{c}\text { Overall Health } \\
\text { Rating }(\%) \mathbf{g}\end{array}$ & Season of Use' & $\begin{array}{c}\text { Length of } \\
\text { Grazing Period }\end{array}$ & $\begin{array}{c}\text { Presence of } \\
\text { Offstream Water }\end{array}$ & $\begin{array}{c}\text { Rosgen Stream } \\
\text { Type }\end{array}$ \\
\hline 92 & Winter & $>45$ days/winter & No & C6 \\
92 & Various $(>8$ days) & $22-35$ days & Yes & E4 \\
90 & Winter & $>45$ days/winter & No & C6 \\
87 & Winter & $>45$ days/winter & No & C6 \\
83 & Winter & $>45$ days/winter & No & C6 \\
$89 \%=$ Average & & & &
\end{tabular}

b. Number of times habitat type appeared in each season of grazing use category

Season of Grazing Use' No. of Polygons

Various (>8 days)

Winter

1

4

\section{c. Number of times habitat type appeared in each length of grazing period category}

$\frac{\text { Length of Grazing Period }}{22-35 \text { days }}$

$>45$ days/winter
No. of Polygons

4

\footnotetext{
'Various ( $\mathbf{8}$ days): Grazing occurred sometime between late April and the end of December; each grazing period lasted no more than eight days, with several periods occurring throughout the year.

Various (>8 days): Grazing occurred at various times between late April and the end of December in a single period longer than eight days.

Early and Late: Pasture was grazed between later April and mid-July, then cattle went back in between mid-October and late December.

Early or Late: Pasture was used once a year, with use alternating annually between late April to mid-July and mid-October to late December.

Early Only: Pasture was grazed for a period exceeding eight days between late April and mid-July.

Middle: Pasture used for a period exceeding eight days between mid-July and late September.

Late Only: Pasture used for a period exceeding eight days between mid-October and late December.

Winter: That period between late December and late April when livestock were being fed hay.
} 
1-8. Carex rostrata HT

(Beaked sedge HT)

a. Summary data on individual polygons containing this habitat type

\begin{tabular}{ccccc}
\hline $\begin{array}{c}\text { Overall Health } \\
\text { Rating (\%) }\end{array}$ & Season of Use' & $\begin{array}{c}\text { Length of } \\
\text { Grazing Period }\end{array}$ & $\begin{array}{c}\text { Presence of } \\
\text { Offstream Water }\end{array}$ & $\begin{array}{c}\text { Rosgen Stream } \\
\text { Type }\end{array}$ \\
\hline 93 & Various $(>8$ days) & $22-35$ days & Yes & $E 5$ \\
91 & Various $(\leq 8$ days) & $\leq 8$ days & No & E5 \\
89 & Late Only & $36-45$ days & No & $E 4$ \\
88 & Various $(>8$ days) & $22-35$ days & Yes & $C 4$ \\
81 & Various $\mid \leq 8$ days) & $\leq 8$ days & No & $B 5 C$ \\
80 & Various $(>8$ days) & $22-35$ days & Yes & $C 4$ \\
79 & Various $(\leq 8$ days) & $\leq 8$ days & Yes & $B 5 C$ \\
79 & Various $\mid \leq 8$ days) & $\leq 8$ days & No & $C 5$ \\
$85 \%=$ Average & & & &
\end{tabular}

b. Number of times habitat type appeared in each season of grazing use

Season of Grazing Use' No. of Polygons

Various $(\leq 8$ days)

Various ( $>8$ days)

Late Only

\section{c. Number of times habitat type appeared in each length of grazing period category}

\section{Length of Grazing Period}

$\leq 8$ days
$22-35$ days
$36-45$ days

No. of Polygons

22-35 days

$36-45$ days

\footnotetext{
IVarious ( $\mathbf{8}$ days): Grazing occurred sometime between late April and the end of December; each grazing period lasted no more than eight days, with several periods occurring throughout the year.

Various (>8 days): Grazing occurred at various times between late April and the end of December in a single period longer than eight days.

Early and Late: Pasture was grazed between later April and mid-July, then cattle went back in between mid-October and late December.

Early or Late: Pasture was used once a year, with use alternating annually between late April to mid-July and mid-October to late December.

Early Only: Pasture was grazed for a period exceeding eight days between late April and mid-July.

Middle: Pasture used for a period exceeding eight days between mid-July and late September.

Late Only: Pasture used for a period exceeding eight days between mid-October and late December.

Winter: That period between late December and late April when livestock were being fed hay.
} 
Appendix J.

\section{Individual reaches (polygons) ranked by overall health rating}

\begin{tabular}{|c|c|c|c|c|}
\hline $\begin{array}{l}\text { Overall Health } \\
\text { Rating }(\%)\end{array}$ & $\begin{array}{l}\text { Season of } \\
\text { Grazing Use' }\end{array}$ & $\begin{array}{c}\text { Length of } \\
\text { Grazing Period }\end{array}$ & $\begin{array}{c}\text { Presence of } \\
\text { Offstream Water }\end{array}$ & $\begin{array}{c}\text { Rosgen Stream } \\
\text { Type }\end{array}$ \\
\hline $\begin{array}{l}98 \\
97 \\
96 \\
95 \\
93 \\
93 \\
93 \\
92 \\
92 \\
92 \\
91 \\
90 \\
90 \\
90 \\
90 \\
89 \\
89 \\
89 \\
88 \\
88 \\
88 \\
88 \\
88 \\
88 \\
88 \\
87 \\
87 \\
87 \\
87 \\
87 \\
86 \\
86 \\
86\end{array}$ & $\begin{array}{c}\text { Early Only } \\
\text { Winter } \\
\text { Middle } \\
\text { Various (>8 days) } \\
\text { Early and Late } \\
\text { Various ( }>8 \text { days) } \\
\text { Late Only } \\
\text { Winter } \\
\text { Various (>8 days) } \\
\text { Various (>8 days) } \\
\text { Various ( } \leq 8 \text { days) } \\
\text { Various (>8 days) } \\
\text { Various ( } \leq 8 \text { days) } \\
\text { Middle } \\
\text { Winter } \\
\text { Early and Late } \\
\text { Late Only } \\
\text { Middle } \\
\text { Various ( }>8 \text { days) } \\
\text { Late Only } \\
\text { Various (>8 days) } \\
\text { Various (>8 days) } \\
\text { Early and Late } \\
\text { Late Only } \\
\text { Various ( }>8 \text { days) } \\
\text { Early and Late } \\
\text { Early Only } \\
\text { Late Only } \\
\text { Winter } \\
\text { Winter } \\
\text { Various ( }>8 \text { days) } \\
\text { Early Only } \\
\text { Winter }\end{array}$ & $\begin{array}{c}22-35 \text { days } \\
>45 \text { days/winter } \\
9-21 \text { days } \\
>45 \text { days/non-winter } \\
>45 \text { days/non-winter } \\
22-35 \text { days } \\
36-45 \text { days } \\
>45 \text { days/winter } \\
22-35 \text { days } \\
36-45 \text { days } \\
\leq 8 \text { days } \\
>45 \text { days/non-winter } \\
\leq 8 \text { days } \\
36-45 \text { days } \\
>45 \text { days/winter } \\
>45 \text { days/non-winter } \\
36-45 \text { days } \\
>45 \text { days/non-winter } \\
22-35 \text { days } \\
>45 \text { days/non-winter } \\
>45 \text { days/non-winter } \\
9-21 \text { days } \\
\leq 8 \text { days } \\
36-45 \text { days } \\
36-45 \text { days } \\
22-35 \text { days } \\
>45 \text { days/non-winter } \\
36-45 \text { days } \\
>45 \text { days/winter } \\
>45 \text { days/winter } \\
9-21 \text { days } \\
22-35 \text { days } \\
>45 \text { days/winter }\end{array}$ & $\begin{array}{l}\text { No } \\
\text { No } \\
\text { No } \\
\text { Yes } \\
\text { Yes } \\
\text { Yes } \\
\text { Yes } \\
\text { No } \\
\text { Yes } \\
\text { Yes } \\
\text { No } \\
\text { No } \\
\text { No } \\
\text { Yes } \\
\text { No } \\
\text { Yes } \\
\text { No } \\
\text { No } \\
\text { Yes } \\
\text { Yes } \\
\text { No } \\
\text { Yes } \\
\text { No } \\
\text { Yes } \\
\text { No } \\
\text { Yes } \\
\text { Yes } \\
\text { Yes } \\
\text { Yes } \\
\text { Yes } \\
\text { Yes } \\
\text { Yes } \\
\text { Yes }\end{array}$ & $\begin{array}{c}\text { E5 } \\
\text { C4 } \\
\text { C4 } \\
\text { B4a } \\
\text { E4 } \\
\text { E5 } \\
\text { E5 } \\
\text { C6 } \\
\text { E4 } \\
\text { E4 } \\
\text { E5 } \\
\text { E5 } \\
\text { C3 } \\
\text { Woody draw } \\
\text { C6 } \\
\text { E4 } \\
\text { E4 } \\
\text { E5 } \\
\text { C4 } \\
\text { B3 } \\
\text { E5 } \\
\text { C5 } \\
\text { E4 } \\
\text { Woody draw } \\
\text { C3 } \\
\text { C3 } \\
\text { C4 } \\
\text { Woody draw } \\
\text { B6C } \\
\text { C6 } \\
\text { B4 } \\
\text { Woody draw } \\
\text { Woody draw }\end{array}$ \\
\hline $\begin{array}{l}\text { more than eight days, } \\
\text { Various (>8 days): G } \\
\text { eight days. } \\
\text { Early and Late: Pastl } \\
\text { December. } \\
\text { Early or Late: Pasture } \\
\text { December. } \\
\text { Early Only: Pasture w } \\
\text { Middle: Pasture used f } \\
\text { Late Only: Pasture use } \\
\text { Winter: That period b }\end{array}$ & $\begin{array}{l}\text { h several periods occu } \\
\text { ng occurred at various } \\
\text { was grazed between I } \\
\text { s used once a year, w } \\
\text { grazed for a period exc } \\
\text { period exceeding eic } \\
\text { or a period exceeding } \\
\text { een late December ar }\end{array}$ & $\begin{array}{l}\text { late April and the end of } \\
\text { hout the year. } \\
\text { een late April and the enc } \\
\text { d mid-July, then cattle we } \\
\text { nating annually between } \\
\text { th days between late April } \\
\text { ween mid-July and late Se } \\
\text { between mid-October and } \\
\text { when livestock were bein }\end{array}$ & $\begin{array}{l}\text { December in a single } p \\
\text { Dack in between mid-oc } \\
\text { April to mid-July and } m \\
\text { d mid-July. } \\
\text { mber. } \\
\text { te December. } \\
\text { d hay. }\end{array}$ & $\begin{array}{l}\text { eriod lasted no } \\
\text { period longer than } \\
\text { ctober and late } \\
\text { hid-October to late }\end{array}$ \\
\hline
\end{tabular}




\begin{tabular}{|c|c|c|c|c|}
\hline $\begin{array}{c}\text { Overall Health } \\
\text { Rating }(\%)\end{array}$ & $\begin{array}{c}\text { Season of } \\
\text { Grazing Use' }\end{array}$ & $\begin{array}{c}\text { Length of } \\
\text { Grazing Period }\end{array}$ & $\begin{array}{c}\text { Presence of } \\
\text { Offstream Water }\end{array}$ & $\begin{array}{c}\text { Rosgen Stream } \\
\text { Type }\end{array}$ \\
\hline 85 & Late Only & $>45$ days/non-winter & Yes & E4 \\
\hline 85 & Late Only & $36-45$ days & Yes & C4 \\
\hline 85 & Various $(\leq 8$ days) & $\leq 8$ days & No & C4 \\
\hline 84 & Various (>8 days) & $>45$ days/non-winter & Yes & C4 \\
\hline 84 & Middle & $36-45$ days & Yes & B4 \\
\hline 84 & Late Only & $9-21$ days & No & C3 \\
\hline 84 & Winter & $>45$ days $/$ winter & No & C6 \\
\hline 83 & Various (>8 days) & $9-21$ days & Yes & B4 \\
\hline 83 & Early or Late & $36-45$ days & Yes & B4 \\
\hline 83 & Late Only & $>45$ days/non-winter & Yes & $\mathrm{C} 4$ \\
\hline 83 & Late Only & 22-35 days & No & C4 \\
\hline 83 & Various $(\leq 8$ days $)$ & $\leq 8$ days & No & C4 \\
\hline 83 & Early Only & $\leq 8$ days & No & $\mathrm{C} 3$ \\
\hline 83 & Various ( $\leq 8$ days) & $\leq 8$ days & No & $\mathrm{C} 3$ \\
\hline 83 & Winter & $>45$ days/winter & No & C6 \\
\hline 82 & Winter & $36-45$ days & No & C5 \\
\hline 82 & Middle & 22-35 days & Yes & B4 \\
\hline 82 & Various $(>8$ days) & $>45$ days/non-winter & Yes & C4 \\
\hline 82 & Early and Late & $9-21$ days & No & C5 \\
\hline 82 & Winter & $>45$ days/winter & No & C5 \\
\hline 82 & Winter & $22-35$ days & No & $c 4 b$ \\
\hline 82 & Various (>8 days) & $22-35$ days & Yes & C4 \\
\hline 81 & Various ( $>8$ days) & $36-45$ days & Yes & E5 \\
\hline 81 & Various $(\leq 8$ days) & $\leq 8$ days & No & $B 5 C$ \\
\hline 81 & Winter & $>45$ days/winter & Yes & $B 4 C$ \\
\hline 81 & Various $(\leq 8$ days) & $\leq 8$ days & Yes & Woody draw \\
\hline 80 & Early or Late & $36-45$ days & Yes & C4 \\
\hline 80 & Various ( $>8$ days) & $36-45$ days & No & B4 \\
\hline 80 & Various $(>8$ days) & 22-35 days & Yes & C4 \\
\hline 80 & Early or Late & $9-21$ days & No & C5 \\
\hline 80 & Various ( $>8$ days) & $22-35$ days & Yes & B4a \\
\hline 79 & Various ( $\leq 8$ days) & $\leq 8$ days & Yes & $B 5 \mathrm{C}$ \\
\hline 79 & Various $(\leq 8$ days) & $\leq 8$ days & No & $\mathrm{C} 5$ \\
\hline 78 & Early Only & $22-35$ days & Yes & Woody draw \\
\hline 78 & Winter & $>45$ days/winter & Yes & Woody draw \\
\hline 78 & Various (> 8 days) & $>45$ days/non-winter & Yes & C6 \\
\hline 77 & Early and Late & $9-21$ days & Yes & $B 6 C$ \\
\hline 77 & Various ( $\leq 8$ days) & $\leq 8$ days & No & $\mathrm{B} 6 \mathrm{C}$ \\
\hline
\end{tabular}

'Various ( $\mathbf{8}$ days): Grazing occurred sometime between late April and the end of December; each grazing period lasted no more than eight days, with several periods occurring throughout the year.

Various (>8 days): Grazing occurred at various times between late April and the end of December in a single period longer than eight days.

Early and Late: Pasture was grazed between later April and mid-July, then cattle went back in between mid-October and late

December.

Early or Late: Pasture was used once a year, with use alternating annually between late April to mid-July and mid-October to late

December.

Early Only: Pasture was grazed for a period exceeding eight days between late April and mid-July.

Middle: Pasture used for a period exceeding eight days between mid-July and late September.

Late Only: Pasture used for a period exceeding eight days between mid-October and late December

Winter: That period between late December and late April when livestock were being fed hay. 


\section{Glossary}

Average Canopy Cover. Refers to the "average" canopy cover of a particular species for the stands in which it was recorded. For example, the number of stands sampled for a habitat type or community type may be 20 . However, a particular species may only occur in 7 of the 20 stands. The average canopy cover therefore represents the "average" canopy cover of that particular species in the 7 stands.

Bankfull (Bankfull stage). Average 1.5-2.0 year high flow; the level of the floodplain and therefore the stage at which flooding occurs.

Bankfull depth. The maximum depth of the channel at bankfull stage.

Bankfull width. The width of the channel at bankfull stage.

Bars (Alluvial). Sediment accumulations along waterways deposited by moving water. Examples include: 1) point bars - bars that are formed on the inside of a meander channel, 2) side bars - bars that are formed along the edges of relatively straight sections of a stream, 3) mid-channel bars - these are found within the channel and generally become more noticeable during low flow periods, and 4) delta bars - formed immediately downstream of the confluences of a tributary and the main stream or river.

Beaver Dams. Dams built by beavers that span the stream channel. In general, water is still flowing through the riparian system.

Browse. Woody forage (from shrubs or trees) consumed by wildlife.

Canopy Coverage. The percentage of ground covered by the gross outline of an individual plant's foliage or collectively covered by all individuals of a species within a stand or a sample plot.
Community (Plant Community). An assembly of plants living together, reflecting no particular ecological status.

Community Type. An aggregation of all plant communities distinguished by floristic and structural similarities in both overstory and undergrowth layers.A unit of vegetation within a classification. For the purposes of this document, a community type represents seral vegetation, and is never considered to be climax.

Diversity. The kind and amount of species in a community per unit area.

Drained. A condition in which ground or surface water has been removed by artificial means.

\section{Dominance Type (Equivalent to Cover} Type). An aggregation of all stands (individual plant communities), grouped and named simply by the species with the greatest canopy coverage in the overstory or upper layer. For this study, canopy cover of dominant species is greater than 25 percent.

Ecosystem. All the land that has potential to produce similar structural life forms and has broad environmental characteristics (nonvegetated, conifer, juniper, shrub, wetland, grassland, etc.)

Ephemeral Stream. A stream or stretch of a stream that flows only in direct response to precipitation. It receives no water from springs and no long-continued supply from melting snow or other surface source. Its stream channel is at all times above the water table. These streams do not normally flow for 30 consecutive days. 
Flooded. A condition in which the soil surface is temporarily covered with flowing water from any source, such as streams overflowing their banks and runoff from adjacent or surrounding slopes, or any combination of sources.

Floodplain. An alluvial plain caused by the overbank deposition of sediment being transported by flowing water.Typically appearing as flat expanses of land bordering a stream or river. Most floodplains are accompanied by a series of alluvial terraces of varying levels.

Fluvial. Pertaining to or produced by the action of moving water.

Forb. A herbaceous plant, usually broadleaved, that is not a graminoid.

Functioning at risk. Riparian areas which are currently performing their riparian functions but which are susceptible to degradation due to an existing soil, water, or vegetation attribute are considered functioning at risk (BLMTechnical Reference 1737-9).

Functioning but with problems. Riparian areas which are performing many but not all of their riparian functions as a result of limitations in existing soil, water, or vegetation attributes are considered Functioning but with problems. This term is not wholly synonymous with the BLM's "Functioning-at-risk" category which is based on susceptibility to degradation (see above).

Gallery Forest. A strip of forest confined to a stream margin or floodplain in an otherwise unforested landscape.

Graminoid. Grass or grass-like plant, such as species of the Poaceae (grasses), Cyperaceae (sedges), and Juncaceae (rushes).

Ground Water. Water occupying the interconnected pore spaces in the soil or geologic material below the water table; this water has a positive pressure.
Habitat Type. The land area that supports, or has the potential of supporting, the same primary climax vegetation. A habitat type classification is a vegetation-based ecological site classification. It is based on the potential of the site to produce a specific plant community (plant association). It has been used to classify grasslands, shrublands, woodlands, and forests throughout the western United States.

Healthy. A riparian system is considered "healthy" when it is capable of performing its normal functions. These may include, but are not limited to, water storage and aquifer recharge, filtering of chemical and organic wastes, sediment trapping, bank building and maintenance, flow energy dissipation, and primary biotic production.As used in this report, "healthy" is synonymous with the BLM's definition of Proper Functioning Condition.

Herbaceous. Nonwoody vegetation, such as graminoids and forbs.

Hydric Soil. A soil that is saturated, flooded, or ponded long enough during the growing season to develop anaerobic conditions in the upper part of the soil profile.

Hydrology. The science dealing with the properties, distribution, and circulation of water.

Hydrophytic Vegetation. Plant life growing in water or on a substrate that is at least potentially deficient in oxygen as a result of excessive water content.

Intermittent Stream. A stream or reach of stream which flows only at certain times of the year when it receives water from springs or from some surface source (e.g., melting snow). Such streams are usually divided with respect to the source of their water into spring-fed or surface-fed intermittent streams. These streams generally flow continuously during periods of at least one month or more during the year.

Inundation. A condition in which water temporarily or permanently covers a land surface.

Irrigation Canal. Includes all types of canals associated with irrigation systems.

Lotic Wetland. See Riparian Wetland. 
Major Type: Refers to a habitat type or community type that occupies an extensive area within a wetland zone.

Nonfunctioning. Riparian areas are considered nonfunctioning when they are clearly not providing adequate vegetation, landform, or large woody debris to perform the functions listed under Properly Functioning Condition. The absence of certain physical attributes such as a floodplain where one should be are indicators of nonfunctioning condition.

Nonwetland. Any area that has sufficiently dry conditions that hydrophytic vegetation, hydric soils, and/or wetland hydrology are lacking; it includes upland as well as former wetlands that are effectively drained.

Overbank Flooding. Any situation in which inundation occurs as a result of the water level of a river or stream rising above bank level.

Overflow Channel. An abandoned channel in a floodplain that may carry water during periods of high stream or river flows.

Oxbow Lake. A meander channel of a stream or river that is formed by breaching of a meander loop during flood stage. The ends of the cut-off meander are blocked by bank sediments.

Parent Material. The unconsolidated and undeveloped mineral or organic matter from which the solum (soil) is developed.

Perennial Stream. A stream or reach of a stream that flows continuously. Such streams are generally fed in part by springs. Surface water elevations are commonly lower than water table elevations in adjacent soils.

Pioneer Species. Species that colonize bare areas (e. g. , gravel bars) where there is little or no competition from other species.

Pond. Bodies of water encircled by wetland vegetation. Wave action is minimal, allowing emergent vegetation to establish.
Ponded. A condition in which free water covers the soil surface, for example, in a closed depression. The water is removed only by percolation, evaporation, or transpiration.

Pooled Channel Stream. An intermittent stream with significant surface pool area and without flowing surface water. The water sources for the pools are springs within the channel.

Primary Succession. Occurs on a bare surface not previously occupied by plants, such as a recently deposited alluvial bar.

Proper Functioning Condition. As defined by the BLM (TR 1737-9 1993), riparian areas are functioning properly when adequate vegetation, landform, or large woody debris is present to: dissipate stream energy associated with high waterflows, thereby reducing erosion and improving water quality; filter sediment, capture bedload, and aid floodplain development; improve flood-water retention and ground-water recharge; develop root masses that stabilize streambanks against cutting action; develop diverse ponding and channel characteristics to provide the habitat and the water depth, duration, and temperature necessary for fish production, waterfowl breeding, and other uses; and support greater biodiversity.

Reservoir. An artificial (dammed) water body with at least 8 ha (20 acres) covered by surface water.

Rhizomatous. Describes species with underground, inter-connected root systems (rhizomes).

Riparian.adj. Of, on, or relating to the banks of a natural course of water (Latin riparius, from ripa,bank).

Riparian area. A geographically delineable area with distinctive functions and characteristics. Includes both the riparian ecosystem and the adjacent aquatic ecosystem. 
Riparian Wetlands (Lotic Wetlands). Riparian wetlands are wetlands associated with running water systems found along rivers, streams, and drainageways. Such wetlands contain a defined channel and floodplain. The channel is an open conduit which periodically or continuously carries flowing water, dissolved and suspended material. Beaver ponds, seeps, springs, and wet meadows on the floodplain of, or associated with, a river or stream are part of the riparian wetland.

Riparian or Wetland Ecosystem. The ecosystem located between aquatic and terrestrial environments. Identified by hydric soil characteristics and riparian or wetland plant species that require or tolerate free water conditions of varying duration.

Riparian or Wetland Species. Plant species occurring within the riparian or wetland area. Obligate riparian or wetland species require the environmental conditions associated with the riparian or wetland area. Facultative riparian or wetland species are tolerant of these environmental conditions, but also occur in uplands.

Riparian Zone. A geographically delineated portion of the riparian ecosystem based on management concerns.

River. Rivers are usually larger than streams. They flow year around in years of normal precipitation and when significant amounts of water are not being diverted out of them.

Riverbank. That portion of the channel bank cross-section that controls the lateral movement of water.

Secondary Succession. The process of changing biotic communities that occurs following disturbances to a site that has previously been occupied by living organisms.

Seep. A groundwater discharge area. In general, seeps have less flow than springs.

Seral. Refers to vegetation that has not theoretically attained a steady state with its environment, and current populations of some species are being replaced by other species; a community or species that is replaced by another community or species as succession progresses.
Shrub. A multi-stemmed woody plant generally shorter than $4.8 \mathrm{~m}$ (16 ft).

Spring. A groundwater discharge area. In general, springs are considered to have more flow than seeps.

Stable Community. The condition of little or no perceived change in plant communities that are in relative equilibrium with existing environmental conditions. Describes persistent but not necessarily climax stages in plant succession.

Stand. A plant community that is relatively uniform in composition, structure, and habitat conditions; a sample unit.

Stream. A natural waterway that is defined as first to third order (see Stream Order).

Streambank. That portion of the channel bank cross-section that controls the lateral movement of water.

Stream Order. A classification of streams according to the number of tributaries. Order 1 streams have no tributaries; a stream of order 2 or higher has 2 or more tributaries of the next lower order.

Stream reach. A specified length of stream, the exact length depending on the objective. In this study a reach is contained in a single polygon.

Stream type (Rosgen stream type). A stream reach delineated by measurable morphological characteristics as defined by Rosgen's (1996) stream type classification; based in the first instance on channel pattern, entrenchment ratio, width/depth ratio, dominant channel materials, slope, and sinuosity.

Stockpond. An artificial (dammed) body of water of less than 8 ha ( 20 acres) covered by surface water.

Subterranean Stream. A stream that flows underground for part of the stream reach. 
Succession. The change or sequence of plant, animal, and microbial communities that successively occupy an area over a period of time. Primary succession begins on a bare surface not previously occupied by living organisms, such as a recently deposited gravel bar.

Secondary succession occurs following disturbances on sites that previously supported living organisms.

Tree. A single-stemmed woody plant generally taller than $4.8 \mathrm{~m}(16 \mathrm{ft})$.

Uplands. Any area that does not qualify as a wetland because the associated hydrologic regime is not sufficiently wet to elicit development of vegetation, soils, and/or hydrologic characteristics associated with wetlands. Such areas occurring in floodplains are more appropriately termed "nonwetlands."

Water Mark. A line on vegetation or other upright structures that represents the maximum height reached during a flood, ponding, or inundation event.

Water Table. The upper surface of the zone of saturation within the soil or geologic material.

Wet Meadow. A herbaceous wetland on mineral soil. Generally, wet meadows occur in seasonally flooded basins and flats. Soils are usually dry for part of the growing season.

Wetlands. Areas that under normal circumstances have hydrophytic vegetation, hydric soils, and wetland hydrology. They include landscape units such as bogs, fens, carrs, marshes, and lowlands covered with shallow and sometimes ephemeral or intermittent waters. Wetlands also include potholes, sloughs, wet meadows, riparian zones, overflow areas, and shallow lakes and ponds having submerged and emergent vegetation. Permanent waters of streams and water deeper than $3 \mathrm{~m}$ (approximately $10 \mathrm{ft}$ ) in lakes and reservoirs are not considered wetlands.

Wetland Hydrology. Permanent or periodic inundation or prolonged soil saturation sufficient to create anaerobic conditions in the soil. 


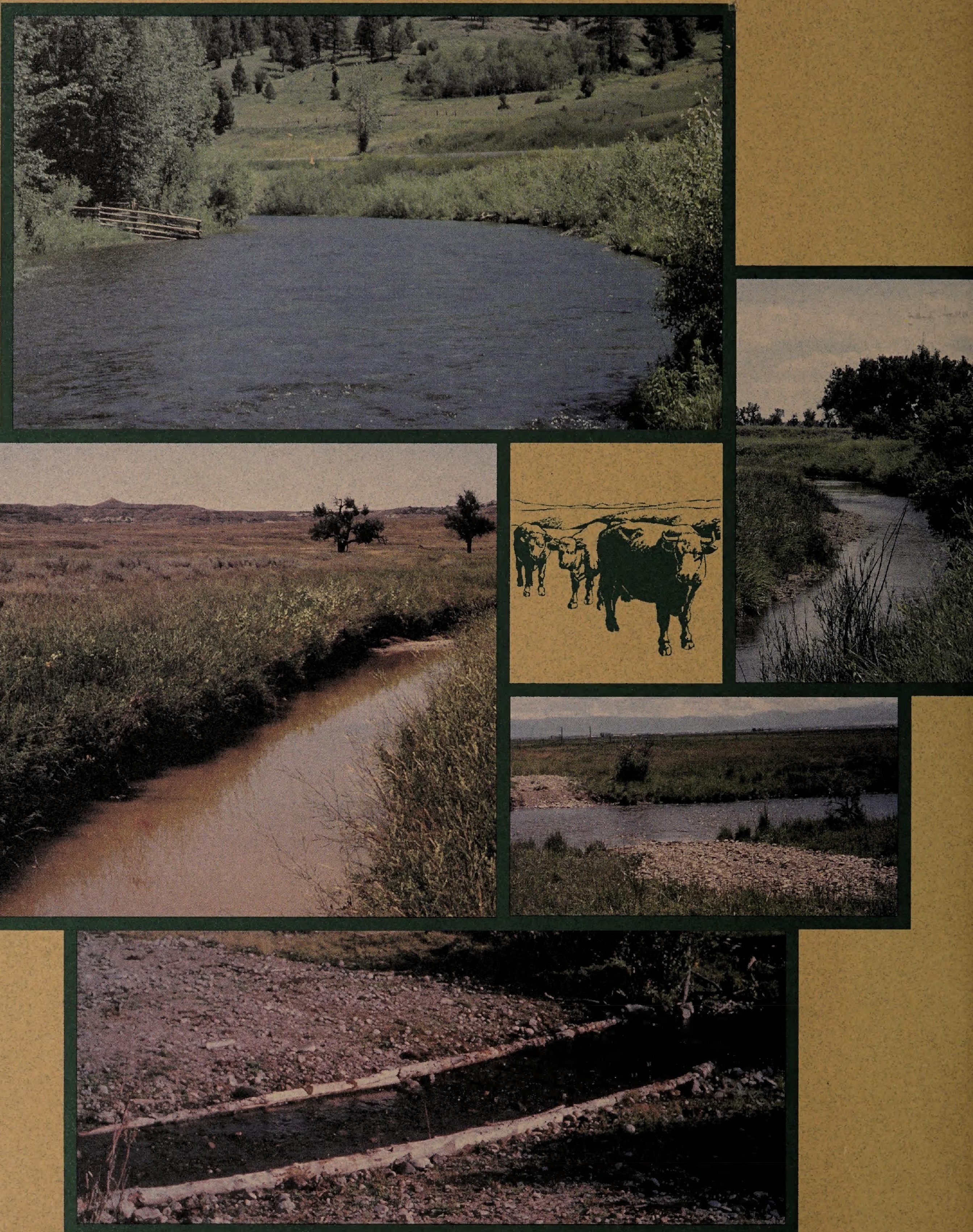

